University of Louisville

ThinkIR: The University of Louisville's Institutional Repository

Electronic Theses and Dissertations

$5-2004$

\title{
The effect of process parameters on laser-deposited TI-6A1-4V.
}

Troy Austin Davis 1981-

University of Louisville

Follow this and additional works at: https://ir.library.louisville.edu/etd

\section{Recommended Citation}

Davis, Troy Austin 1981-, "The effect of process parameters on laser-deposited TI-6A1-4V." (2004).

Electronic Theses and Dissertations. Paper 319.

https://doi.org/10.18297/etd/319

This Master's Thesis is brought to you for free and open access by ThinkIR: The University of Louisville's Institutional Repository. It has been accepted for inclusion in Electronic Theses and Dissertations by an authorized administrator of ThinkIR: The University of Louisville's Institutional Repository. This title appears here courtesy of the author, who has retained all other copyrights. For more information, please contact thinkir@louisville.edu. 


\title{
THE EFFECT OF PROCESS PARAMETERS ON LASER DEPOSITED TI-6Al-4V
}

\author{
By \\ Troy Austin Davis \\ B.S., University of Louisville, 2003

\begin{abstract}
A Thesis
Submitted to the Faculty of the

University of Louisville

Speed Scientific School
\end{abstract}

as Partial Fulfillment of the Requirements

for the Professional Degree

MASTER OF ENGINEERING

Department of Chemical Engineering

May 2004 


\section{THE EFFECT OF PROCESS PARAMETERS \\ ON LASER DEPOSITED TI-6AL-4V}

Submitted by:

Troy Austin Davis

A Thesis Approved on

$$
\text { May } 5^{\text {th }}, 2004
$$

by the Following Reading and Examination Committee:

Thomas L. Starr, Thesis Director

Dr. James C. Watters

Dr. William P. Hnat 
ABSTRACT

The purpose of this research is to understand how the process parameters surrounding the Direct Metal Deposition (DMD) process affect the properties of the deposition. The powder used in this research is pre-alloyed titanium powder (Ti-6Al$4 \mathrm{~V})$, containing $6 \% \mathrm{wt}$. aluminum and $4 \%$ wt. vanadium. The DMD process involves injecting metallic powder into a weld pool created by a high power industrial laser. As the laser traverses across the substrate in a layer-by-layer fashion, a fully dense metal is left in its path. A few process parameters involved with the DMD include the laser power, traverse speed, powder flow rate, and gas flow rates. Due to the detrimental effect of oxygen on titanium, oxygen content is one of the main deposition properties of significance involved with this research. In addition to the oxygen content, the powder efficiency, build rate, and build height per layer are also properties of importance.

The experiments varied process parameters such as the laser power, CNC velocity, gas flow rate, powder flow rate, and final deposition geometry. In addition to calculating tool path factors such as the line width and build height per layer, the oxygen content, hardness, density, and mechanical properties were determined for each experiment.

From these results, it is concluded that increasing the laser power enhanced the powder efficiency and build rate, but eventually negatively affects the oxygen pickup. Also, it is proven that it is beneficial to the deposition properties to increase the powder flow rate or decrease the gas flow rate. The results verified the repeatability of the DMD process and demonstrated that it can produce depositions with equivalent properties to that of commercial Ti-6Al-4V. A successful model for predicting the build height per 
layer was validated. Further research is recommended to continue examining the effect of the process parameters and to investigate additional factors of interest uncovered by this research. In addition to extending the trends noticed with the powder flow rate and gas flow rates, further research should examine additional process parameters such as the tool path factors, laser beam diameter, or laser frequency. The uncovered factors of interest include understanding the relationship between laser width and build height per layer, or the effect of powder flow rate on the powder efficiency. 
APPROVAL PAGE........................................................... ii

ACKNOWLEDGEMENTS.................................................. iii

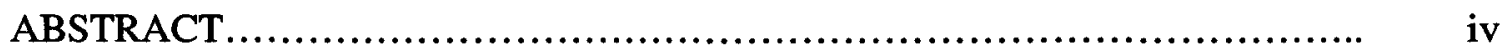

NOMENCLATURE....................................................... vii

LIST OF TABLES......................................................... viii

LIST OF FIGURES........................................................ ix

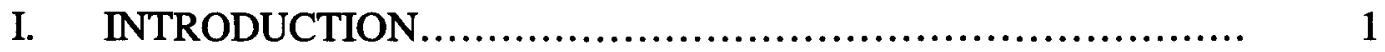

A. Overview................................................ 1

B. Literature Review....................................... 5

II. INSTRUMENTATION, EQUIPMENT, AND MATERIALS........... 8

A. Direct Metal Deposition Machine (DMD 3000)................ 8

B. Isomet ${ }^{\mathrm{TM}}$ Low Speed Saw................................. 10

C. Rockwell Hardness Tester..................................... 11

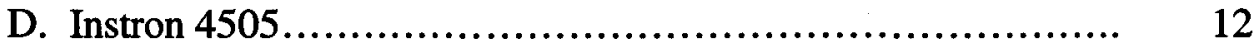

E. Calipers and Electronic Scales............................... 13

F. Materials................................................... 13

III. PROCEDURE...................................................... 15

IV. RESULTS AND DISCUSSION OF RESULTS...................... 24

V. CONCLUSIONS.................................................... 44

VI. RECOMMENDATIONS....................................... 45

LIST OF REFERENCES..................................................... 46

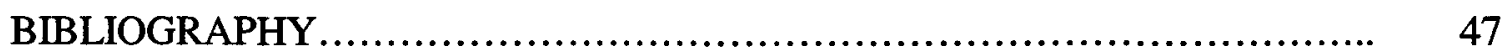

APPENDIX I. Tables............................................................ 49

APPENDIX II. Graphs/Pictures............................................. 58

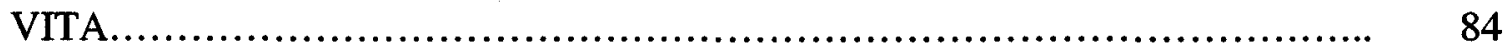




$$
\begin{aligned}
& \text { ALW }=\text { actual line width } \\
& \mathrm{AZ}=\text { actual build height per layer } \\
& \mathrm{BR}=\text { build rate } \\
& \mathrm{d}=\text { laser beam diameter } \\
& \mathrm{H}=\text { height of deposition } \\
& \text { HR = powder flow rate, hopper rate } \\
& \mathrm{L}=\text { length of deposition } \\
& \mathrm{LP}=\text { number of length passes } \\
& \mathrm{LW}=\text { line width } \\
& \mathbf{N}=\text { number of deposition layers } \\
& \mathbf{P}=\text { laser power } \\
& \mathrm{PE}=\text { powder efficiency } \\
& t=\text { total deposition time } \\
& \mathbf{u}=\mathrm{CNC} \text { velocity } \\
& \mathrm{V}=\text { volume of deposition } \\
& \text { VR }=\text { volumetric deposition rate } \\
& \mathrm{W}=\text { width of deposition } \\
& \mathrm{WP}=\text { number of width passes } \\
& \mathrm{Z}=\text { build height per layer } \\
& \rho=\text { density of deposition }
\end{aligned}
$$




\section{LIST OF TABLES}

$\underline{\text { Page }}$

TABLE I: Experiments 1-6 with Results...................................... 24

TABLE II: Additional Results of Experiments 1-6........................... 27

TABLE III: Objectives of Experimental Set Two................................ 28

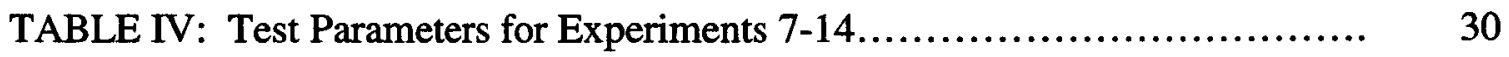

TABLE V: Comparison of Tool Path Factors for Experiment 1-6................. 31

TABLE VI: Experiments 7-14 with Results................................... 34

TABLE VII: Additional Results of Experiments $7-14 \ldots \ldots \ldots \ldots \ldots \ldots \ldots \ldots \ldots \ldots \ldots . . \ldots \ldots$

TABLE VIII: Comparison of Tool Path Factors for Experiments 7-14........... 40

TABLE IX: Process Gas Flow Rates........................................... $\quad 50$

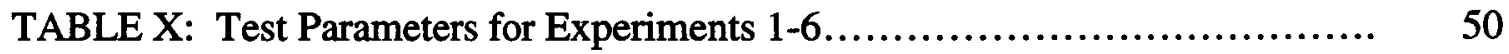

TABLE XI: Estimation of Tool Path Factors for Experiments 7-13.............. 51

TABLE XII: Verification of Build Height Equation using Experiments 1-6........ 51

TABLE XIII: Verification of Build Height Equation using Experiments 7-13..... 52

TABLE XIV: Calculation Spreadsheet - Experiments 1-6..................... 53

TABLE XV: Calculation Spreadsheet - Experiments 7a, 8a, 11a, 13a........... 54

TABLE XVI: Calculation Spreadsheet - Experiments $7 \mathrm{c}-14 \mathrm{c} \ldots \ldots \ldots \ldots \ldots \ldots \ldots . . \ldots \ldots$

TABLE XVII: Calculation Spreadsheet - Experiments 7d-14d................. 56

TABLE XVIII: Sample Bar Dimensions for Experiments 1-6.................. 57

TABLE XIX: Sample Bar Dimensions for Experiments 7-14................. 57 


\section{LIST OF FIGURES}

Page

FIGURE 1 - Titanium Alloying Effects on Structure and Characteristics........... 3

FIGURE 2 - Nozzle Apparatus and Hoppers................................. 9

FIGURE 3- DMD Machine................................................ 9

FIGURE 4 - Isomet $^{\mathrm{TM}}$ Low Speed Saw.................................... 11

FIGURE 5 - Rockwell Hardness Tester...................................... 12

FIGURE 6 - Instron Flexural Jaws....................................... 13

FIGURE 7 - Oxygen Analysis Certificate for Experiments 7c-14c............... 59

FIGURE 8 - Flexure Test Results for Experiments 7c-14c.................... 60

FIGURE 9 - Stress-Strain Curve of Experiment 7c......................... 61

FIGURE 10 - Stress-Strain Curve of Experiment 8c............................................... 62

FIGURE 11 - Stress-Strain Curve of Experiment 9c........................... 63

FIGURE 12 - Stress-Strain Curve of Experiment 10c........................ 64

FIGURE 13 - Stress-Strain Curve of Experiment 11c.......................... 65

FIGURE 14 - Stress-Strain Curve of Experiment 12c.......................... 66

FIGURE 15 - Stress-Strain Curve of Experiment 13c......................... 67

FIGURE 16 - Stress-Strain Curve of Experiment $14 c \ldots \ldots \ldots \ldots \ldots \ldots \ldots \ldots \ldots . .68$

FIGURE 17 - Oxygen Analysis Certificate for Experiments 7d-14d.............. 69

FIGURE 18 - Equations used in Flexural Calculations.......................... 70

FIGURE 19 - Symbols used in Flexural Calculations........................... 71

FIGURE 20 - Stress-Strain Curve of Experiment 7d.......................... 72

FIGURE 21 - Stress-Strain Curve of Experiment 8d.......................... 73 
FIGURE 22 - Stress-Strain Curve of Experiment 9d.......................... 74

FIGURE 23 - Stress-Strain Curve of Experiment 10d......................... 75

FIGURE 24 - Stress-Strain Curve of Experiment 11d.......................... 76

FIGURE 25 - Stress-Strain Curve of Experiment 12d.......................... 77

FIGURE 26 - Stress-Strain Curve of Experiment 13d......................... 78

FIGURE 27 - Stress-Strain Curve of Experiment 14d........................... 79

FIGURE 28 - Stress-Strain Curve of Commercial Ti-6Al-4V ................... 80

FIGURE 29 - Sample bar of Commercial Ti-6Al-4V after Mechanical Testing..... 81

FIGURE 30 -Depositions.............................................. 81

FIGURE 31 - Ti-6Al-4V ELI Powder Specifications......................... 82

FIGURE 32 - Commercial Ti-6Al-4V Specifications........................... 83 


\section{INTRODUCTION}

\section{A. $\underline{\text { Overview }}$}

The purpose of this research is to understand how the process parameters surrounding the Direct Metal Deposition (DMD) process affect the properties of the deposition using pre-alloyed titanium powder (Ti-6Al-4V). The process parameters involved with the DMD include the laser power, traverse speed, powder flow rate, and gas flow rates. Due to the effects of oxygen on titanium, oxygen content is one of the main deposition properties of significance involved with titanium powder metallurgy. In addition to the oxygen content, the powder efficiency, build rate, and build height per layer are also properties of importance. The following is a brief review of the DMD manufacturing process and titanium metallurgy.

The Direct Metal Deposition process is a near-net shape fabrication method used to manufacture metallic components directly from Computer Aided Drafting (CAD) files. This process involves focusing a high power laser beam onto a metallic substrate, creating a pool of molten metal. The laser beam then traverses across the substrate while a metal powder is injected into the melt pool at the laser focal zone. The melting and resolidification of the added metal powder results in a fully dense metal in the wake of the moving molten pool. The process continues in a layer-by-layer fashion, re-melting the previous layers, until the entire component of fused metal is complete.

This near-net shape production is used in rapid prototyping for many beneficial reasons. Cost reduction is the major reason especially when dealing with titanium. Using conventional alloy production, the bulk of the cost of titanium component fabrication is concentrated in forging and machining. Forging and machining costs for 
titanium components are directly proportional to the size and complexity of the part. Near-net shape production reduces the material costs by reducing the buy-to-fly ratio, which is the ratio of the weight of the purchased material to the weight of the finished part. Another benefit of near-net shape rapid prototyping is the large reduction in turnaround time for producing a titanium part. For one such near-net shape process, Arcella and Froes (2000) state that delivery times are about 30-60 days as compared to as much as 15 months for the forge plus machine approach. In addition to the near-net shape method being ideal for fabricating titanium components, titanium's physical and mechanical properties make it especially advantageous in certain situations.

One such situation of interest is the corrosive environment of the human body. Titanium has exceptional corrosion resistance, which often exceeds that of stainless steel in most environments, including the human body. Titanium and some of its alloys generally are biologically compatible with human tissues and bones. "The excellent corrosion resistance and biocompatibility coupled with good strengths make titanium and its alloys useful in chemical and petrochemical applications, marine environments, and biomaterials applications" (Donachie, 1988, pg.9).

Titanium is an allotropic element, which means that it exists in more than one crystallographic form. At room temperature, titanium has a hexagonal close-packed crystal structure, referred to as "alpha" ( $\alpha$ ) phase, which transforms to a body-centered cubic crystal structure at $883^{\circ} \mathrm{C}\left(1671^{\circ} \mathrm{F}\right)$, called "beta" $(\beta)$ phase. These different crystal structures, the $\alpha$ and $\beta$ phases, determine the properties of the titanium alloy. For example, alpha and near-alpha titanium alloys generally demonstrate the best corrosion resistant qualities as well as the most weldable of the titanium/titanium alloy family. The 
most significant benefit provided by a $\beta$ structure is the increased formability of such alloys relative to the hexagonal crystal structure types. The crystal structure is influenced by the alloyed element(s), which stabilize either the $\alpha$ or $\beta$ phase in the titanium. In addition to showing the effects of alloying on the structure and characteristics, Figure 1 from Donachie $(1988,4)$ includes examples of alpha-stabilizing elements and betastabilizing elements.

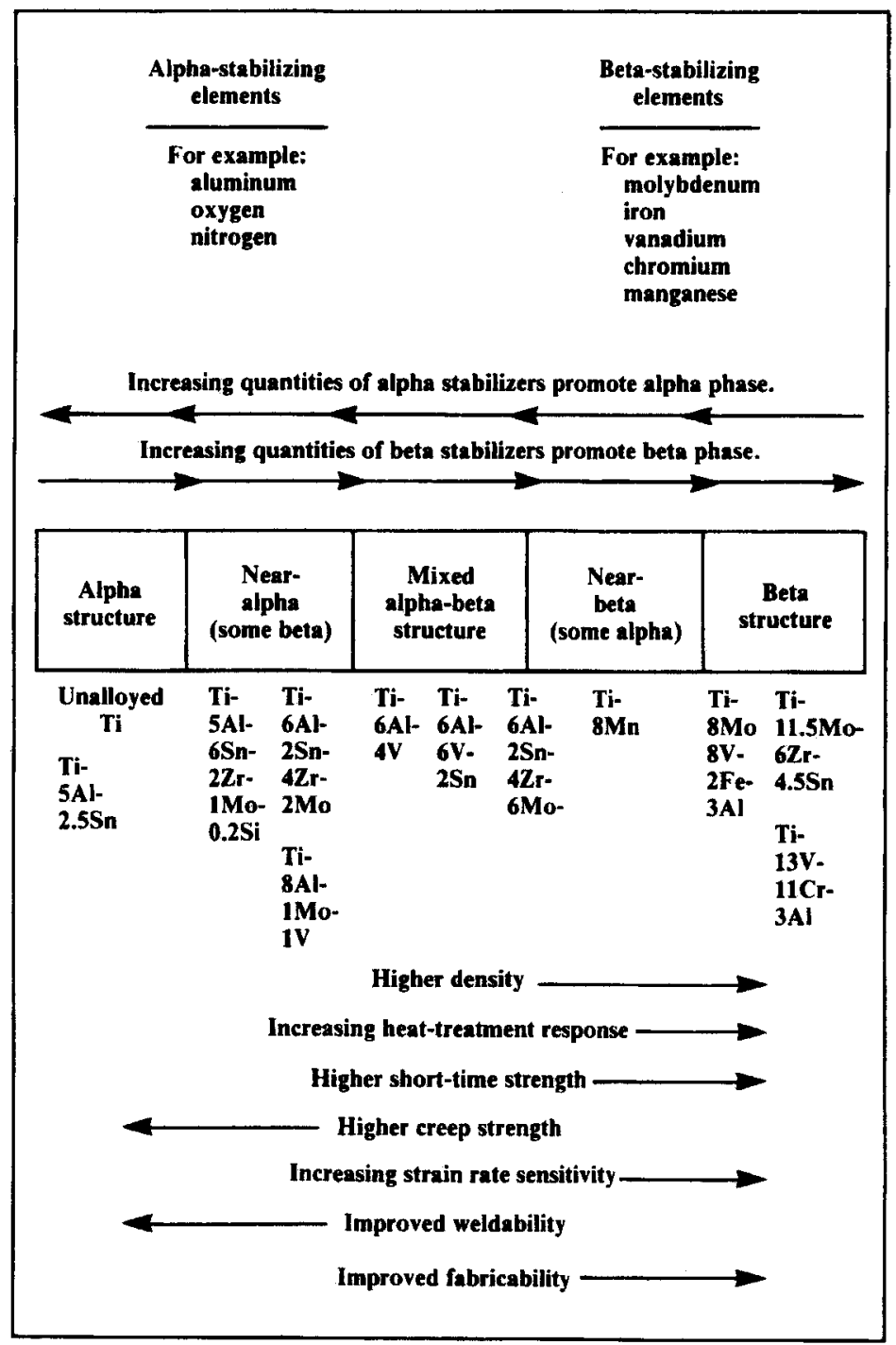

FIGURE 1 - Titanium Alloying Effects on Structure and Characteristics 
The alpha-beta alloys have an excellent combination of strength and ductility, and they are stronger than the alpha or the beta alloys. One of the most widely used titanium alloys is an alpha-beta type contained $6 \%$ aluminum and $4 \%$ vanadium, denoted as Ti$6 \mathrm{Al}-4 \mathrm{~V}$. "It has an excellent combination of strength and toughness along with excellent corrosion resistance. Typical uses include aerospace applications, pressure vessels, aircraft turbine and compressor blades and disks, surgical implants, etc" (Donachie, 1988, pg. 31). "The most common and widely used titanium alloy is Ti-6Al-4V which accounts for about $50 \%$ of the total weight of all titanium alloys shipped" (Donachie, 1988, pg. $13)$.

However, titanium is unique among metals in that it has a high solubility for the interstitial elements of oxygen and nitrogen, creating a problem not of concern in most other metals. For example, heating titanium in air at high temperature results not only in oxidation but also in solid-solution hardening of the surface as a result of inward diffusion of oxygen (and nitrogen). Because oxygen and nitrogen are alpha-stabilizing elements, the surface-hardened zone is comprised predominantly of alpha phase titanium, and therefore called the "alpha-case" (or "air-contamination layer"). The alpha case is detrimental because of the brittle nature of the oxygen-enriched alpha structure, and therefore must be removed. "Oxygen content is a matter of concern regarding titanium alloy castings since strength increases and ductility (toughness) decreases as oxygen level increases" (Donachie, 1988, pg. 106). More importantly, due to their higher surface area, titanium powders must be handled very carefully, because they have a very high affinity for oxygen. "One of the more important considerations in the manufacture of a titanium 
powder metallurgy product is control of oxygen content, because oxygen has the same undesirable effects on properties of powder metallurgy parts as it has on those of wrought products" (Donachie, 1988, pg. 191).

The focus of this research is to understand how oxygen content, powder efficiency, and build rate in Ti-6Al-4V depositions are affected by the DMD process parameters, such as laser power, traverse speed, powder flow rate, and process gas flow rates.

\section{B. Literature Review}

Previous research in laser deposition involves similar processes like that of the Direct Metal Deposition (DMD) employed in this study. One such similar method is called the Lasform process being commercialized by the AeroMet Corporation. In JOM May 2000, Arcella and Froes describe the Lasform process and the characteristics of the Lasformed Ti-6Al-4V components. The article states that the Lasform process successfully manufactures lasformed Ti-6Al-4V components with mechanical properties equivalent to cast and wrought (ingot metallurgy) material. The Lasform process uses a sealed chamber to eliminate oxygen pickup and requires significant final machining and heat treatment. One goal of this study is to fabricate Ti-6Al-4V components with equivalent mechanical properties and low oxygen content using the DMD process with an open chamber and improve dimensional accuracy to reduce or eliminate post-deposition machining or heat treatment.

In addition, another article in Scripta Materialia by Kobryn, Moore, and Semiatin (2000) examine the effects of laser power and traverse speed on microstructure, porosity, and build height in laser-deposited Ti-6Al-4V. The research is conducted using a Laser 
Engineered Net Shaping (LENS ${ }^{T M}$ ) system which uses a 750W Nd:YAG laser where the DMD uses a $3000 \mathrm{~W} \mathrm{CO}_{2}$ laser. Similar to Arcella and Froes (2000), the system is contained within a glove box, which is evacuated and back-filled with argon to reduce oxygen pickup. This research investigates additional process parameters such as powder flow rate and gas flow rates, and their effect on oxygen content, powder efficiency, and build rate.

Srivastava, Chang, and Loretto (2000) studied the influence of processing parameters on the build height and width and on the micro- and macrostructure. A similar research studied the effect of process parameters and heat treatment on the microstructure of TiAl alloy samples (Srivastava, 2001). Their studies used $\gamma$-titanium aluminide alloys and a $600 \mathrm{~W} \mathrm{CO}_{2}$ laser, compared to this research using Ti-6Al-4V and a $3000 \mathrm{~W} \mathrm{CO}_{2}$ laser. Although similar process parameters are investigated, the issue of oxygen content is not addressed because the laser deposition is conducted in an enclosure pressurized with argon shielding gas. This research attempts to efficiently fabricate Ti$6 \mathrm{Al}-4 \mathrm{~V}$ components with equivalent properties to that of commercial $\mathrm{Ti}-6 \mathrm{Al}-4 \mathrm{~V}$ without the used of a pressurized enclosure.

Another article discusses the microstructure of compositionally graded titaniumvanadium and titanium-molybdenum (Collins, 2003). This article also uses the LENS ${ }^{\mathrm{TM}}$ fabrication process but uses a $760 \mathrm{~W}$ Nd:YAG laser in a controlled environment glove box. It focuses more on the microstructure difference in changing composition of vanadium and molybdenum and does not deal with the process parameters. Once again, the oxygen content is never mentioned because of the use of the glove box. 
Wu, Sharman, Mei, and Voice (2002) is the only article found that discusses oxygen content and examines the oxygen pickup in different processing atmospheres. The article studies the microstructure and morphology of a burn-resistant beta Ti alloy onto a Ti-6Al-4V substrate using a $1.75 \mathrm{~kW} \mathrm{CO} 2$ laser either in air on in an argon atmosphere with $\mathrm{O}_{2}<5 \mathrm{ppm}$. In the argon atmosphere, the oxygen pickup was "negligible", but for the samples manufactured in air, "there was significant oxygen pickup throughout the sample." This research aims at successfully fabricating titanium parts in air without significant oxygen pickup. 


\section{INSTRUMENTATION, EQUIPMENT, AND MATERIALS}

\section{A. Direct Metal Deposition Machine (DMD 3000)}

According to POM, the Direct Metal Deposition (DMD 3000) machine is a collection of integrated components designed to execute the DMD process.

Manufactured by Precision Optical Manufacturing (POM), the DMD machine includes several different components such as the CNC (Computer Numerical Control) Enclosure, the DMD Process Panel, and the Trumpf TLF 3000 Laser.

The CNC Enclosure is the process area of the DMD machine that also consists of several components including the work area, CNC, powder feeders, and the nozzle assembly. The CNC controls the positioning of the optics and nozzle assembly using a 3axis gantry robot. The powder feeders, also known as the "hoppers", consist of a powder storage canister and the mechanism to dispense powder to the nozzle in a controlled manner. The nozzle assembly is the device through which the powdered metal, laser, and process gases are delivered to the work piece. Figure 2 is a picture of the nozzle apparatus and powder feeders inside the process chamber.

The DMD Process Panel houses the DMD process control equipment, including closed-loop powder feeder control, gas control and optical feedback control systems, according to POM. Figure 3 is a frontal picture of the DMD machine with the DMD Process Panel to the right of the open chamber doors. 


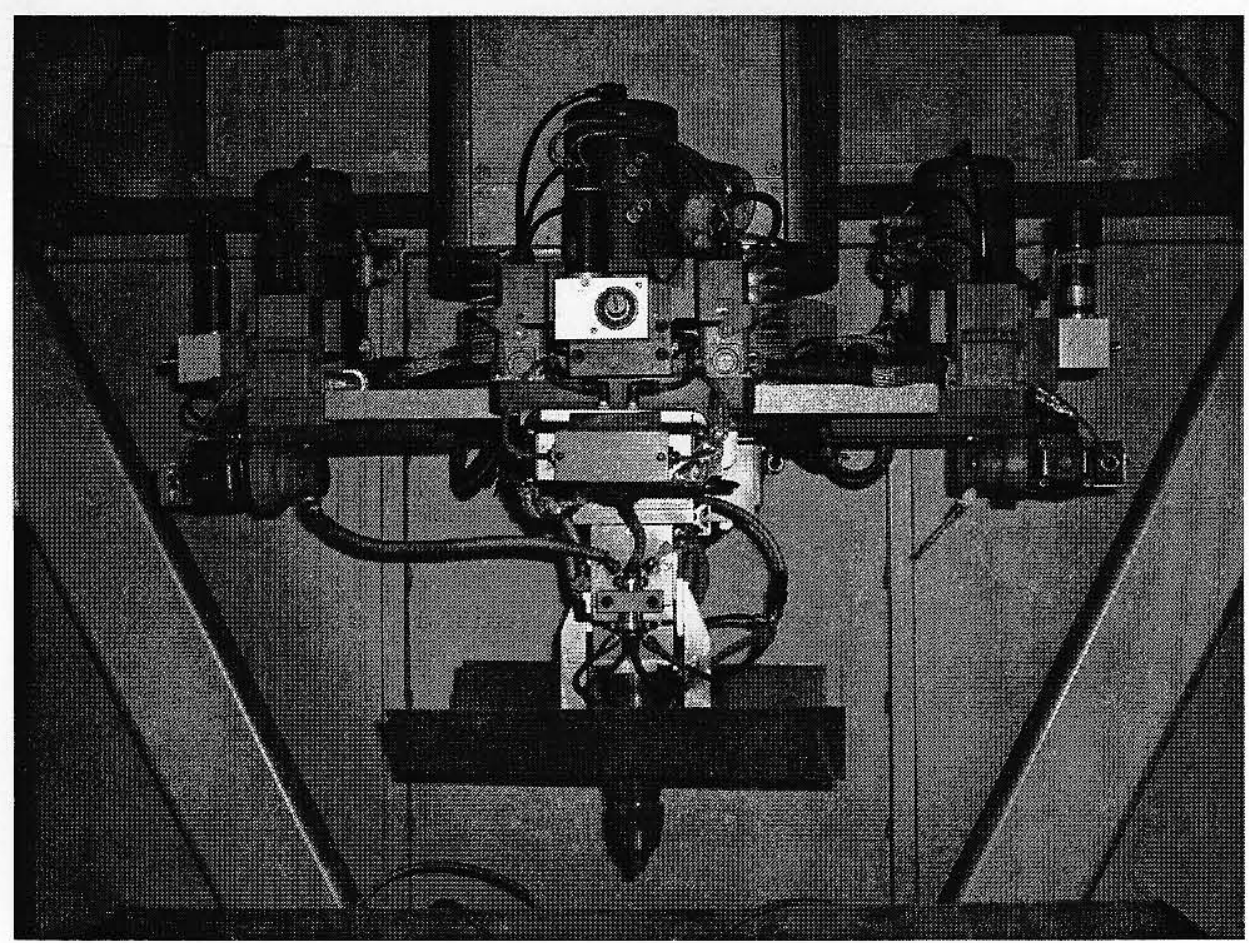

FIGURE 2 - Nozzle Apparatus and Hoppers

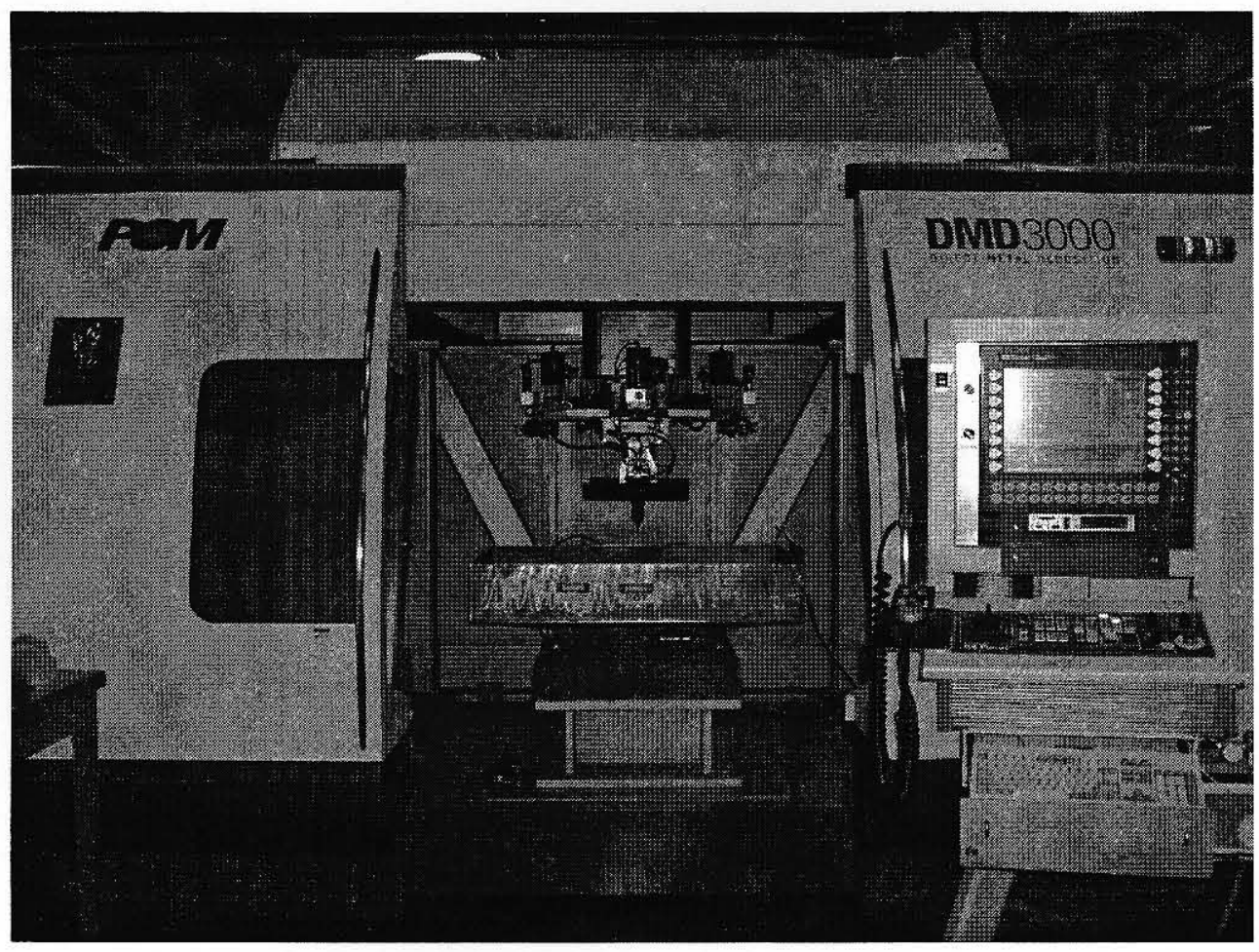

FIGURE 3- DMD Machine 
The process gases used include the cover and shaping composed of argon, and the carrier and nozzle gas composed of argon/helium mixtures. The cover gas is used to pressurize the powder feeder above the powder where the carrier gas is used to transport the powder from the feed to the nozzle tip. The shaping gas focuses and shapes the powder stream into the weld pool after it leaves the nozzle and the nozzle gas provides an inert gas "shield" around the deposition.

The Trumpf TLF $3000 \mathrm{~W} \mathrm{CO}_{2}$ laser is a heavy-duty industrial grade laser that provides high power output with shallow surface penetration, ideal for laser-based deposition of powdered metals.

\section{B. Isomet ${ }^{\mathrm{TM}}$ Low Speed Saw}

The Isomet ${ }^{\mathrm{TM}}$ Low Speed Saw, manufactured by Buehler Ltd., is equipped with a Series $15 \mathrm{H}$. C. Diamond Wafering Blade and is used for cutting the Ti-6Al-4V depositions. Figure 4 shows a frontal view of the Isomet ${ }^{\mathrm{TM}}$ Low Speed Saw. The sample is placed in the chuck on the support arm and positioned above the blade using the micrometer. The desired blade speed is adjusted using the Speed Control Knob on the front of the saw. Isocut $\circledast$ lubricating fluid is used in the lubricant pan beneath the blade. Three weights, 25, 50 and 75 grams, can be added to the weight shaft attached on top of the support arm. An adjustable thumbscrew is used to trigger an automatic cut-off switch after a single cut has been completed. 


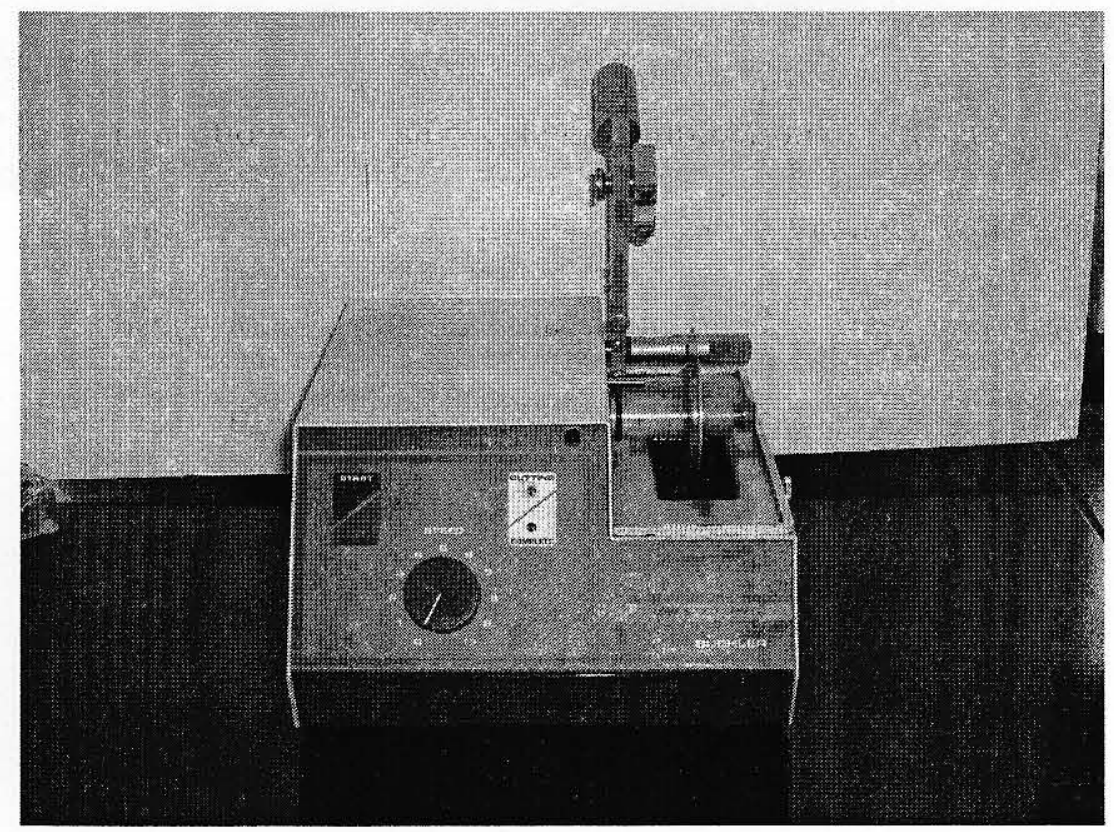

FIGURE 4 - Isomet ${ }^{\mathrm{TM}}$ Low Speed Saw

\section{Rockwell Hardness Tester}

The Rockwell Hardness Tester was used for measuring the Rockwell Hardness C values of the deposited titanium samples. The Rockwell Hardness C values use the Brale indenter, which is a conical diamond penetrator. The hardness is determined by the difference in penetration depth under a $10 \mathrm{kgf}$ load and $150 \mathrm{kgf}$ load. The Rockwell Hardness $\mathrm{C}$ scale ranges from 0 to 100 with higher values corresponding to harder materials. Figure 5 shows a frontal view of the Rockwell Hardness Tester. 


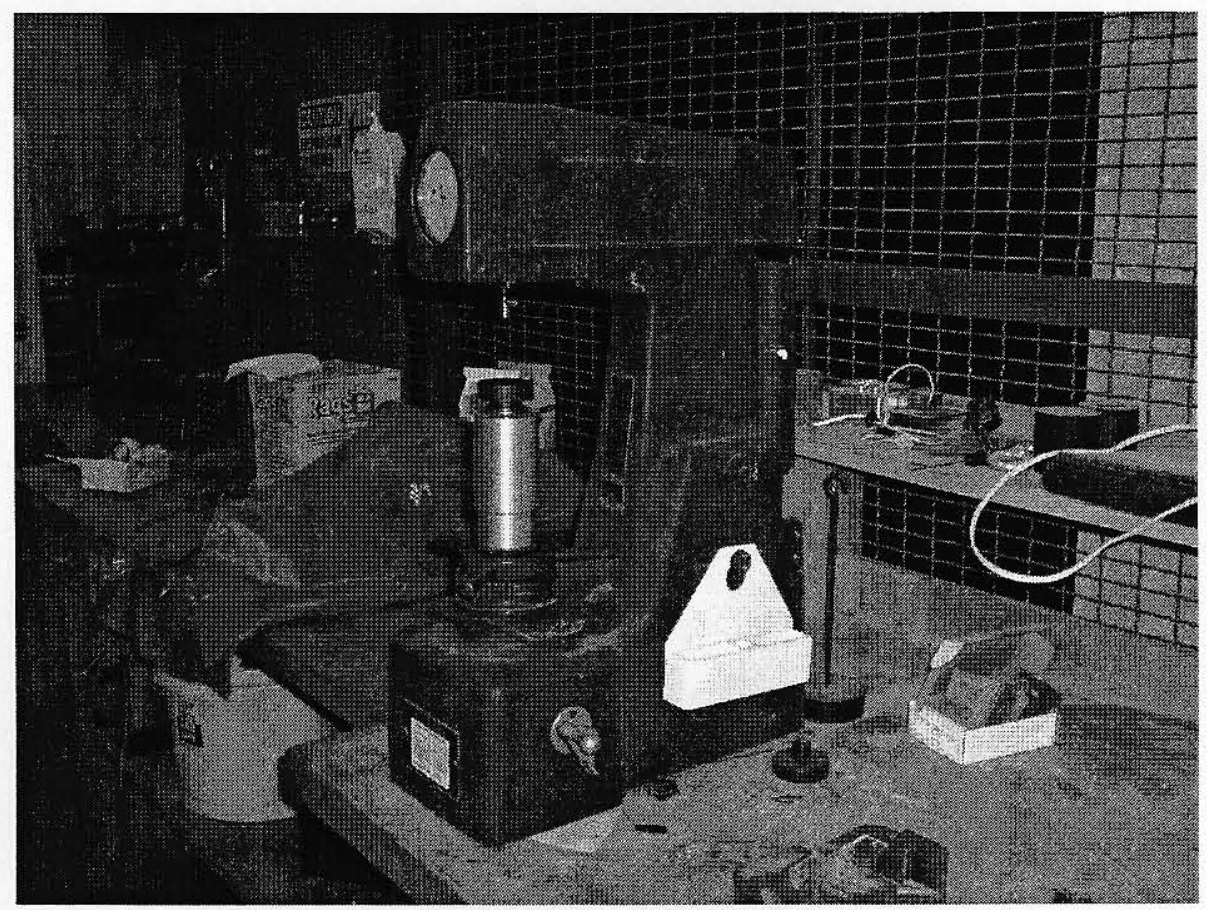

FIGURE 5 - Rockwell Hardness Tester

\section{Instron 4505}

The Instron 4505, manufactured by Instron Corporation, is Universal Materials Testing Machine, capable of tension, compression, flexure, peel, shear, and friction testing. The Instron 4505 was used in measuring the mechanical properties of the depositions and comparing them to that of commercial Ti-6Al-4V. A three-point flexure test was used to test the samples. The stress-strain results are contained in Appendix II. Figure 6 is a frontal picture of the flexural fixture used in the testing. 


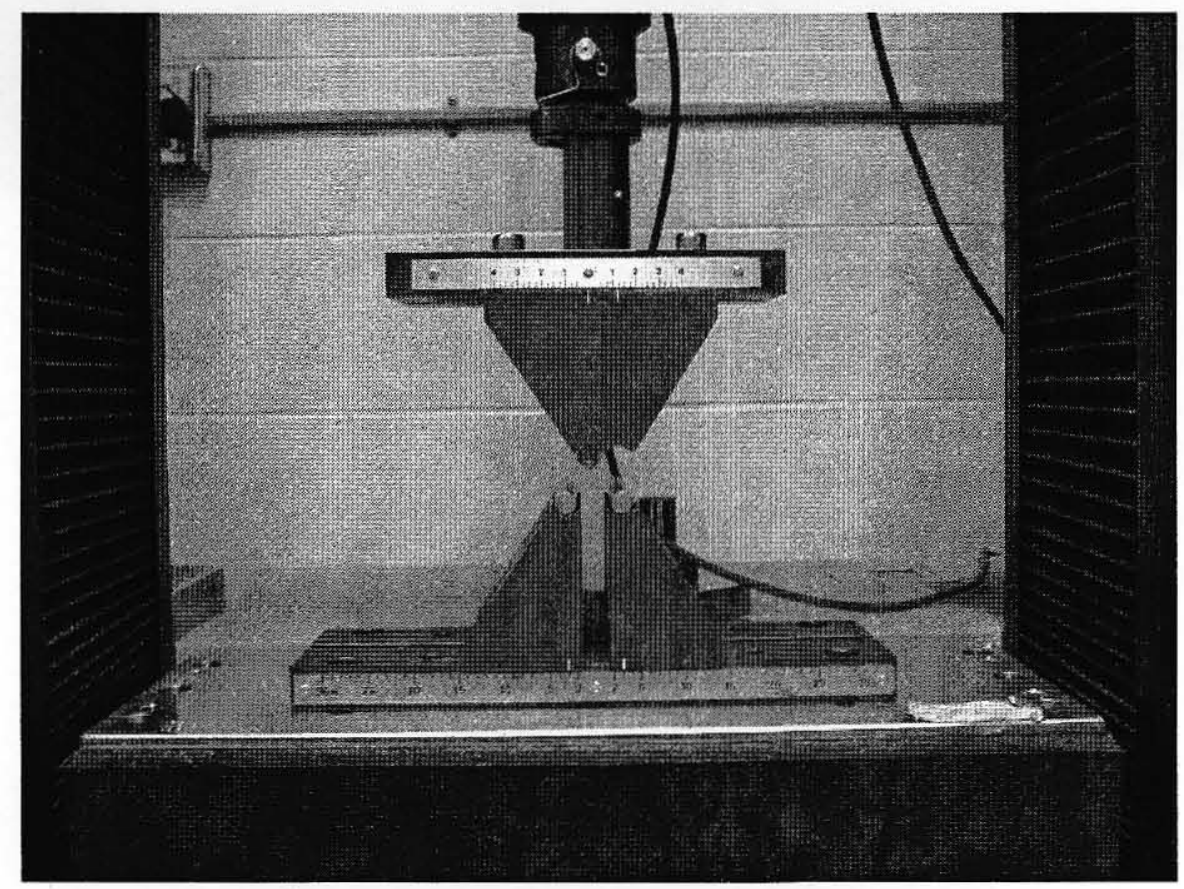

FIGURE 6 - Instron Flexural Fixture

\section{E. Calipers and Electronic Scales}

Build dimensions of the depositions and titanium sample bars were measured using the Starrett caliper by the L. S. Starrett Company, model No. 721. In order to obtain the densities of the depositions, the mass of the sample bars were measured by an electronic scale manufactured by the Denver Instrument Company, model TR-64. The mass of the powder during powder flow calibrations was measured using an electronic scale.

\section{F. Materials}

The titanium powder used in this research was gas atomized Ti-6Al-4V ELI powder, where ELI denotes extra low interstitial content, obtained from Crucible Research. Figure 31, in Appendix II, is the test certificate for the powder, which contains 
its chemical analysis. Of these specifications, the oxygen content of the powder is the most important; it is $0.124 \%$. The substrate material used is commercial Ti-6Al-4V, which was acquired from RMI Titanium Company and its test report with the chemical analysis is contained in Figure 32, in Appendix II. The substrate is the base material upon which the deposition is built. The oxygen content for the commercial Ti- $6 \mathrm{Al}-4 \mathrm{~V}$ substrate is $0.17 \%$. The process gases, argon and helium, were obtained from Welding and Therapy Inc. The process gases are industrial grade, corresponding to $99.99 \%$ pure argon and helium. The next section describes the experimental procedure using this equipment, instrumentation, and materials. 


\section{PROCEDURE}

The procedure for conducting and preparing a typical experiment is outlined in the following steps. The procedure is divided into three main categories, developing the tool path, executing the deposition program, and preparing the sample for testing.

\section{A. Develop the tool path}

1. Choose the desired dimensions of the complete deposition as well as the DMD parameters for the experiment. Assign a value for the width of the laser path, defined as the deposition line width.

2. From the chosen DMD parameters and assigned line width, estimate the vertical build height offset per layer.

3. Input the values of the deposition final dimensions, line width, and build height offset into the tool path program called Edge Cam in order to develop the tool path program.

B. Deposition process

4. Open gas valves, turn the laser on, and put the powder into the correct hopper.

5. Verify the powder flow rate is correct

a. Load the powder flow verification tool path, tare powder collecting container, and execute the powder flow program

b. After the program ends after two minutes, weigh the powder container to obtain the powder flow rate in grams per minute and verify the value is in the correct range. 
6. Load the experiment tool path and DMD parameters into the DMD recipe program. Place substrate on worktable in the process chamber and execute the program to begin the deposition process.

\section{Sample preparations}

7. After the program has finished, wait for the substrate and deposition to cool before cutting the substrate area containing the deposition.

8. Use the Starrett caliper to measure the dimensions of the deposition

9. Use the Isomet ${ }^{\mathrm{TM}}$ Low Speed Saw with the diamond-wafering blade to cut the deposition into sample bars for mechanical testing, hardness testing and oxygen analysis.

The following parameters are involved in the Direct Metal Deposition process, some of which were not addressed in this research. The parameters that were investigated within this research include the laser power, $\mathrm{CNC}$ velocity, powder flow rate, and the shaping and nozzle gas flow rates. Parameters, such as the laser power, gas flow rates, and powder flow rate, are entered into the DMD recipe program using an analog value. These analog values correspond linearly to the actual values of the parameter. For example, when entering the laser power, the analog values of 0-2000 relate linearly to $0-3000 \mathrm{~W}$. Therefore, when choosing experimental parameters, the analog values are set in order to attain the desired actual values within $\pm 10 \%$.

1. Gas flow rates: The gas flow system involves the carrier, cover, nozzle, and shaping gas streams, described under the DMD 3000 machine in the 
Instrumentation and Equipment Section. Of the four types of process gases, only the shaping and nozzle gas flow rates were altered. These gas flow rates were changed based on a fraction of the gas flow rate used in experiments one through four. Table IX, in Appendix I, contains the analog values and actual gas flow rates in liters per minutes (LPM) for these process gases.

2. Hopper rates: The powder flow rates used in this research include analog values of 200 and 400 which correspond to values of 4.9 and 11.0 grams per minutes. For this research, only hopper number two containing Ti-6Al-4V powder was used.

3. Laser power: The laser power was varied from 250 to 1800 analog values, which correspond to approximately 400 to 2800 Watts. The separate values for the control and gating laser power are implemented in the optical feedback system, which was not used.

4. CNC Velocity: The CNC velocity varied from 127 to 711.2 millimeters per minute (5 to $28 \mathrm{in} / \mathrm{min}$ ).

5. Camera $A$ and $B$ position: The value in the camera $A$ and camera $B$ position selects which filter lens in the two cameras is to be used. The cameras are a part of the optical feedback system, which was not utilized.

6. Laser frequency: The laser frequency value used in this research is 1280 , which is a hexadecimal number corresponding to $5 \mathrm{kHz}$.

Several of these DMD parameters were not examined in this research, including the carrier and cover gases, powder flow rates of hopper one and two, separate values for 
the control and gating laser powers, camera $\mathrm{A}$ and $\mathrm{B}$ positions, and the laser frequency. The control and gating laser powers and the camera $\mathrm{A}$ and $\mathrm{B}$ positions are involved with the optical feedback system, which was not employed.

After the experimentation, several measured quantities are determined, including the deposition dimensions, oxygen content, hardness, density, and mechanical properties. The length, width, and height of the final deposition are measured using the Starrett caliper, from which the deposition volume, actual build height per layer, and actual line width can be determined. The hardness value was tested using the Rockwell Hardness Tester described in Instrumentation and Equipment. After sample bars were cut for mechanical testing, the mass and volume were used to calculate the density of each deposition. Mechanical properties were determined by a three-point flexure test using the Instron 4505, also described in the Instrumentation and Equipment section.

The build height per layer is the height of a single deposition layer. The value in Step two, which is inputted into the tool path program, specifies how far up the nozzle assembly moves after each layer. The actual build height per layer is the final deposition height divided by the number of layers. Ideally, the actual build height per layer is close to the input build height per layer. If not, then the nozzle is moving vertically faster or slower than the deposition is building. The laser beam does not have a constant diameter through the nozzle to the substrate, rather, there is a focusing mirror that reduces and then expands the beam diameter. In its current arrangement, the laser beam diameter is 1.35 millimeters at 20 millimeters from the tip of the nozzle. Therefore, as the distance between the nozzle and the deposition surface increases or decreases, the beam diameter 
increases or decreases, respectively. Clearly, this affects the effective surface area that the laser beam impinges on, as well as the energy density, discussed later.

The line width, mentioned in step one of the experimental procedure, is the width of the deposition after a single laser pass. In procedure step two, the line width is used in determining the vertical build height per layer. However, the input line width in step three is 1.43 times this line width because there is a $30 \%$ overlap in the laser passes. Just as the weld pool is spherical in shape, a single laser pass produces a deposition that has a rounded top to it. In order to build each layer evenly without any gaps, a 30\% overlap is included. Therefore, after each laser pass, the nozzle moves over $70 \%$ of the "inputted line width" $(0.7 \times 1.43=1.0)$. This distance is called the step over distance, which is also the line width. This line width, used in determining the build height per layer, is compared to the actual line width. The actual line width is calculated using

$$
A L W=\frac{W}{W P}
$$

where $\mathrm{W}$ is the total width of the deposition and WP is the number of width passes. Similarly, the actual build height per layer is

$$
A Z=\frac{H}{N}
$$

where $\mathrm{H}$ is the final deposition height and $\mathrm{N}$ is the number of layers. The letter $\mathrm{Z}$ is used to denote the build height per layer because the build direction is along the z-axis in the 
DMD $x, y, z$ coordinate system. The dimensions of the deposition that were input into the tool path program were $6.35 \mathrm{~mm}(1 / 4 \mathrm{in})$ in width, $44.45 \mathrm{~mm}(13 / 4 \mathrm{in})$ in length, and 12.7 $\mathrm{mm}(1 / 2$ in $)$ in height. The tool path program sets the deposition width from center line to center line and does not account for the additional line width on the edges. Therefore, one actual line width has to be added to this input width to obtain the actual desired width of the deposition.

The oxygen content is the weight percent of oxygen within the deposition. As previously discussed, the oxygen content is investigated because of its direct affect on the mechanical properties of the deposition. The titanium samples were sent to IMR Metallurgical Services where the oxygen content was determined by combustion-infrared absorbance, a method in accordance with ASTM E 1019-00. Ti-6Al-4V ELI powder was used for all experiments, where the ELI stands for extra low interstitials. The oxygen content of the Ti-6Al-4V ELI powder is approximately $0.12 \%$ wt. According to Donachie, the "maximum" impurity limit of oxygen for commercial Ti-6Al-4V is $0.20 \%$ wt. However, there is no absolute limit for the oxygen content, and other sources report acceptable values of 0.25 to $0.26 \%$. Hence, the allowable oxygen gain, from the starting powder oxygen content, ranges from 0.08 to $0.14 \%$ wt.

The powder efficiency is the percent of powder that is deposited divided by the amount of powder from the hopper. For example, the best powder efficiency is $100 \%$, which means that all of the powder fed from the hopper is melted in the weld pool and solidified into the deposition. Currently, the powder that is not deposited is not recovered and reused, because it is assumed that after exposure to high temperature and the air, the powder has excessive oxygen contamination. The powder efficiency is important in 
lowering the processing costs due the expensive cost of titanium powder, approximately $\$ 100$ dollars per pound. The powder efficiency is calculated by

$$
P E=100 \% * \frac{V * \rho}{H R^{*} t}
$$

where $\mathrm{V}$ is the final deposition volume, $\rho$ is the density, $\mathrm{HR}$ is the powder flow rate, and $\mathrm{t}$ is the total deposition time.

The build rate is the mass of titanium that is deposited per time. A high build rate not only correlates to a reduction in manufacturing time, but also a decrease in turn around time for the part. The short turnaround time is essential in rapid prototyping as previously discussed. In addition to increasing the productivity, the reduction in fabrication time reduces the manufacturing cost, by reducing the amount of process gases used. The build rate is

$$
B R=\frac{V * \rho}{t}
$$

where $\mathrm{V}$ is the deposition volume, $\rho$ is the density, and $\mathrm{t}$ is the total time.

The total build time, $t$, was calculated using

$$
t=\frac{(W P * L+L P * W) * N}{2 * u}
$$


in which WP and LP are the width and length passes, respectively, $L$ is the length, $W$ is the width, $\mathrm{N}$ is the number of layers, and $\mathrm{u}$ is the $\mathrm{CNC}$ velocity. The time is determined by multiplying the average distance traveled in one layer by the number of layers and dividing by the $\mathrm{CNC}$ velocity.

The energy density is a measure of the amount of energy into a specific amount of surface area. The energy density is determined by

$$
E D=\frac{P}{u^{*} d}
$$

where $\mathrm{P}$ is the laser power, $\mathrm{u}$ is the CNC velocity, and $\mathrm{d}$ is the beam diameter. The denominator in the equation (6) is the surface area traveled per time that the laser beam is in contact with. The energy density provides a way of grasping the "concentration" of energy that is being delivered to the build surface. For example, at a low power and fast CNC velocity, the energy density would be low because the low power laser is moving rapidly across the surface. On the other hand, at a high power setting and slow CNC velocity, the energy density would be high because the laser is supplying more energy over a shorter surface area.

The initial experiments, numbers one through four, were designed using a $2^{k}$ factorial design. The $2^{\mathrm{k}}$ factorial design of experiments involves setting $\mathrm{k}$ variables at two different values, usually a high and low value. Experiments one through four involve high and low values of laser power and CNC velocity. Experiments five and six repeated two of these runs at reduced gas flow rate. Table X, in Appendix I, shows the test parameters for conducting experiments one through six. Table IV on page xx contains 
the parameters for experiments seven through fourteen. The Results and Discussion of Results section explains the reasoning for choosing these parameters for experiments seven through fourteen based on experiments one through six. 


\section{RESULTS AND DISCUSSION OF RESULTS}

The test results from experiments one through six are contained in Table I. The spreadsheets in Appendix II have the complete analysis of the data including the parameters, test results, and calculated values.

\section{TABLE I}

EXPERIMENTS 1-6 WITH RESULTS

\begin{tabular}{|c|c|c|c|c|c|c|c|}
\hline \multirow{2}{*}{\multicolumn{2}{|c|}{$\begin{array}{c}\text { Test Number: } \\
\text { Laser Power (W) }\end{array}$}} & 1 & 2 & 3 & 4 & 5 & 6 \\
\hline & & 1860 & 1860 & 387 & 387 & 387 & 1860 \\
\hline \multirow{2}{*}{$\begin{array}{c}\text { CNC } \\
\text { Velocity }\end{array}$} & $(\mathrm{mm} / \mathrm{min})$ & 508 & 127 & 508 & 127 & 508 & 508 \\
\hline & (in/min) & 20 & 5 & 20 & 5 & 20 & 20 \\
\hline \multicolumn{2}{|c|}{ Gas Flow Rate } & 1 & 1 & 1 & 1 & $1 / 2$ & $1 / 2$ \\
\hline \multicolumn{2}{|c|}{$\begin{array}{c}\text { Powder Flow Rate } \\
(\mathrm{g} / \mathrm{min})\end{array}$} & 4.63 & 4.63 & 4.63 & 4.63 & 4.63 & 4.63 \\
\hline \multicolumn{2}{|c|}{ Oxygen gain $(\%)$} & 0.143 & 0.229 & 0.127 & 0.355 & 0.068 & 0.077 \\
\hline \multicolumn{2}{|c|}{$\begin{array}{c}\text { Powder efficiency } \\
(\%)\end{array}$} & 34 & 58 & 5 & 5 & 8 & 42 \\
\hline \multicolumn{2}{|c|}{ Build rate $(\mathrm{g} / \mathrm{min})$} & 1.57 & 2.70 & 0.214 & 0.254 & 0.349 & 1.92 \\
\hline
\end{tabular}

As previously discussed, the starting oxygen content of the powder is $0.124 \%$ and the impurity limit on oxygen is between 0.20 and $0.26 \%$. Therefore, when discussing the oxygen gain, it is desired to maintain an oxygen gain between 0.08 and $0.14 \%$ or less. The overall aim of the experiments is to obtain values for the powder efficiency and build rate as high as possible, while maintaining low oxygen gain.

There are several findings from the results of experiments one through six. Examining experiments one through four with high and low values of laser power and CNC velocity, experiment one has the "best" values of the four. Although experiment 
two has the highest values for powder efficiency and build rate, the oxygen gain was unacceptable. It is also observed that both the low velocity experiments have higher oxygen contents. In addition, at high and low velocities, increasing the laser power increases the powder efficiency and build rate. Therefore, the "best" experiment, with relatively low oxygen gain and relatively high powder efficiency and build rate, is the experiment at high laser power and high $\mathrm{CNC}$ velocity. This suggests that it is better to operate at high values of laser power and CNC velocity.

One of the main findings is the effect of reducing the gas flow rates on the oxygen content, powder efficiency, and build rate. Experiments five and six are identical to experiments one and three except the gas flow rate is decreased by $50 \%$. Comparing experiments one and six as well as three and five show an impressive difference. For both the high and low laser power experiments, decreasing the gas flow rate decreases the oxygen gain, and increases the powder efficiency and build rate. Looking at experiments one and six, the oxygen gain declined $46 \%$ from 0.143 to $0.077 \%$, below the maximum desired $0.08 \%$ gain. The powder efficiency increased $8 \%$ from $34 \%$ to $42 \%$ and the build rate increased $0.35 \mathrm{~g} / \mathrm{min}$ from $1.57 \mathrm{~g} / \mathrm{min}$ to $1.92 \mathrm{~g} / \mathrm{min}$. The same trend occurred when comparing the low laser power experiments, but not to the same extent as in the high laser power experiments. The low laser power experiments still had a $46 \%$ reduction in oxygen gain from 0.127 to $0.068 \%$, but the powder efficiency when up only $3 \%$. This suggests that the laser power has more of an effect on powder efficiency and build rate than the $\mathrm{CNC}$ velocity.

After gas flow calculations were conducted, it was found that the high gas flow rate produced a gas circulation pattern around the deposition. The high gas flow rate out 
of the nozzle was "drawing" in oxygen from the surrounding air environment into the shielding gas and contaminating the samples. In addition, it was concluded that the high gas flow rate was not accurately directing the powder into the weld pool. Rather, the gas flow rate was so high that it was blowing the powder away from the weld pool. These conclusions explain why the oxygen content decreased and the powder efficiency increased when the gas flow rate was reduced.

When comparing experiment five to six, the same trend in increasing laser power while maintain constant velocity is noticed as in experiment three to one. At the original gas flow rate, augmenting the laser power from 387 to $1860 \mathrm{~W}$ boosted the powder efficiency $29 \%$, while maintaining the same oxygen content. Similarly, at $50 \%$ gas flow rate, increasing the laser power from 387 to $1860 \mathrm{~W}$ enhanced the powder efficiency $34 \%$, while maintaining the same oxygen content. This implies that increasing the laser power at the same $\mathrm{CNC}$ velocity will increase the power efficiency and build rate, while maintaining low oxygen content. This hypothesis is tested in a subsequent experiment when the laser power is increased 50\% from 1860 to $2800 \mathrm{~W}$. Table II contain the results from mechanical testing, hardness testing, and density measurements, where UTS denotes the Ultimate Tensile Strength. The dimensions of the sample bars for these experiments are included in Table XVIII. Stress-strain curves were not obtained for experiments one through six. 
TABLE II

ADDITIONAL RESULTS OF EXPERIMENTS 1-6

\begin{tabular}{|c|c|c|c|c|c|c|c|}
\hline & 1 & 2 & 3 & 4 & 5 & 6 & $\begin{array}{c}\text { Commercial } \\
\text { Ti-6Al-4V }\end{array}$ \\
\hline UTS (MPa) & 2100 & 977 & 1323 & -- & 1894 & 2100 & 2200 \\
\hline Modulus (GPa) & 102 & 100 & 109 & --- & 109 & 107 & 105 \\
\hline Rockwell Hardness & 41 & 40 & 42 & 32 & 27 & 34 & 33 \\
\hline Density $\left(\mathrm{g} / \mathrm{cm}^{3}\right)$ & 4.33 & 4.31 & 4.19 & 4.21 & 4.21 & 4.37 & 4.34 \\
\hline Oxygen content (\%) & 0.26 & 0.35 & 0.25 & 0.47 & 0.19 & 0.20 & 0.17 \\
\hline
\end{tabular}

The most important observation from the testing results is that depositions five and six had very similar properties to the commercial Ti-6Al-4V. This shows the ability to successfully deposit Ti-6Al-4V with equivalent properties to those of regular Ti-6Al$4 \mathrm{~V}$. The mechanical properties of further experimentation were also compared to the commercial Ti-6Al-4V properties to confirm the quality of the deposition.

Although experiment one has similar ultimate tensile strength, modulus, and density to that of the commercial Ti-6Al-4V, the hardness and the oxygen content were different. Hardness is affected by many factors, one of which is oxygen content, so hardness values alone cannot indicate the degree of oxygen contamination. Comparing the hardness values and oxygen content of runs one through three to five and six, it might be concluded that increasing oxygen content causes higher hardness values. But test four exhibits a relatively "good" hardness value, however, it has the highest oxygen contamination. Therefore, the hardness value alone cannot be used to determine the extent of oxygen contamination. 
Figure 30 in Appendix II is a picture of two depositions. The deposition on the left has a shiny, silvery coloration with a moderate amount of discoloration around it, while the deposition on the right has a dull, dark brownish coloration. This alpha casing coloration is an indication of the degree of oxygen contamination, but similar to the hardness values, cannot be used alone to gage the level of oxygen contamination.

Of the first six experiments, the "best" experiment from the first series is number six. It had low oxygen content, while achieving a high powder efficiency and a high build rate. Therefore, the next set of experiments uses number six as its basis for the continued testing. The goal was to be able to further improve values of the powder efficiency and build rate, while maintaining low oxygen gain. Table III specifies the desired values of oxygen gain, powder efficiency, and build rate for the next experiments.

\section{TABLE III}

\section{OBJECTIVES OF EXPERIMENTAL SET TWO}

\begin{tabular}{|c|c|c|c|c|}
\hline $\begin{array}{c}\text { Experimental } \\
\text { Objective }\end{array}$ & $\begin{array}{c}\text { Build rate } \\
(\mathrm{g} / \mathrm{min})\end{array}$ & $\begin{array}{c}\text { Oxygen gain } \\
(\%)\end{array}$ & $\begin{array}{c}\text { Powder } \\
\text { efficiency }(\%)\end{array}$ & $\begin{array}{c}\text { Material } \\
\text { properties }\end{array}$ \\
\hline Basis (\#6) & 2.0 & 0.08 & 43 & Dense, ductile \\
\hline $\begin{array}{c}\text { Increase build } \\
\text { rate (\#8) }\end{array}$ & 4.0 & $\leq 0.08$ & $\geq 40$ & Dense, ductile \\
\hline $\begin{array}{c}\text { Increase Powder } \\
\text { Efficiency (\#9) }\end{array}$ & $\geq 2.0$ & $\leq 0.08$ & 60 & Dense, ductile \\
\hline $\begin{array}{c}\text { Increase both } \\
(\# 10)\end{array}$ & $\geq 4.0$ & $\leq 0.08$ & $\geq 60$ & Dense, ductile \\
\hline
\end{tabular}

As Table III indicates, the subsequent trials seek to double the build rate, increase the powder efficiency, and then increase both the build rate and powder efficiency, all while keeping low oxygen gain and dense, ductile material. It was hypothesized that 
doubling the powder flow rate would double the build rate and that increasing the laser power and CNC velocity would increase the powder efficiency. Previously discussed, experiments one through four showed that operating at higher laser power and CNC velocity provided better values for the powder efficiency and build rate with low oxygen gain. Hence, the hypothesis that increasing the laser power and CNC velocity would increase the powder efficiency is valid based on these results. A laser power of $2600 \mathrm{~W}$ and CNC velocity of $711.2 \mathrm{~mm} / \mathrm{min}$ ( $28 \mathrm{in} / \mathrm{min}$ ) were chosen in order to maintain the same energy density as $1860 \mathrm{~W}$ and $508 \mathrm{~mm} / \mathrm{min}(20 \mathrm{in} / \mathrm{min})$.

The results from experiments five and six suggest that increasing the laser power at constant CNC velocity would maintain low oxygen content as the powder efficiency and build rate increased. To test this trend, the laser power was increased 50\% from 1860 to $2800 \mathrm{~W}$. The first set of tests implied that decreasing the gas flow rate, diminished oxygen gain, and boosted powder efficiency and build rate. So another experiment was added to test the effect of reducing the gas flow rate another 50\%. Another experiment was added to test the effect of the deposition dimensions by reducing the final deposition width. Table IV lists the parameters for numbers seven through fourteen. 
TABLE IV

TEST PARAMETERS FOR EXPERIMENTS 7-14

\begin{tabular}{|c|c|c|c|c|c|c|c|c|c|}
\hline \multicolumn{2}{|c|}{ Test Number } & 7 & 8 & 9 & 10 & 11 & 12 & 13 & 14 \\
\hline \multicolumn{2}{|c|}{ Laser Power (W) } & 1860 & 1860 & 2600 & 2600 & 1860 & 2800 & 1860 & 1860 \\
\hline $\begin{array}{c}\text { CNC } \\
\text { Velocity }\end{array}$ & $(\mathrm{mm} / \mathrm{min})$ & 508 & 508 & 711.2 & 711.2 & 508 & 508 & 508 & 508 \\
\hline \multicolumn{2}{|c|}{ Gas Flow Rate } & 20 & 20 & 28 & 28 & 20 & 20 & 20 & 20 \\
\hline \multicolumn{2}{|c|}{$\begin{array}{c}\text { Powder Flow Rate } \\
\text { (g/min) }\end{array}$} & 4.63 & 9.26 & 4.63 & 9.26 & 4.63 & 4.63 & 4.63 & 4.63 \\
\hline
\end{tabular}

Tests seven through thirteen use a different scheme for determining the tool path factors than what was previously used. Accordingly, experiment seven is just like experiment six except it includes these tool path differences. Test number eight has double powder flow rate and nine has increased laser power and CNC velocity, while experiment 10 has both parameter changes. Number 11 incorporates the $50 \%$ reduction in final deposition width, and test 12 tests the increase in laser power at constant $\mathrm{CNC}$ velocity. Experiment 13 investigates the trend in gas flow rate by reducing it another $50 \%$. Lastly, number 14 is an exact replicate of six in order to test the repeatability of the DMD process. The next step in conducting these experiments is to calculate the required tool path factors, using the process parameters, and develop the tool path programs.

These deposition factors involve the line width and build height per layer. The line width and build height per layer were determined for the first series from a preliminary "line width" experiment. In this "line width" experiment, single deposition lines at different laser powers and CNC velocities were used to obtain the line width and build height for tests one through six. Table $V$ contains a comparison of the input values 
to the actual values of these tool path factors, such as line width and build height per layer.

\section{TABLE V}

COMPARISON OF TOOL PATH FACTORS FOR EXPERIMENTS 1-6

\begin{tabular}{|c|c|c|c|c|c|c|}
\hline & 1 & 2 & 3 & 4 & 5 & 6 \\
\hline $\begin{array}{c}\text { Desired deposition } \\
\text { height (mm) }\end{array}$ & 4.57 & 4.19 & 1.52 & 13.2 & 1.52 & 2.74 \\
\hline $\begin{array}{c}\text { Actual deposition } \\
\text { height (mm) }\end{array}$ & 9.00 & 10.90 & 5.00 & 7.60 & 8.40 & 6.50 \\
\hline $\begin{array}{c}\text { Input build height } \\
\text { (mm/layer) }\end{array}$ & 0.229 & 0.838 & 0.076 & 1.02 & 0.076 & 0.229 \\
\hline $\begin{array}{c}\text { Actual build height } \\
\text { (mm/layer) }\end{array}$ & 0.450 & 2.18 & 0.250 & 0.585 & 0.420 & 0.542 \\
\hline $\begin{array}{c}\text { Input line width } \\
\text { (mm) }\end{array}$ & 1.19 & 1.65 & 0.14 & 0.35 & 0.14 & 1.19 \\
\hline $\begin{array}{c}\text { Actual line width } \\
\text { (mm) }\end{array}$ & 1.43 & 2.13 & 0.400 & 0.811 & 0.386 & 1.45 \\
\hline
\end{tabular}

With the exception of experiment four, all the depositions had a greater actual build height per layer than what was input into the tool path. Consequently, the deposition built faster than the nozzle was progressing vertically so the deposition surface was advancing toward the nozzle. This reduces the effective beam diameter on the deposition surface. Clearly, the input values were inaccurate, indicating the need for a model to accurately predict the required tool path factors.

The proposed model for predicting these factors is based on a simple conservation of volume calculation. For a single deposition line, the volume deposition 
rate is the line width times the build height per layer times the CNC velocity. The build height per layer is

$$
Z=\frac{V R}{u^{*} L W}
$$

where VR is the volumetric deposition rate, $\mathrm{LW}$ is the line width, and $\mathrm{u}$ is the CNC velocity. The volume deposition rate is calculated with

$$
V R=\frac{B R}{\rho}
$$

in which BR is the build rate and $\rho$ is the deposition density. The build rate is determined by

$$
B R=P E^{*} H R
$$

where $\mathrm{PE}$ is the powder efficiency and HR is the powder flow rate. Combining these three equations, the build height per layer was calculated using

$$
Z=\frac{P E^{*} H R}{\rho^{*} u^{*} L W}
$$

for experiments seven through thirteen. 
The powder flow rate and the CNC velocity are DMD parameters that are specified for each experiment. Obtained from literature, the density of Ti-6Al-4V used in the prediction calculations was $4.507 \mathrm{~g} / \mathrm{cm}^{3}$. For experiments seven through thirteen, the line width was specified as the same value as the laser beam width, $1.35 \mathrm{~mm}$. This value was chosen because it would allow for the entire deposition surface to be exposed to the laser beam. The powder efficiency was calculated by trending the limited data from tests one through six. The estimation of the powder efficiency attempted to include effects from laser power, $\mathrm{CNC}$ velocity, and gas flow rates. These estimations and the corresponding values for build height per layer are contained in Table XI in Appendix I.

The estimation for the powder efficiency is incorrect because experiments nine and ten, that are supposed to increase the powder efficiency by $20 \%$, only increased it by 1\%. However, the prediction did double the build rate for numbers eight and ten. The validity of the estimation method and equations are evaluated when compared to actual values from seven through thirteen. Using these estimated values, the tool paths for each experiment were developed and conducted.

The spreadsheet in Appendix I contains the complete analysis of all the experiments. In this spreadsheet, experiments seven through fourteen that were conducted correctly are indicated with a letter $\mathrm{D}$ beside the test number. Tests with an $\mathrm{A}$ introduced an additional, unnecessary variable into the process, a time delay between layers. No calculations or testing was done with B experiments, in which the incorrect tool path was used. Those with a letter $\mathrm{C}$ were conducted when there were leaks in the gas flow system, resulting in extreme oxygen contamination of the samples. The oxygen gain ranged from 0.260 to $1.115 \%$ wt of oxygen with an average oxygen gain of 
0.7061\%. Although this experimentation incorporated critical errors, it shows the severe effect of gas leaks on oxygen contamination and the importance of maintaining a leakfree gas system. The subsequent discussion of the results of tests seven through fourteen deals only with those conducted correctly.

The results of numbers seven through fourteen are included in Table VI.

\section{TABLE VI}

EXPERIMENTS 7-14 WITH RESULTS

\begin{tabular}{|c|c|c|c|c|c|c|c|c|c|}
\hline \multicolumn{2}{|c|}{ Test Number } & 7 & 8 & 9 & 10 & 11 & 12 & 13 & 14 \\
\hline \multicolumn{2}{|c|}{ Laser Power (W) } & 1860 & 1860 & 2600 & 2600 & 1860 & 2800 & 1860 & 1860 \\
\hline \multirow{2}{*}{$\begin{array}{c}\text { CNC } \\
\text { Velocity }\end{array}$} & $(\mathrm{mm} / \mathrm{min})$ & 508 & 508 & 711.2 & 711.2 & 508 & 508 & 508 & 508 \\
\cline { 2 - 11 }$(\mathrm{in} / \mathrm{min})$ & 20 & 20 & 28 & 28 & 20 & 20 & 20 & 20 \\
\hline \multicolumn{2}{|c|}{ Gas Flow Rate } & $1 / 2$ & $1 / 2$ & $1 / 2$ & $1 / 2$ & $1 / 2$ & $1 / 2$ & $1 / 4$ & $1 / 2$ \\
\hline $\begin{array}{c}\text { Powder Flow Rate } \\
\text { (g/min) }\end{array}$ & 4.63 & 9.26 & 4.63 & 9.26 & 4.63 & 4.63 & 4.63 & 4.63 \\
\hline \multicolumn{2}{|c|}{ Oxygen gain (\%) } & 0.070 & 0.052 & 0.200 & 0.136 & 0.108 & 0.181 & 0.084 & 0.079 \\
\hline $\begin{array}{c}\text { Powder efficiency } \\
(\%)\end{array}$ & 33 & 35 & 51 & 54 & 40 & 59 & 44 & 46 \\
\hline \multicolumn{2}{|c|}{ Build rate (g/min) } & 1.55 & 3.26 & 2.34 & 4.97 & 1.83 & 2.74 & 2.06 & 2.12 \\
\hline
\end{tabular}

Comparing the results of experiments six and fourteen show that both have almost identical values for oxygen gain, powder efficiency, and build rate. This confirms that the results from the DMD process can be repeated and reproduced for future operation. In addition to verifying the repeatability, comparison validates similar operating conditions between the two series, allowing for cross evaluation. Comparing experiments fourteen and seven show the effect of the tool path changes on the powder efficiency and build rate. The oxygen gain decreased from 0.079 to $0.070 \%$, while the 
powder efficiency declined $13 \%$ and the build rate $0.57 \mathrm{~g} / \mathrm{min}$, suggesting that these properties are affected by the manner in which the component is built. Additional research is necessary to understand the effect of tool path factors on deposition characteristics such as oxygen content, powder efficiency, and build rate.

The objective in test eight was to double the build rate, so the powder flow rate was doubled. Comparing seven and eight shows that not only did the build rate double, but also the oxygen gain decreased $0.018 \%$. The aim of number nine was to increase the powder efficiency approximately $20 \%$, while maintaining an oxygen gain of less that $0.08-0.14 \%$. Comparing experiments seven and nine shows an improvement in powder efficiency of $18 \%$. This indicates that an increase in the laser power and $\mathrm{CNC}$ velocity yields higher powder efficiency, but the higher laser power increases the oxygen gain. Test 10 successfully increased both the build rate and the powder efficiency. However, similar to nine, increasing the laser power and $\mathrm{CNC}$ velocity to improve the powder efficiency resulted in an increase in the oxygen gain. These results show that the powder efficiency can be improved, but at the price of increasing the oxygen contamination.

In comparing experiments seven to eight and nine to ten, it is observed that in addition to the decrease in oxygen gain and increase in build rate, both maintain the same powder efficiency. This means that even though the amount of powder delivered to the surface is double, the same percentage of the powder is deposited, hence, directly doubling the build rate. However, if the powder flow rate continued to increase, it is theorized that eventually there would be a limit on the quantity of powder able to be successfully injected into the weld pool. Until this maximum, the powder efficiency would be the same, but once this theoretical maximum is attained, the powder efficiency 
would begin to decrease because the excess powder would be blown away and not deposited. Also, if the powder rate approaches this hypothetical maximum, rather than a decrease in powder efficiency, there could be a decline in the deposition quality due to a lack of fusion of all the injected powder. Obviously, at higher laser powers, more energy is delivered to the surface of the deposition, allowing for a larger amount of powder to be deposited. Based on this, further testing must be conducted before concluding that the powder efficiency is independent of the powder flow rate.

The results from experiment 11 , in which the final deposition width was less than that of experiment seven, suggests that decreasing the width had little effect on the deposition properties. The oxygen gain only increased $0.0308 \%$, while the powder efficiency improved $7 \%$ and build rate $0.28 \mathrm{~g} / \mathrm{min}$.

Test 12 attempted to extent the trend noticed between numbers five and six, where the powder efficiency and build rate dramatically increased with no additional oxygen gain. Due to the decrease in powder efficiency and build rate because of the tool path difference, the values for experiment 12 are actually lower than if conducted using a similar tool path program as five or six. Aside from this difference, the powder efficiency and build rate did improve as predicted, but the oxygen gain did not continue at an acceptable level. Similar to the conclusion from increasing the laser power and CNC velocity, the enhancement of the powder efficiency and build rate occurred at the cost of increased oxygen contamination.

Experiment 13 had an increase in powder efficiency of $11 \%$ and build rate of 0.51 $\mathrm{g} / \mathrm{min}$ as a consequence of reducing the gas flow rate by another $50 \%$ from number seven. Additionally, the oxygen gain increased only a minor amount from $0.070 \%$ to 
$0.084 \%$. This increase in powder efficiency supports the previous proposition that the high gas flow rates are forcing some powder away from the deposition instead of focusing it into the weld pool. However, the minor addition in oxygen gain is hypothesized to indicate inadequate shielding around the deposition. The process gases that are reduced include the shaping gas, that directs the powder into the weld pool, and the nozzle gas, that forms a layer of inert shielding gas around the deposition. Therefore, this experiment suggests that the reduction in the shaping gas is still beneficial toward powder efficiency, while the simultaneous reduction in the nozzle gas could become detrimental to the oxygen pickup. Clearly, as the gas flow rate is diminished to zero, the absence of both a powder-focusing gas and shielding gas would drastically drop the powder efficiency and amplify the oxygen contamination. Consequently, there is a maximum powder efficiency and a minimum oxygen gain that can be achieved at a particular shaping and nozzle gas flow rate. Research should continue to investigate further reduction in gas flow rates, examine manipulating each individual process gas, and test the hypothesis of maximum powder efficiency and minimum oxygen pickup.

Table VII consists of the results from oxygen analysis, mechanical testing, hardness testing, and density measurement. The dimensions of the tested sample bars for this set of experiments are included in Table XIX. The certificate of oxygen analysis and mechanical testing stress-strain curves are contained in Appendix II. When examining the stress-strain curves, the curves do not begin at the origin because the Instron fixture was not directly against the specimen when the test started. 


\section{TABLE VII}

\section{ADDITIONAL RESULTS OF EXPERIMENTS 7-14}

\begin{tabular}{|c|c|c|c|c|c|c|c|c|c|}
\hline & 7 & 8 & 9 & 10 & 11 & 12 & 13 & 14 & $\begin{array}{l}\text { Commercial } \\
\text { Ti-6Al-4V }\end{array}$ \\
\hline $\begin{array}{c}\text { UTS } \\
\text { (MPa) }\end{array}$ & 2350 & * & * & 2067 & 2300 & 1870 & 2200 & 2366 & 2700 \\
\hline $\begin{array}{l}\text { Modulus } \\
(\mathrm{GPa})\end{array}$ & 92 & * & * & 88 & 100 & 99 & 93 & 96 & 130 \\
\hline $\begin{array}{c}\text { Strain to } \\
\text { failure (\%) }\end{array}$ & $\begin{array}{c}>10 . \\
3\end{array}$ & * & * & 6.15 & 9.25 & 2.95 & 7.61 & 7.33 & $>10.57$ \\
\hline $\begin{array}{l}\text { Rockwell } \\
\text { Hardness }\end{array}$ & 34 & 33 & 34 & 31 & 31 & 33 & 30 & 33 & \\
\hline $\begin{array}{l}\text { Density } \\
\left(\mathrm{g} / \mathrm{cm}^{3}\right)\end{array}$ & 4.54 & 4.46 & 4.52 & 4.35 & 4.34 & 4.30 & 4.28 & 4.41 & \\
\hline $\begin{array}{c}\text { Oxygen } \\
\text { content }(\%)\end{array}$ & 0.196 & 0.178 & 0.326 & 0.262 & 0.234 & 0.307 & 0.210 & 0.205 & 0.17 \\
\hline
\end{tabular}

*Testing conducted at incorrect span setting

The three-point flexure testing was accidentally conducted under a compression test program instead of a flexure test, but the flexural calculation equations, in Appendix II, were used to calculate the correct stress-strain values. In addition, experiment eight and nine were conducted at an incorrect span setting, so no acceptable values for the mechanical testing were obtained.

The commercial Ti-6Al-4V sample has slightly higher values of the ultimate tensile strength and modulus than the sample tested with experiments one through six. Nevertheless, comparing these samples with the values of the commercial Ti-6Al-4V indicate that with the exception of tests 10 and 12, all the samples have comparable properties to that of commercial Ti-6Al-4V. Examining the stress-strain curves of experiments seven through fourteen, in Appendix II, show that after a linear region of increasing stress, there is a deformation region where the sample bars were bending. The 
comparison of the stress-strain curves of the samples with that of the commercial Ti-6Al$4 \mathrm{~V}$ material confirms their equivalent mechanical properties. The strain-to-failure is a value of the amount of strain the sample endured until it failed, and hence is a means of comparing the ductility of the samples. Comparing the strain-to-failure values show that sample seven, which never failed, has the highest value, which is almost identical to the commercial Ti-6Al-4V substrate. Again, samples 11, 13, and 14 have similar strain-tofailure values, but samples 10 and 12 have reduced values.

Looking at the stress-strain curves of experiments seven through fourteen $\mathrm{C}$ in Appendix II, with extremely high oxygen content, it is clearly noticeable that there is very little strain until failure with no deformation section due to its enbrittlement by the oxygen. This again confirms that experiments seven through fourteen $\mathrm{D}$ have relatively good ductility and mechanical properties. Figure 29 in Appendix II is a picture of the bent sample bar of the commercial Ti-6Al-4V substrate after the mechanical testing. Experiments with similar stress-strain diagrams to the substrate, exhibited this same type of ductility and deformation. Mainly, these results show that experiments seven, eleven, thirteen, and fourteen are fully dense depositions with mechanical properties comparable to commercial Ti-6Al-4V, including having low oxygen content, and acceptable hardness.

Table VIII involves the comparison between the tool path factors inputted and the actual factors. 
TABLE VIII

COMPARISON OF TOOL PATH FACTORS FOR EXPERIMENTS 7-14

\begin{tabular}{|c|c|c|c|c|c|c|c|c|}
\hline & 7 & 8 & 9 & 10 & 11 & 12 & 13 & 14 \\
\hline $\begin{array}{c}\text { Desired } \\
\text { deposition height } \\
\text { (mm) }\end{array}$ & 12.70 & 12.70 & 12.70 & 12.19 & 12.70 & 12.95 & 12.70 & 3.89 \\
\hline $\begin{array}{c}\text { Actual deposition } \\
\text { height (mm) }\end{array}$ & 7.59 & 7.99 & 10.11 & 10.23 & 7.84 & 10.92 & 10.69 & 10.23 \\
\hline $\begin{array}{c}\text { Input build height } \\
\text { (mm/layer) }\end{array}$ & 0.635 & 1.270 & 0.508 & 1.016 & 0.635 & 0.762 & 0.635 & 0.229 \\
\hline $\begin{array}{c}\text { Actual build } \\
\text { height (mm/layer) }\end{array}$ & 0.380 & 0.799 & 0.405 & 0.853 & 0.392 & 0.643 & 0.535 & 0.602 \\
\hline $\begin{array}{c}\text { Input line width } \\
\text { (mm) }\end{array}$ & 1.35 & 1.35 & 1.35 & 1.35 & 1.35 & 1.35 & 1.35 & 1.19 \\
\hline $\begin{array}{c}\text { Actual line width } \\
\text { (mm) }\end{array}$ & 1.69 & 1.70 & 1.71 & 1.78 & 1.85 & 1.82 & 1.68 & 1.44 \\
\hline
\end{tabular}

Unlike the first series of experiments where the deposition built faster than the nozzle progressed, these results show that the deposition built slower than the nozzle progression. Every experiment, except the duplicate experiment 14, had values of the actual final deposition height and actual build height per layer less than the input values. Like the previous experiment, these differences between the actual build height per layer and the vertical progression of the nozzle causes a change in the effective beam diameter on the deposition surface. For the first set of experiments, when the deposition surface begins to get close to the nozzle, the effective beam diameter is reduced. Conversely, when the nozzle begins to move away from the deposition surface, the effective beam diameter begin to increase, which enlarges the surface area exposed to the laser beam and possibly enlarging the effective weld pool size. 
If the increased surface area exposed to the laser beam increases the size of the weld pool, then it could be deduced that the effective line width would also increase. This is true when examining the second series of experiments, but the actual line width is greater in the first set of experiments where the effective beam diameter decreased. The first group of experiments had larger values of both the line width as well as the build height per layer. This means that a greater volume of titanium was actually deposited then what was estimated, which could account for the increase in the actual line width. Therefore, further research is needed to be able to draw any conclusions about the effect of beam diameter on line width or other factors.

Examining the differences between the actual and inputted values for the line width and the build height per layer shows that the actual deposition built shorter and wider than what was anticipated. This could imply an "aspect ratio" exists between the build width and the height of the deposition. Rather than building taller and narrower as predicted, the deposition built shorter and wider. Also, experiments seven through thirteen all had the same inputted line width of $1.35 \mathrm{~mm}$. But the difference between the actual line width and the inputted line width is different for each experiment. In fact, the line width increased when the powder flow rate was increased, for experiments eight and ten, and then when the laser power increased, for experiments nine, ten, and twelve. Additional research is required in order to examine this build "aspect ratio" between the line width and build height as well as further experimentation on the effect of process parameters on these tool path factors.

Experiment 11, with the reduced final deposition width, had the largest actual line width and therefore the largest deviation from the inputted values. The reason for this is 
because the number of width passes set by the tool path program is not exact to produce the desired width. Using the same line width, a larger deposition width could be produced more accurately than a smaller deposition width because the number of width passes for the larger deposition would better correspond to the desired width than the smaller width. In addition, using a smaller line width would produce more accurate results than using a larger line width for the same final width. The actual line width for experiments three, four and five at low laser power were much smaller than those of at higher power levels, indicating a direct correlation between the line width and the laser power. Not only is this important with regards to the ability to build accurate dimensions, but also indicates a minimum allowable width at a particular laser power. For instance, the smallest width using the process parameters of experiment 11 would be $1.85 \mathrm{~mm}$ whereas the smallest width using experiment five would be $0.386 \mathrm{~mm}$. Therefore, in order to build thin wall structures such as internal ribs, this relationship suggests a maximum laser power level that will produce the desired line width, above which would produce a larger line width.

Although the predicted values of the powder efficiency were incorrect, the conservation of volume equation,

$$
Z=\frac{P E^{*} H R}{\rho^{*} u^{*} L W}
$$

, which calculates the build height per layer based on volumetric deposition rate, still may be a valid equation. Hence, Table XII and Table XIII in Appendix I compares the actual values of the build height per layer to those calculated by equation (10) using the actual 
values for the powder efficiency and line width. The percent errors between the actual and calculated build heights per layer are shown in Tables XII and XIII. Using the correct values of line width and powder efficiency for equation (10), there is an average error of only $5.0 \%$ between the actual and calculated build heights per layer. This confirms that equation 10 is a valid model for predicting the build height per layer if the other input values are correct. This research shows that the powder efficiency is affected by several parameters, such as the laser power, CNC velocity, gas flow rates, and the tool path. Additional research is necessary to develop an accurate model for the powder efficiency. 


\section{CONCLUSIONS}

- The DMD process can produce depositions with equivalent properties, such as oxygen content, hardness, density, and mechanical properties, to those of commercial Ti-6Al-4V.

- Increasing the laser power and $\mathrm{CNC}$ velocity or increasing only the laser power increases the powder efficiency and build rate but at high laser powers also increases the oxygen pickup.

- Decreasing the gas flow rate decreases oxygen gain as well as increasing the powder efficiency and build rate.

- Increasing the powder flow rate proportionally increases the build rate while maintaining similar powder efficiency and slightly lowering the oxygen pickup.

- Change in build geometry has minor effect on the deposition properties but is a concern with regard to depositing accurate dimensions.

- Results from the DMD process are repeatable and reproducible.

- Conservation of volume is confirmed to be an adequate model for predicting the build height per layer, using correct input values. 


\section{RECOMMENDATIONS}

- Determine an accurate model for predicting the powder efficiency.

- Examine the effect of further reduction in gas flow rates as well as the effect of the individual gas flow rates.

- Test the effect of further increasing the powder flow rate on powder efficiency.

- Investigate the relationship between the line width and build height per layer and the effect of laser power on this relationship.

- Assess the effect of tool path factors on deposition properties, such as oxygen content, powder efficiency, and build rate.

- Examine the effect of laser beam diameter on factors, such as line width and powder efficiency.

- Utilize the optical feedback system for more accurate dimensional control. 


\section{LIST OF REFERENCES}

Arcella, F. G. and Froes, F. H. 2000. Producing Titanium Aerospace Components from Powder Using Laser Forming. JOM May:29-30.

Donachie , M. J. Jr. 1988. Titanium; A Technical Guide. Ohio: ASM International.

Collins, P. C., Banerjee, R., Banerjee, S., and Fraser, H. L. 2003. Laser deposition of compositionally graded titanium-vanadium and titanium-molybdenum alloys. Materials Science and Engineering A352:118-128.

Kobryn, P. A., Moore, E. H., and Semiatin, S. L. 2000. The effect of laser power and traverse speed on microstructure, porosity, and build height in laser-deposited Ti6Al-4V. Scripta mater 43:299-305.

Srivastava, D., Chang, I. T. H., and Loretto, M. H. 2000. The optimization of processing parameters and characterization of microstructure of direct laser fabricated TiAl alloy components. Materials and Design 21:425-433.

Srivastava, D., Chang, I. T. H., and Loretto, M. H. 2001. The effect of process parameters and heat treatment on the microstructure of direct laser fabricated TiAl alloy samples. Intermetallics 9:1003-1013.

Wu, X., Sharman, R., Mei, J. and Voice, W. 2002. Direct laser fabrication and microstructure of a burn-resistant Ti alloy. Materials and Design 23:239-247. 


\section{BIBLIOGRAPHY}

Arcella, F. G. and Froes, F. H. 2000. Producing Titanium Aerospace Components from Powder Using Laser Forming. JOM May:29-30.

Donachie , M. J. Jr. 1988. Titanium; A Technical Guide. Ohio: ASM International.

Collins, P. C., Banerjee, R., Banerjee, S., and Fraser, H. L. 2003. Laser deposition of compositionally graded titanium-vanadium and titanium-molybdenum alloys. Materials Science and Engineering A352:118-128.

Griffith, M. L., Schlienger, M. E., Harwell, L. D., Oliver, M. S., Baldwin, M. D., Ensz, M. T., Essien, M., Brooks, J., Robino, C. V., Smugeresky, J. E., Hofmeister, W. H., Wert, M. J. and Nelson, D. V. 1999. Understanding the thermal behavior in the LENS process. Materials and Design 20:107-113.

Kobryn, P. A. and Semiatin, S. L. 2003. Microstructure and texture evolution during solidification processing of Ti-6Al-4V. Journal of Materials Processing Technology 135:330-339.

Kobryn, P. A., Zimmer, W. H., Perkins, L. P., Bohun, M. H., and Ivey, R. B. 2002. Rapid fabrication of replacement components via laser additive manufacturing of titanium. $6^{\text {th }}$ Joint FAA/DoD/NASA Aging Aircraft Conference - Sept.16-19 $: 1-7$

Kobryn, P. A., Moore, E. H., and Semiatin, S. L. 2000. The effect of laser power and traverse speed on microstructure, porosity, and build height in laser-deposited Ti6Al-4V. Scripta mater 43:299-305.

Lewis, G. K. and Schlienger, E. 2000. Practical considerations and capabilities for laser assisted direct metal deposition. Materials and Design 21:417-423.

Moll, J. H. 2000. Utilization of Gas-Atomized Titanium and Titanium-Aluminide Powder. JOM May: 32-34,42.

Pinkerton, A. J. and Li, L. 2003. Rapid prototyping using direct laser-deposition--the effect of powder atomization type and flowrate. Proc. Instn Mech. Engrs 217 B:741-752.

Schwendner, K. I., Banerjee, R., Collins, P. C., Brice, C. A., and Fraser, H. L. 2001. Direct laser deposition of alloys from elemental powder blends. Scripta Materialia 45:1123-1129. 
Srivastava, D., Chang, I. T. H., and Loretto, M. H. 2000. The optimization of processing parameters and characterization of microstructure of direct laser fabricated TiAl alloy components. Materials and Design 21:425-433.

Srivastava, D., Chang, I. T. H., and Loretto, M. H. 2001. The effect of process parameters and heat treatment on the microstructure of direct laser fabricated TiAl alloy samples. Intermetallics 9:1003-1013.

Starr, T. L. 2004. Private communication.

Thomas, A. 2004. Fabrication of Ti-6Al-4V using direct metal deposition (DMD) process. M.S. Thesis, University of Louisville.

Vicars, J. W. III 2004. Private communication.

Wu, X., Sharman, R., Mei, J. and Voice, W. 2002. Direct laser fabrication and microstructure of a burn-resistant Ti alloy. Materials and Design 23:239-247. 
APPENDIX I 
TABLE IX

PROCESS GAS FLOW RATES

\begin{tabular}{|c|c|c|c|c|c|c|c|}
\hline \multirow{2}{*}{ Process Gas } & \multirow{2}{*}{ Gas Type } & \multicolumn{2}{|c|}{1} & \multicolumn{2}{|c|}{$1 / 2$} & \multicolumn{2}{|c|}{$1 / 4$} \\
\cline { 3 - 8 } & & Analog & $\begin{array}{c}\text { Actual } \\
(\text { LPM })\end{array}$ & Analog & $\begin{array}{c}\text { Actual } \\
(\text { LPM) }\end{array}$ & Analog & $\begin{array}{c}\text { Actual } \\
(\text { LPM) }\end{array}$ \\
\hline Shaping gas & Argon & 1900 & 28.4 & 950 & 14.2 & 475 & 7.02 \\
\hline Cover Gas & Argon & 80 & 2.8 & 80 & 1.4 & 80 & 1.38 \\
\hline \multirow{2}{*}{ Carrier Gas } & Argon & 150 & 4.74 & 150 & 2.37 & 150 & 2.34 \\
\cline { 2 - 8 } & Helium & 100 & 2.22 & 100 & 1.11 & 100 & 1.07 \\
\hline \multirow{2}{*}{ Nozzle Gas } & Argon & 1300 & 20.2 & 650 & 10.1 & 325 & 5.09 \\
\cline { 2 - 8 } & Helium & 400 & 5.64 & 200 & 2.82 & 100 & 1.49 \\
\hline
\end{tabular}

TABLE X

TEST PARAMETERS FOR EXPERIMENTS 1-6

\begin{tabular}{|c|c|c|c|c|c|c|c|}
\hline \multicolumn{2}{|c|}{ Test Number } & 1 & 2 & 3 & 4 & 5 & 6 \\
\hline \multicolumn{2}{|c|}{ Laser Power (W) } & 1860 & 1860 & 387 & 387 & 387 & 1860 \\
\hline \multirow{2}{*}{$\begin{array}{c}\text { CNC } \\
\text { Velocity }\end{array}$} & (mm/min) & 508 & 127 & 508 & 127 & 508 & 508 \\
\cline { 2 - 8 } & (in/min) & 20 & 5 & 20 & 5 & 20 & 20 \\
\hline \multicolumn{2}{|c|}{ Gas Flow Rate } & 1 & 1 & 1 & 1 & $1 / 2$ & $1 / 2$ \\
\hline $\begin{array}{c}\text { Powder Flow Rate } \\
\text { (g/min) }\end{array}$ & 4.63 & 4.63 & 4.63 & 4.63 & 4.63 & 4.63 \\
\hline
\end{tabular}


TABLE XI

ESTIMATION OF TOOL PATH FACTORS FOR EXPERIMENTS 7-13

\begin{tabular}{|c|c|c|c|c|c|c|c|}
\hline & 7 & 8 & 9 & 10 & 11 & 12 & 13 \\
\hline $\begin{array}{c}\text { Powder flow rate } \\
\text { (g/min) }\end{array}$ & 4.63 & 9.26 & 4.63 & 9.26 & 4.63 & 4.63 & 4.63 \\
\hline $\begin{array}{c}\text { CNC } \\
\text { velocity }\end{array}$ (mm/min) & 508 & 508 & 711.2 & 711.2 & 508 & 508 & 508 \\
\hline $\begin{array}{c}\text { Line width } \\
\text { (mm) }\end{array}$ & 20 & 20 & 28 & 28 & 20 & 20 & 20 \\
\hline $\begin{array}{c}\text { Estimate powder } \\
\text { efficiency (\%) }\end{array}$ & 43 & 43 & 44 & 44 & 43 & 54 & 47 \\
\hline $\begin{array}{c}\text { Calculated build rate } \\
\text { (g/min) }\end{array}$ & 2.0 & 4.0 & 2.0 & 4.1 & 2.0 & 2.5 & 2.2 \\
\hline $\begin{array}{c}\text { Calculated build } \\
\text { height (mm/layer) }\end{array}$ & 0.64 & 1.3 & 0.51 & 1.0 & 0.64 & 0.76 & 0.64 \\
\hline
\end{tabular}

TABLE XII

VERIFICATION OF BUILD HEIGHT EQUATION USING EXPERIMENTS 1-6

\begin{tabular}{|c|c|c|c|c|c|c|}
\hline & 1 & 2 & 3 & 4 & 5 & 6 \\
\hline $\begin{array}{c}\text { Powder efficiency } \\
(\%)\end{array}$ & 34 & 58 & 5 & 5 & 8 & 42 \\
\hline $\begin{array}{c}\text { Powder flow rate } \\
\text { (g/min) }\end{array}$ & 4.63 & 4.63 & 4.63 & 4.63 & 4.63 & 4.63 \\
\hline $\begin{array}{c}\mathrm{CNC} \text { (mm/min) } \\
\text { velocity }\end{array}$ & 508 & 127 & 508 & 127 & 508 & 508 \\
\hline $\begin{array}{c}\text { Actual Line Width } \\
\text { (mm) }\end{array}$ & 20 & 5 & 20 & 5 & 20 & 20 \\
\hline $\begin{array}{c}\text { Actual build height } \\
\text { (mm/layer) }\end{array}$ & 0.450 & 2.18 & 0.250 & 0.585 & 0.420 & 0.542 \\
\hline $\begin{array}{c}\text { Calculated build } \\
\text { height (mm/layer) }\end{array}$ & 0.478 & 2.22 & 0.234 & 0.548 & 0.396 & 0.581 \\
\hline Error (\%) & 6.3 & 1.7 & 6.4 & 6.2 & 5.8 & 7.3 \\
\hline
\end{tabular}


TABLE XIII

VERIFICATION OF BUILD HEIGHT EQUATION USING EXPERIMENTS 7-13

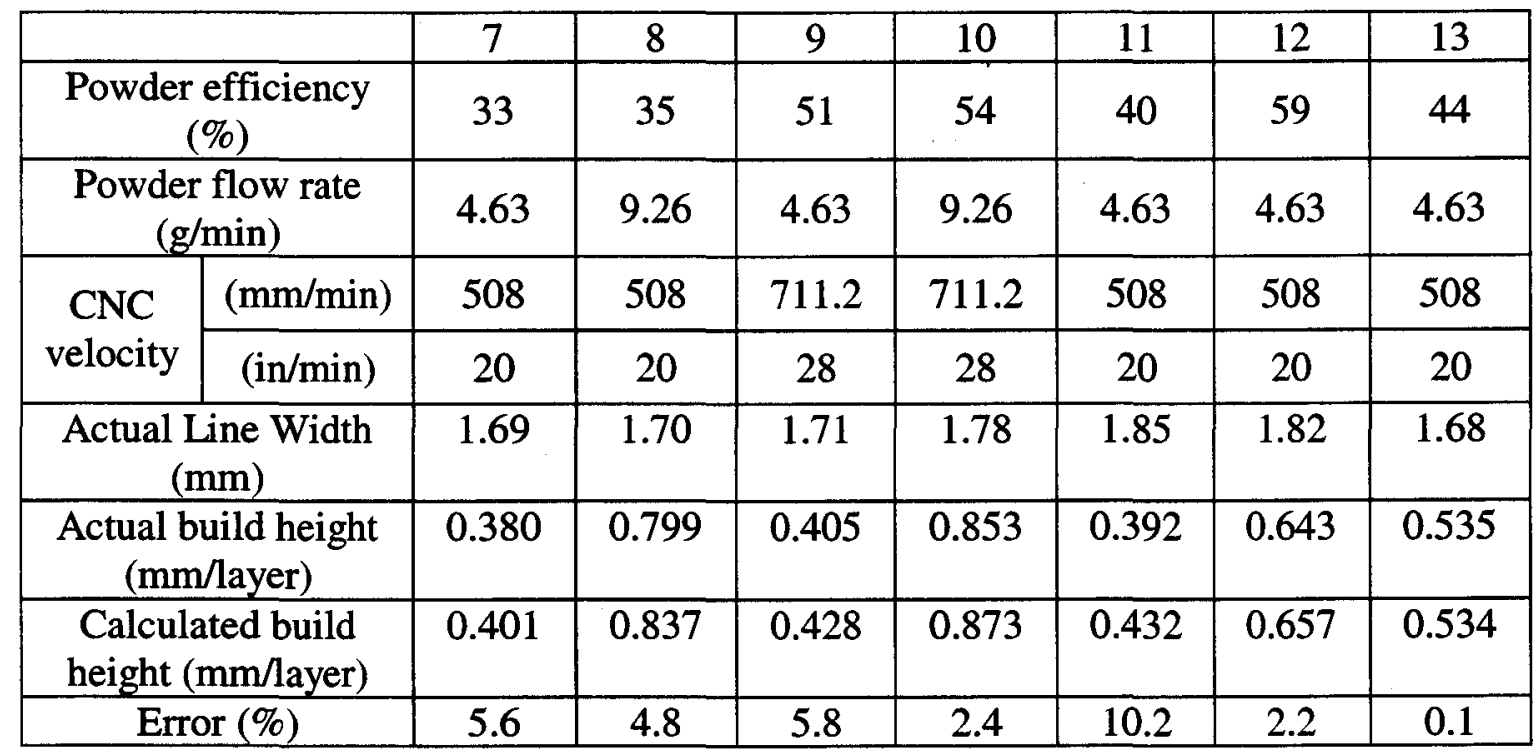


TABLE XIV

\section{CALCULATION SPREADSHEET - EXPERIMENTS 1-6}

\begin{tabular}{|c|c|c|c|c|c|c|}
\hline & 1 & 2 & 3 & 4 & 5 & \\
\hline Laser Power (W) & 1860 & 1860 & 387.5 & 387.5 & 387.5 & 1860 \\
\hline Laser Power (Analog Value) & 1200 & 1200 & 250 & 250 & 250 & 1200 \\
\hline CNC velocity $(\mathrm{mm} / \mathrm{min})$ & 508 & 127 & 508 & 127 & 508 & 508 \\
\hline CNC velocity (in/min) & 20 & 5 & 20 & 5 & 20 & 20 \\
\hline Input width (mm) & 8.78 & 9.72 & 6.64 & 7.06 & 6.64 & 8.78 \\
\hline Input width (in) & 0.346 & 0.383 & 0.261 & 0.278 & 0.261 & 0.346 \\
\hline Input length (mm) & 44.45 & 44.45 & 44.45 & 44.45 & 44.45 & 44.45 \\
\hline Input length (in) & 1.75 & 1.75 & 1.75 & 1.75 & 1.75 & 1.75 \\
\hline Input Height (mm) & 4.57 & 4.19 & 1.52 & 13.21 & 1.52 & 2.74 \\
\hline Input Height (in) & 0.180 & 0.165 & 0.060 & 0.520 & 0.060 & 0.108 \\
\hline Number of width passes & 6 & 4 & 18 & 9 & 18 & 6 \\
\hline Number of Length passes & 37 & 27 & 127 & 64 & 127 & 37 \\
\hline Number of layers & 20 & 5 & 20 & 13 & 20 & 12 \\
\hline Build Height (in/layer) & 0.009 & 0.033 & 0.003 & 0.040 & 0.003 & 0.009 \\
\hline Build height (mm/layer) & 0.229 & 0.838 & 0.076 & 1.016 & 0.076 & 0.229 \\
\hline Line Width (mm) & 1.19 & 1.652 & 0.14 & 0.35 & 0.14 & 1.19 \\
\hline Width $(\mathrm{mm})$ & 8.60 & 8.50 & 7.20 & 7.30 & 6.94 & 8.67 \\
\hline Length (mm) & 46.3 & 46.4 & 45.0 & 45.0 & 45.0 & 46.3 \\
\hline Height (mm) & 9.00 & 10.90 & 5.00 & 7.60 & 8.40 & 6.50 \\
\hline Hardness (RC) & 41 & 40 & 42 & 32 & 27 & 34 \\
\hline Oxygen Content (\%) & 0.263 & 0.349 & 0.247 & 0.475 & 0.188 & 0.197 \\
\hline Modulus (GPa) & 102 & 100 & 109 & & 109 & 107 \\
\hline UTS (MPa) & 2100 & 977 & 1323 & & 1894 & 2100 \\
\hline Strain at failure & $2.9 \%$ & $1.2 \%$ & $1.5 \%$ & & $2.2 \%$ & $7.1 \%$ \\
\hline Yield Stress & 1700 & & & & 1700 & 1500 \\
\hline Strain at yield & $1.8 \%$ & & & & $1.7 \%$ & $1.5 \%$ \\
\hline Density ( $\mathrm{g} / \mathrm{cm} 3)$ & 4.33 & 4.31 & 4.19 & 4.21 & 4.21 & 4.37 \\
\hline Gas Rate & 1 & 1 & 1 & 1 & 0.5 & 0.5 \\
\hline Hopper Rate (g/min) & 4.63 & 4.63 & 4.63 & 4.63 & 4.63 & 4.63 \\
\hline Hopper Rate (analog value) & 200 & 200 & 200 & 200 & 200 & 200 \\
\hline Total Volume $\left(\mathrm{cm}^{\wedge} 3\right)$ & 3.584 & 4.299 & 1.620 & 2.497 & 2.623 & 2.609 \\
\hline Length traveled ( $\mathrm{mm} / \mathrm{layer}$ ) & 266.7 & 177.8 & 800.1 & 400.1 & 800.1 & 266.7 \\
\hline Width traveled (mm/layer) & 235.0 & 171.5 & 806.5 & 406.4 & 806.5 & 235.0 \\
\hline Average distance (mm/layer) & 250.8 & 174.6 & 803.3 & 403.2 & 803.3 & 250.8 \\
\hline Average distance (in/layer) & 9.88 & 6.88 & 31.63 & 15.88 & 31.63 & 9.88 \\
\hline Total distance (in) & 197.5 & 34.4 & 632.5 & 206.4 & 632.5 & 118.5 \\
\hline Total Time (min) & 9.88 & 6.88 & 31.63 & 41.28 & 31.63 & 5.93 \\
\hline Total Time (sec) & 592.5 & 412.5 & 1897.5 & 2476.5 & 1897.5 & 355.5 \\
\hline Powder Used (g) & 45.72 & 31.83 & 146.42 & 191.10 & 146.42 & 27.43 \\
\hline Total Mass (g) & 15.50 & 18.54 & 6.78 & 10.50 & 11.05 & 11.39 \\
\hline Powder Usage (\%) & $34 \%$ & $58 \%$ & $5 \%$ & $5 \%$ & $8 \%$ & $42 \%$ \\
\hline Powder oxygen (\%) & 0.12 & 0.12 & 0.12 & 0.12 & 0.12 & 0.12 \\
\hline Ending oxygen content (\%) & 0.263 & 0.349 & 0.247 & 0.475 & 0.188 & 0.197 \\
\hline Oxygen gain $(\%)$ & 0.143 & 0.229 & 0.127 & 0.355 & 0.068 & 0.077 \\
\hline Build rate ( $\mathrm{g} / \mathrm{min})$ & 1.570 & 2.697 & 0.214 & 0.254 & 0.349 & 1.922 \\
\hline Energy Density $\left(\mathrm{kJ} / \mathrm{cm}^{\wedge} 2\right)$ & 16.27 & 65.09 & 3.39 & 13.56 & 3.39 & 16.27 \\
\hline Vol dep rate $\left(\mathrm{cm}^{\wedge} 3 / \mathrm{min}\right)$ & 0.3629 & 0.6253 & 0.0512 & 0.0605 & 0.0830 & 0.4404 \\
\hline
\end{tabular}




\section{TABLE XV}

\section{CALCULATION SPREADSHEET - EXPERIMENTS 7A, 8A, 11A, 13A}

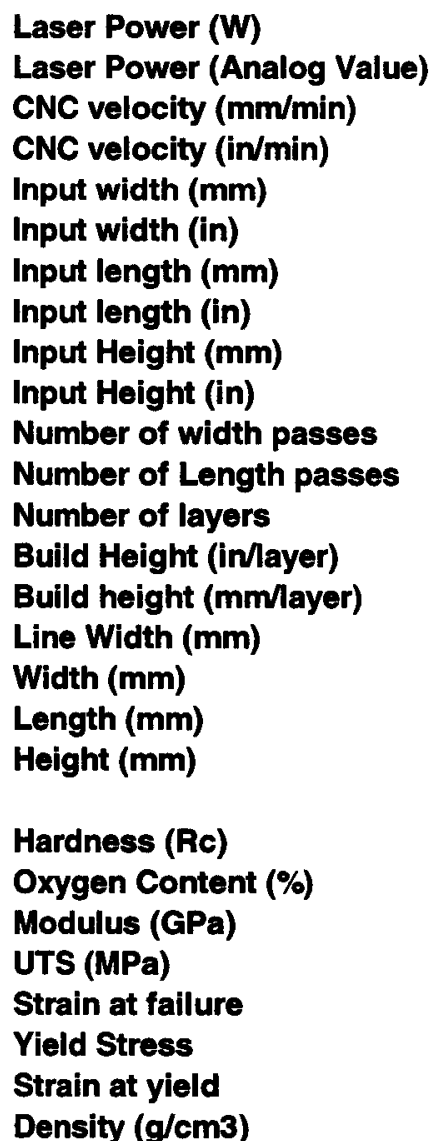

Gas Rate

Hopper Rate ( $\mathbf{g} / \mathrm{min})$

Hopper Rate (analog value)

Total Volume $\left(\mathrm{cm}^{\wedge} 3\right)$

Length traveled (mm/layer)

Width traveled (mm/layer)

Average distance (mm/layer)

Average distance (in/layer)

Total distance (in)

Total Time (min)

Total Time (sec)

Powder Used (g)

Total Mass (g)

Powder Usage (\%)

Powder oxygen (\%)

Ending oxygen content (\%)

Oxygen gain (\%)

Build rate ( $\mathrm{g} / \mathrm{min})$

Energy Density $\left(\mathrm{kJ} / \mathrm{cm}^{\wedge} 2\right)$

Vol dep rate $\left(\mathrm{cm}^{\wedge} 3 / \mathrm{min}\right)$
7 a

\begin{tabular}{rrrr} 
& \multicolumn{2}{c}{$11 \mathrm{a} a \mathrm{a}$} \\
1860 & 1860 & 1860 & 1860 \\
1200 & 1200 & 1200 & 1200 \\
508 & 508 & 508 & 508 \\
20 & 20 & 20 & 20 \\
9.05 & 9.05 & 9.05 & 9.05 \\
0.356 & 0.356 & 0.356 & 0.356 \\
44.45 & 44.45 & 44.45 & 44.45 \\
1.75 & 1.75 & 1.75 & 1.75 \\
12.82 & 12.82 & 12.82 & 12.82 \\
0.505 & 0.505 & 0.505 & 0.505 \\
5 & 5 & 3 & 5 \\
34 & 34 & 34 & 34 \\
20 & 10 & 20 & 20 \\
0.025 & 0.050 & 0.025 & 0.025 \\
0.641 & 1.282 & 0.641 & 0.641 \\
1.35 & 1.35 & 1.35 & 1.35 \\
8.45 & 8.05 & 4.85 & 8.40 \\
46.1 & 45.6 & 45.4 & 45.5 \\
7.90 & 8.35 & 7.55 & 8.60
\end{tabular}

41

38

0.649

87

902.6

$2.3 \%$

4.51

4.54

4.11

4.31

0.5

4.63

200

3.077

222.3

215.9

219.1

8.63

172.5

11.84

710.5

54.83

13.87

$25 \%$

0.126

0.649

0.523

1.171

16.27

0.5

9.26

400

3.065

222.3

215.9

38

0.884

37
0.352

91

545.4

$4.8 \%$

2162

$4.0 \%$

$$
219.1
$$

8.63

86.3

5.86

351.8

54.29

13.93

$26 \%$

0.126

0.457

0.331

2.376

16.27

0.5228
0.5

0.25

4.63

4.63

200

200

1.662

3.287

133.4

222.3

215.9

$174.6 \quad 219.1$

6.88

8.63

137.5

172.5

10.09

11.84

$605.5 \quad 710.5$

$46.72 \quad 54.83$

$6.83 \quad 14.18$

$15 \% \quad 26 \%$

$0.126 \quad 0.126$

$0.884 \quad 0.352$

0.758

0.226

0.677

1.197

16.27

0.1647 


\section{TABLE XVI}

\section{CALCULATION SPREADSHEET - EXPERIMENTS 7C-14C}

\begin{tabular}{|c|c|c|c|c|c|c|c|c|}
\hline \multirow{2}{*}{\multicolumn{9}{|c|}{ Laser Power (M) }} \\
\hline & & & & & & & & \\
\hline Laser Power (Analog Value) & 1200 & 1200 & 1700 & 1700 & 1200 & 1800 & 1200 & 1200 \\
\hline CNC velocity (mm/min) & 508 & 508 & 711.2 & 711.2 & 508 & 508 & 508 & 508 \\
\hline CNC velocity (in/min) & 20 & 20 & 28 & 28 & 20 & 20 & 20 & 20 \\
\hline Input width (mm) & 9.05 & 9.05 & 9.05 & 9.05 & 5.88 & 9.05 & 9.05 & 8.28 \\
\hline Input width (in) & 0.356 & 0.356 & 0.356 & 0.356 & 0.231 & 0.356 & 0.356 & 0.326 \\
\hline Input length (mm) & 44.45 & 44.45 & 44.45 & 44.45 & 44.45 & 44.45 & 44.45 & 44.45 \\
\hline Input length (in) & 1.75 & 1.75 & 1.75 & 1.75 & 1.75 & 1.75 & 1.75 & 1.75 \\
\hline Input Height (mm) & 12.70 & 12.70 & 12.70 & 12.19 & 12.70 & 12.95 & 12.70 & 4.57 \\
\hline Input Height (in) & 0.500 & 0.500 & 0.500 & 0.480 & 0.500 & 0.510 & 0.500 & 0.180 \\
\hline Nimber of width passes & 5 & 5 & 5 & 5 & 3 & 5 & 5 & 6 \\
\hline Number of Length passes & 34 & 34 & 34 & 34 & 34 & 34 & 34 & 38 \\
\hline Number of layers & 20 & 10 & 25 & 12 & 20 & 17 & 20 & 20 \\
\hline Build Height (imayer) & 0.025 & 0.050 & 0.020 & 0.040 & 0.025 & 0.030 & 0.025 & 0.009 \\
\hline Build height (mmlayer) & 0.635 & 1.270 & 0.508 & 1.016 & 0.635 & 0.762 & 0.635 & 0.229 \\
\hline Line Width $(m m)$ & 1.35 & 1.35 & 1.35 & 1.35 & 1.35 & 1.35 & 1.35 & 0.95 \\
\hline Width (mm) & 7.98 & 8.05 & 8.64 & 8.42 & 5.06 & 8.89 & 8.50 & 8.00 \\
\hline Length (mm) & 45.3 & 45.6 & 46.0 & 46.0 & 45.5 & 46.5 & 45.9 & 45.9 \\
\hline Height (mm) & 8.35 & 8.41 & 10.24 & 10.15 & 7.87 & 10.72 & 9.35 & 10.15 \\
\hline Herdness (RC) & 39 & 38 & 43 & 38 & 39 & 43 & 36 & 41 \\
\hline Oxygen Content (\%) & 0.884 & 0.500 & 1.235 & 0.637 & 1.077 & 1.203 & 0.380 & 0.693 \\
\hline Mochlus (GPa) & 96 & 100 & 94 & 91 & 103 & 85 & 94.07407 & 96.23 \\
\hline UTS(MPa) & 867 & 1802 & 754 & 1495 & 974 & 791 & 1778 & 962 \\
\hline $\begin{array}{l}\text { Strain at failure } \\
\text { Yield Strees }\end{array}$ & $4.7 \%$ & $3.9 \%$ & $3.6 \%$ & $5.2 \%$ & $4.5 \%$ & $2.0 \%$ & $5.5 \%$ & $3.3 \%$ \\
\hline Strain at yield & & & & & & & & \\
\hline Density $(\mathrm{g} / \mathrm{cm} \mathbf{3})$ & 4.40 & 4.47 & 4.42 & 4.36 & 4.26 & 4.31 & 4.38 & 4.32 \\
\hline Cas Rate & 0.5 & 0.5 & 0.5 & 0.5 & 0.5 & 0.5 & 0.25 & 0.5 \\
\hline Hopper Rate (g/min) & 4.63 & 9.26 & 4.63 & 9.26 & 4.63 & 4.63 & 4.63 & $4 . \circledast$ \\
\hline Hopper Rate (analog valuo) & 200 & 400 & 200 & 400 & 200 & 200 & 200 & 200 \\
\hline Total Volume (cm3) & 3.019 & 3.085 & 4.070 & 3.934 & 1.812 & 4.431 & 3.650 & 3.725 \\
\hline Length traveled (mmlayer) & 222.3 & 222.3 & 222.3 & 222.3 & 133.4 & 222.3 & 222.3 & 266.7 \\
\hline Width traveled (mmayer) & 215.9 & 215.9 & 215.9 & 215.9 & 108.0 & 215.9 & 215.9 & 241.3 \\
\hline Average distance (mmlayer) & 219.1 & 219.1 & 219.1 & 219.1 & 120.7 & 219.1 & 219.1 & 254.0 \\
\hline Average distance (in/ayer) & 8.63 & 8.63 & 8.63 & 8.63 & 4.75 & 8.63 & 8.63 & 10.00 \\
\hline Total distance (in) & 172.5 & 86.3 & 215.6 & 103.5 & 95.0 & 146.6 & 172.5 & 200.0 \\
\hline Total Time (min) & 8.63 & 4.31 & 7.70 & 3.70 & 4.75 & 7.33 & 8.63 & 10.00 \\
\hline Total Time (sec) & 517.5 & 258.8 & 462.1 & 221.8 & 285.0 & 439.9 & 517.5 & 600.0 \\
\hline Powder Used (g) & 39.93 & 39.93 & 35.66 & 34.23 & 21.99 & 33.94 & 39.93 & 46.30 \\
\hline Total Mass (g) & 13.27 & 13.78 & 17.99 & 17.17 & 7.72 & 19.11 & 16.00 & 16.11 \\
\hline Powder Usage (\%) & $33 \%$ & $34 \%$ & $50 \%$ & $50 \%$ & $35 \%$ & $56 \%$ & $40 \%$ & $35 \%$ \\
\hline Pounder oxygen (\%) & 0.126 & 0.126 & 0.126 & 0.126 & 0.126 & 0.126 & 0.126 & 0.126 \\
\hline Ending oxygen content ( $\%$ ) & 0.884 & 0.500 & 1.235 & 0.637 & 1.077 & 1.203 & 0.380 & 0.693 \\
\hline Oxygen gain $(\%)$ & 0.758 & 0.374 & 1.109 & 0.511 & 0.951 & 1.077 & 0.254 & 0.567 \\
\hline Build rate (g/min) & 1.539 & 3.194 & 2.336 & 4.644 & 1.625 & 2.607 & 1.855 & 1.611 \\
\hline Energy Density (kJ/cm^2) & 16.27 & 16.27 & 16.47 & 16.47 & 16.27 & 24.41 & 16.27 & 16.27 \\
\hline Vol dep rate (cm/3/min) & 0.3500 & 0.7154 & 0.5285 & 1.0642 & 0.3815 & 0.6044 & 0.4232 & 0.3725 \\
\hline
\end{tabular}


TABLE XVII

\section{CALCULATION SPREADSHEET - EXPERIMENTS 7D-14D}

\begin{tabular}{|c|c|c|c|c|c|c|c|c|}
\hline Laser Power (W) & 1860 & 1860 & 2635 & 2635 & 1860 & 2790 & 1860 & 1860 \\
\hline Laser Power (Analog Value) & 1200 & 1200 & 1700 & 1700 & 1200 & 1800 & 1200 & 1200 \\
\hline CNC velocity $(\mathrm{mm} / \mathrm{min})$ & 508 & 508 & 711.2 & 711.2 & 508 & 508 & 508 & 508 \\
\hline CNC velocity (in/min) & 20 & 20 & 28 & 28 & 20 & 20 & 20 & 20 \\
\hline Input width (mm) & 9.05 & 9.05 & 9.05 & 9.05 & 5.88 & 9.05 & 9.05 & 8.78 \\
\hline Input width (in) & 0.36 & 0.36 & 0.36 & 0.36 & 0.23 & 0.36 & 0.36 & 0.35 \\
\hline Input length (mm) & 44.45 & 44.45 & 44.45 & 44.45 & 44.45 & 44.45 & 44.45 & 44.45 \\
\hline Input length (in) & 1.75 & 1.75 & 1.75 & 1.75 & 1.75 & 1.75 & 1.75 & 1.75 \\
\hline Input Height (mm) & 12.7 & 12.7 & 12.7 & 12.192 & 12.7 & 12.954 & 12.7 & 3.8862 \\
\hline Input Height (in) & 0.5 & 0.5 & 0.5 & 0.48 & 0.5 & 0.51 & 0.5 & 0.153 \\
\hline Number of width passes & 5 & 5 & 5 & 5 & 3 & 5 & 5 & \\
\hline Number of Length passes & 34 & 34 & 34 & 34 & 34 & 34 & 34 & 38 \\
\hline Number of layers & 20 & 10 & 25 & 12 & 20 & 17 & 20 & 17 \\
\hline Build Height (in/layer) & 0.025 & 0.05 & 0.02 & 0.04 & 0.025 & 0.03 & 0.025 & 0.009 \\
\hline Build height (mm/layer) & 0.635 & 1.270 & 0.508 & 1.016 & 0.635 & 0.762 & 0.635 & 0.229 \\
\hline Line Width (mm) & 1.35 & 1.35 & 1.35 & 1.35 & 1.35 & 1.35 & 1.35 & 1.19 \\
\hline Width (mm) & 8.44 & 8.49 & 8.53 & 8.88 & 5.56 & 9.12 & 8.42 & 8.64 \\
\hline Length (mm) & 45.98 & 46.36 & 46.23 & 46.43 & 46.01 & 47 & 46.11 & 46.16 \\
\hline Height (mm) & 7.59 & 7.99 & 10.11 & 10.23 & 7.84 & 10.92 & 10.69 & 10.23 \\
\hline Hardnese & 34.00 & 33.22 & 33.60 & 31.25 & 31.20 & 33.00 & 29.90 & 33.40 \\
\hline Oxygen Co & 0.196 & 0.178 & 0.326 & 0.262 & 0.234 & 0.307 & 0.21 & 0.205 \\
\hline Modulus (GPa) & 92 & & & 88 & 100 & 99 & 93 & 96 \\
\hline UTS (MPa) & 2350 & & & 2000 & 2300 & 1900 & 2200 & 2400 \\
\hline \multicolumn{9}{|l|}{ Strain at failure } \\
\hline \multirow{2}{*}{\multicolumn{9}{|c|}{$\begin{array}{l}\text { Yield Stress } \\
\text { Strain at vield }\end{array}$}} \\
\hline & & & & & & & & \\
\hline Density (g/cm3) & 4.54 & 4.46 & 4.52 & 4.35 & 4.34 & 4.30 & 4.28 & 4.41 \\
\hline Gas Rate & 0.5 & 0.5 & 0.5 & 0.5 & 0.5 & 0.5 & 0.25 & 0.5 \\
\hline Hopper Rate (g/min) & 4.63 & 9.26 & 4.63 & 9.26 & 4.63 & 4.63 & 4.63 & 4.63 \\
\hline Hopper Rate (analog value) & 200 & 400 & 200 & 400 & 200 & 200 & 200 & 200 \\
\hline Total Volume $\left(\mathrm{cm}^{\wedge} 3\right)$ & 2.95 & 3.15 & 3.99 & 4.22 & 2.00 & 4.68 & 4.15 & 4.08 \\
\hline Length traveled (mm/layer) & 222.3 & 222.3 & 222.3 & 222.3 & 133.4 & 222.3 & 222.3 & 266.7 \\
\hline Width traveled (mm/layer) & 307.7 & 307.7 & 307.7 & 307.7 & 199.8 & 307.7 & 307.7 & 333.6 \\
\hline Average distance (mm/layer) & 265.0 & 265.0 & 265.0 & 265.0 & 166.6 & 265.0 & 265.0 & 300.1 \\
\hline Average dis & 10.4 & 10.4 & 10.4 & 10.4 & 6.6 & 10.4 & 10.4 & 11.8 \\
\hline Total distan & 208.6 & 104.3 & 260.8 & 125.2 & 131.1 & 177.3 & 208.6 & 200.9 \\
\hline Total & 10.43 & 5.22 & 9.31 & 4.47 & 6.56 & 8.87 & 10.43 & 10.04 \\
\hline Total Time (sec) & 626 & 313 & 559 & 268 & 393 & 532 & 626 & 603 \\
\hline Powder Used (g) & 48.30 & 48.30 & 43.13 & 41.40 & 30.36 & 41.06 & 48.30 & 46.50 \\
\hline Total Mass (g) & 13.37 & 14.04 & 18.02 & 18.36 & 8.70 & 20.11 & 17.76 & 18.00 \\
\hline Powder Usage (\%) & $28 \%$ & $29 \%$ & $42 \%$ & $44 \%$ & $29 \%$ & $49 \%$ & $37 \%$ & $39 \%$ \\
\hline Powder oxygen (\%) & 0.126 & 0.126 & 0.126 & 0.126 & 0.126 & 0.126 & 0.126 & 0.126 \\
\hline Ending oxygen content (\%) & 0.196 & 0.178 & 0.326 & 0.262 & 0.234 & 0.307 & 0.21 & 0.205 \\
\hline Oxygen gain $(\%)$ & 0.07 & 0.052 & 0.2 & 0.136 & 0.108 & 0.181 & 0.084 & 0.079 \\
\hline Build rate ( $g / \mathrm{min})$ & 1.281 & 2.692 & 1.934 & 4.108 & 1.327 & 2.267 & 1.703 & 1.792 \\
\hline Energy Density $\left(\mathrm{kJ} / \mathrm{cm}^{\wedge} 2\right)$ & 16.27 & 16.27 & 16.47 & 16.47 & 16.27 & 24.41 & 16.27 & 16.27 \\
\hline Vol dep rate $\left(\mathrm{cm}^{\wedge} 3 / \mathrm{min}\right)$ & 0.282 & 0.603 & 0.428 & 0.943 & 0.306 & 0.528 & 0.398 & 0.406 \\
\hline
\end{tabular}


TABLE XVIII

SAMPLE BAR DIMENSIONS FOR EXPERIMENTS 1-6

\begin{tabular}{|c|c|c|c|c|c|c|}
\hline & 1 & 2 & 3 & 4 & 5 & 6 \\
\hline Width (mm) & 6.44 & 5.74 & 4.90 & 3.97 & 5.46 & 6.44 \\
\hline Height (mm) & 2.68 & 3.54 & 2.71 & 2.71 & 2.80 & 2.49 \\
\hline Length (mm) & 46.20 & 46.46 & 44.95 & 32.27 & 45.23 & 46.2 \\
\hline Mass (grams) & 3.832 & 4.060 & 2.508 & 1.448 & 2.923 & 3.239 \\
\hline
\end{tabular}

TABLE XIX

SAMPLE BAR DIMENSIONS FOR EXPERIMENTS 7-14

\begin{tabular}{|c|c|c|c|c|c|c|c|c|}
\hline & 7 & 8 & 9 & 10 & 11 & 12 & 13 & 14 \\
\hline Width (mm) & 6.15 & 6.49 & 6.16 & 6.58 & 3.76 & 6.70 & 7.01 & 7.31 \\
\hline Height (mm) & 2.33 & 2.88 & 2.32 & 2.34 & 3.18 & 2.88 & 2.98 & 2.59 \\
\hline Length (mm) & 46.21 & 46.21 & 45.68 & 45.94 & 45.83 & 46.20 & 45.69 & 46.00 \\
\hline Mass (grams) & 3.855 & 3.855 & 2.944 & 3.080 & 2.379 & 3.820 & 4.081 & 3.835 \\
\hline
\end{tabular}


APPENDIX II 


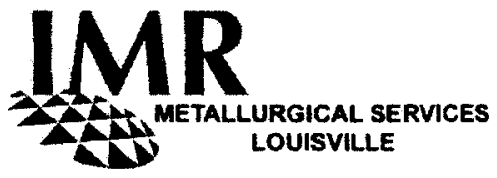

University of Louisville

J. B. Speed Scientific School

Louisville, KY 40292

Aftention: Tom Starr
WR Metallurgical Services

4102 Bishop Lane

Louisville, Kentucky $\mathbf{4 0 2 1 8}$

(502) $810-9007$ Fax: (502) 810-0380 www.imrlouisville.com Email: imra imrouisvilte.com

Report No. 21406

Date Received:

$3 / 5 / 2004$

Date Tested: $\quad 3 / 11 / 2004$

Date Reported: $\quad 3 / 12 / 2004$

CERTIFICATE OF ANALYSIS

\section{RECEIVED}

Fourteen samples were received for oxygen analyses.

\section{CHEMISTRY}

\begin{tabular}{|c|c|c|c|c|c|}
\hline Element & $\begin{array}{c}\text { Sample } \\
\text { Ti Powder }\end{array}$ & $\begin{array}{c}\text { Sample } \\
\text { Ti Substrate }\end{array}$ & $\begin{array}{c}\text { Sample } \\
\mathbf{7 a}\end{array}$ & $\begin{array}{c}\text { Sample } \\
\mathbf{7 c}\end{array}$ & $\begin{array}{c}\text { Sample } \\
\mathbf{8 a}\end{array}$ \\
\hline $\mathrm{O}^{\prime}$ & 0.126 & 0.170 & 0.649 & $\mathbf{0 . 8 8 4}$ & 0.457 \\
\hline
\end{tabular}

\begin{tabular}{|c|c|c|c|c|c|}
\hline Element & $\begin{array}{c}\text { Sample } \\
\mathbf{8 c}\end{array}$ & $\begin{array}{c}\text { Sample } \\
\mathbf{9 c}\end{array}$ & $\begin{array}{c}\text { Sample } \\
\mathbf{1 0 c}\end{array}$ & $\begin{array}{c}\text { Sample } \\
\mathbf{1 1 a}\end{array}$ & $\begin{array}{c}\text { Sample } \\
\mathbf{1 1 c}\end{array}$ \\
\hline $\mathrm{O}^{\prime}$ & 0.500 & 1.235 & 0.637 & 0.884 & 1.077 \\
\hline
\end{tabular}

\begin{tabular}{|c|c|c|c|c|}
\hline Element & $\begin{array}{c}\text { Sample } \\
12 \mathrm{c}\end{array}$ & $\begin{array}{c}\text { Sample } \\
\mathbf{1 3 a}\end{array}$ & $\begin{array}{c}\text { Sample } \\
\mathbf{1 3 c}\end{array}$ & $\begin{array}{c}\text { Sample } \\
\mathbf{1 4 c}\end{array}$ \\
\hline $\mathrm{O}^{\prime}$ & 1.203 & 0.352 & 0.380 & 0.693 \\
\hline
\end{tabular}

Determined by combustion-infrared absorbance.

Results in weight percent unless otherwise indicated.

Method in accordance with ASTM E 1019-00.

Respectfully submitted,

\begin{tabular}{|c|c|c|c|}
\hline & $3 / 12 / 03$ & & $3 / 12 / 03$ \\
\hline $\begin{array}{l}\text { Hector J. Marini, Ph.D. } \\
\text { Senior Analytical Chemist }\end{array}$ & Date & $\begin{array}{l}\text { David Zauler. } \\
\text { Senior Chemist }\end{array}$ & Date \\
\hline
\end{tabular}

Page 1 of 1

FIGURE 7 - Oxygen Analysis Certificate for Experiments 7c-14c 


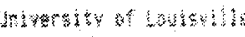

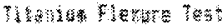

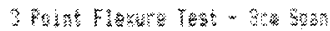

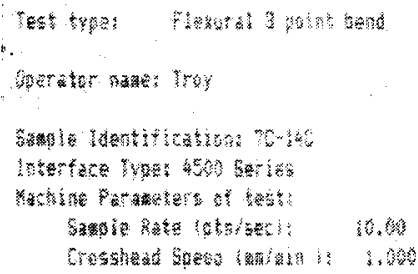

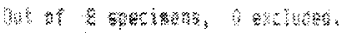

\begin{tabular}{|c|c|c|c|c|c|}
\hline 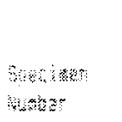 & 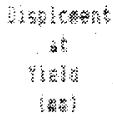 & 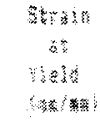 & 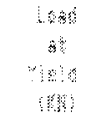 & 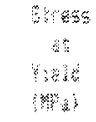 & Wobolu \\
\hline$\xi$ & 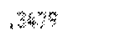 & 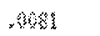 & $i+4 \leq 3$ & 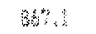 & $\ldots$ \\
\hline$\hat{\imath}$ & , bha & OHE & 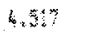 & $\operatorname{sanes}$ & 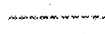 \\
\hline 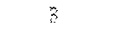 & $2 x^{2}$ & $x \times 3$ & 2xa & 753.6 & \\
\hline 宩 & 3 & .515 & $3,0.04$ & M. & \\
\hline 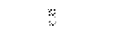 & 36 & .039 & 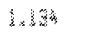 & 97. is & \\
\hline$b$ & $2 \pi$, & $20 \%$ & 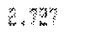 & Yด! & \\
\hline$\eta$ & $27 \%$ & 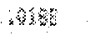 & 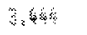 & byent & \\
\hline 8 & 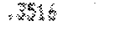 & Whe & $\ddot{2}+4$ & $800 \% 3$ & $\operatorname{manmimen+\infty }$ \\
\hline 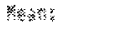 & wat & $\times \hat{A} \geq 2$ & $2 . \mathrm{xpo}$ & mas & $-m$ \\
\hline \multicolumn{6}{|l|}{ 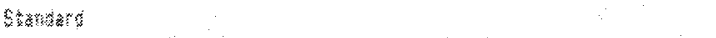 } \\
\hline Wewathos & $.18 \%$ & 68 & 1.123 & 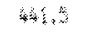 & \\
\hline \multicolumn{6}{|c|}{$\sin 5$} \\
\hline $\left.2_{2}+4\right) 5 x=$ & , oxt &, 620 & 3 & Non & $+4 \sin (-\infty)$ \\
\hline 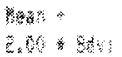 & คrx & & & & \\
\hline & 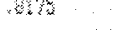 & $82 x^{2}$ & $4,3 \%$ & 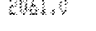 & \\
\hline
\end{tabular}

FIGURE 8 - Flexure Test Results for Experiments 7c-14c 


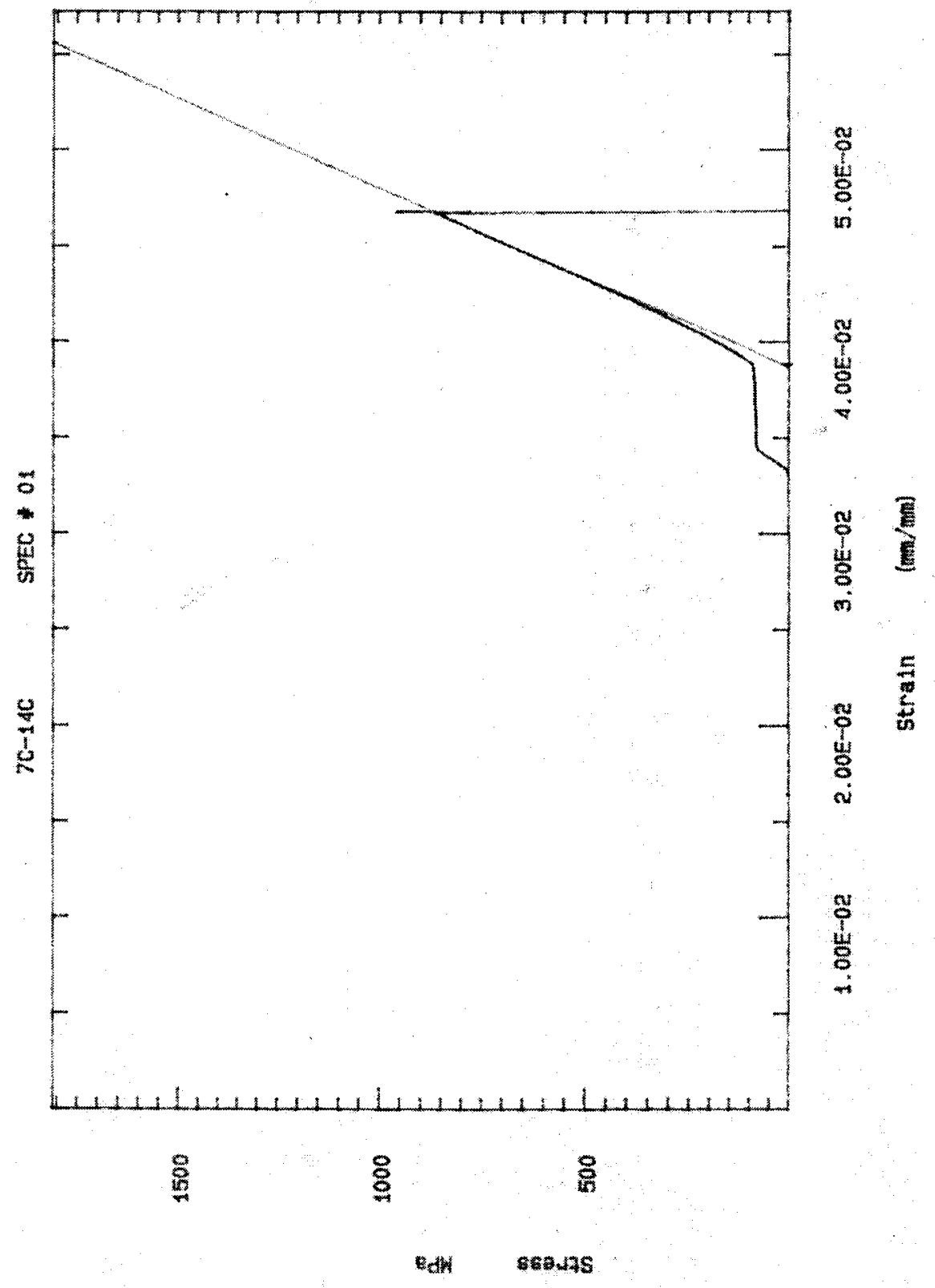

FIGURE 9 - Stress-Strain Curve of Experiment 7c 


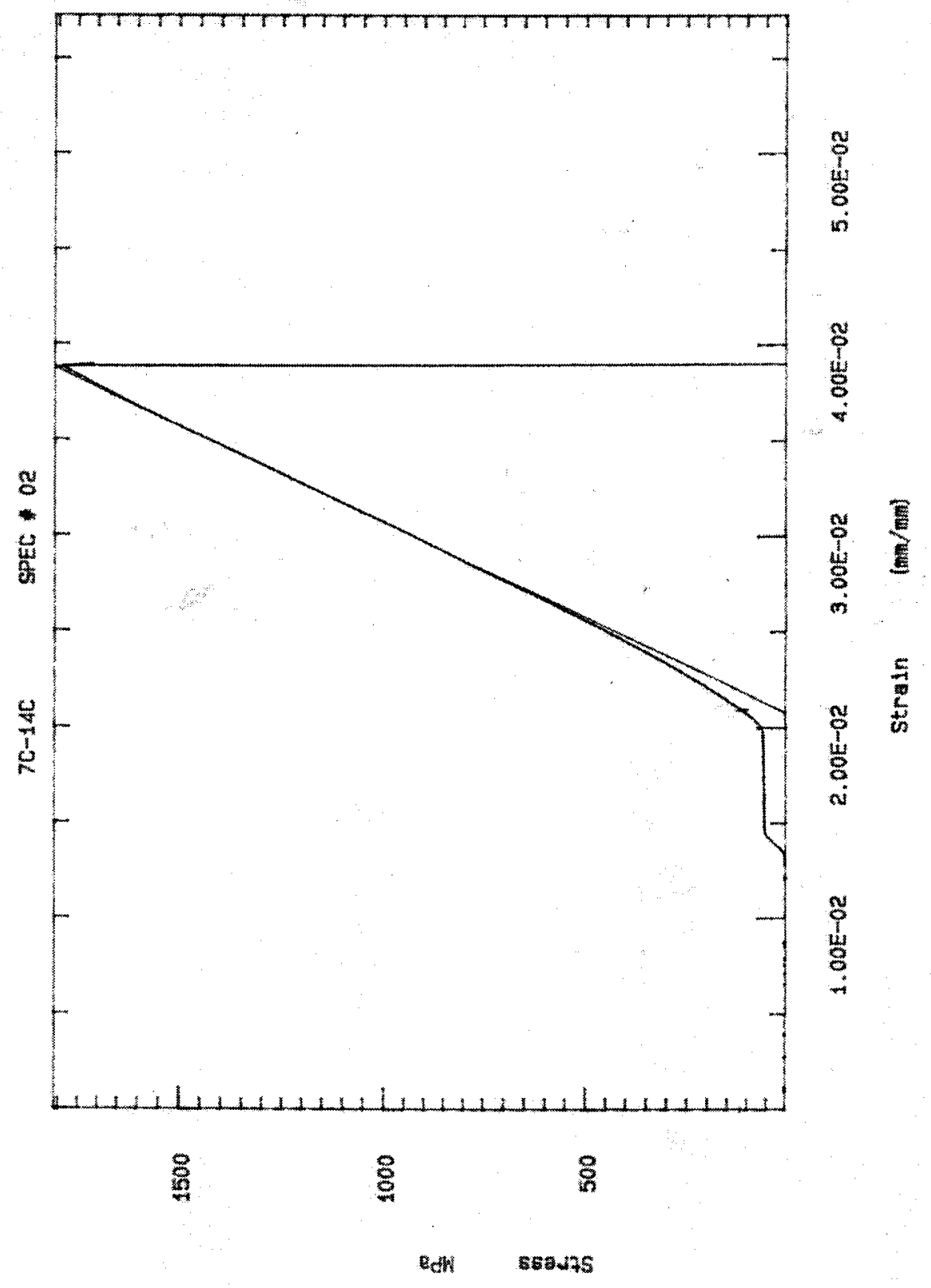

FIGURE 10 - Stress-Strain Curve of Experiment 8c 


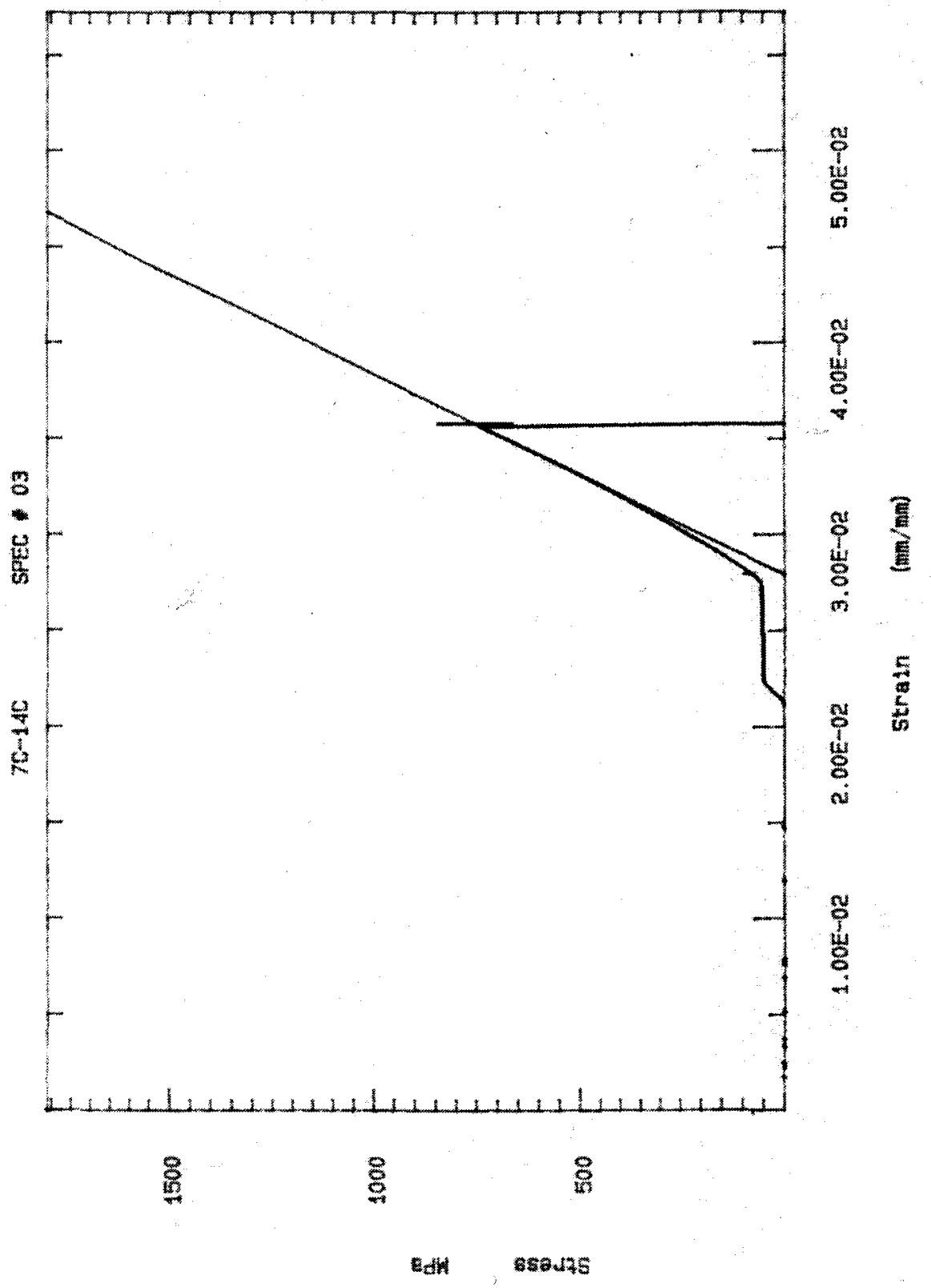

FIGURE 11 - Stress-Strain Curve of Experiment 9c 


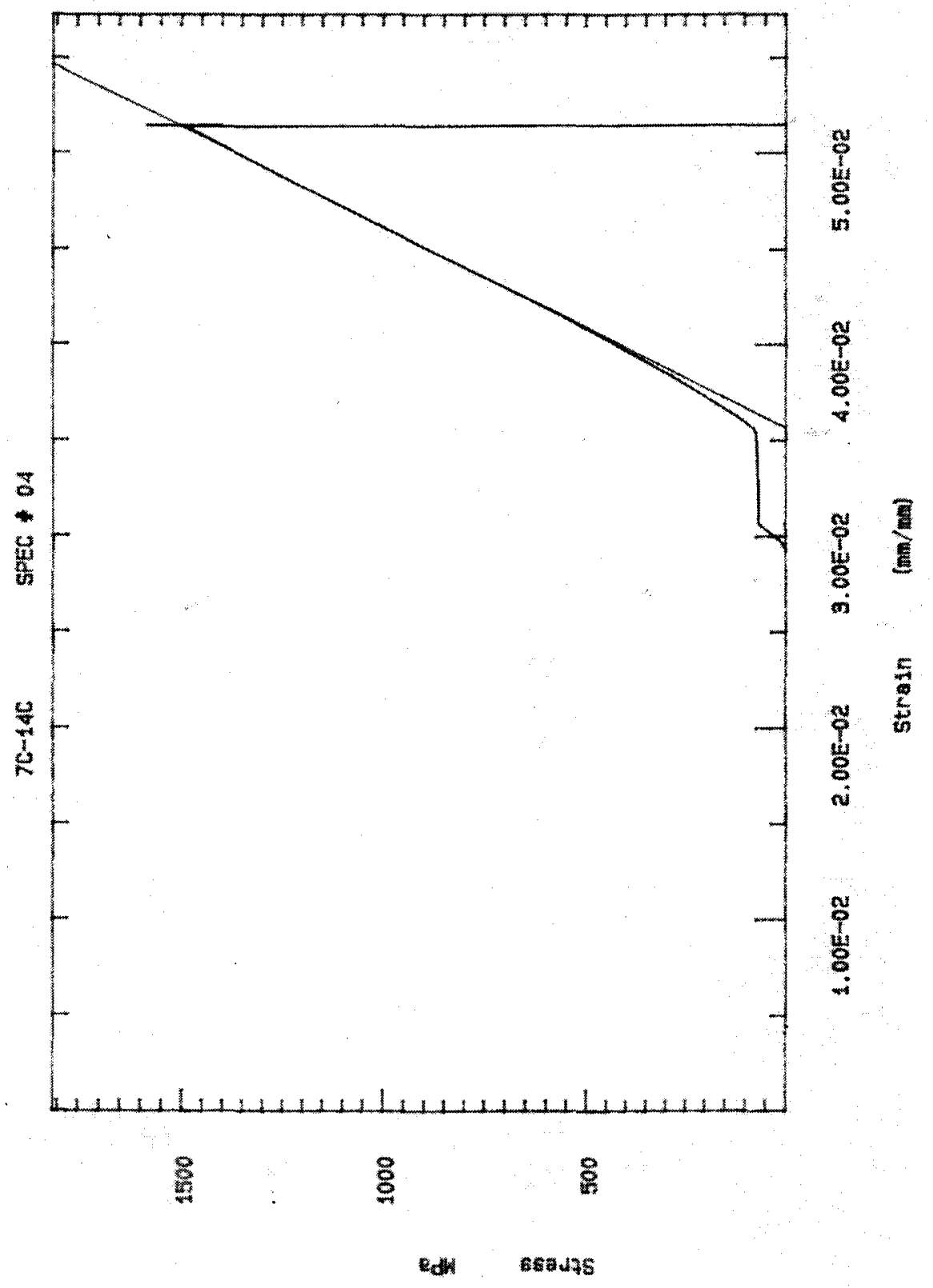

FIGURE 12 - Stress-Strain Curve of Experiment 10c 


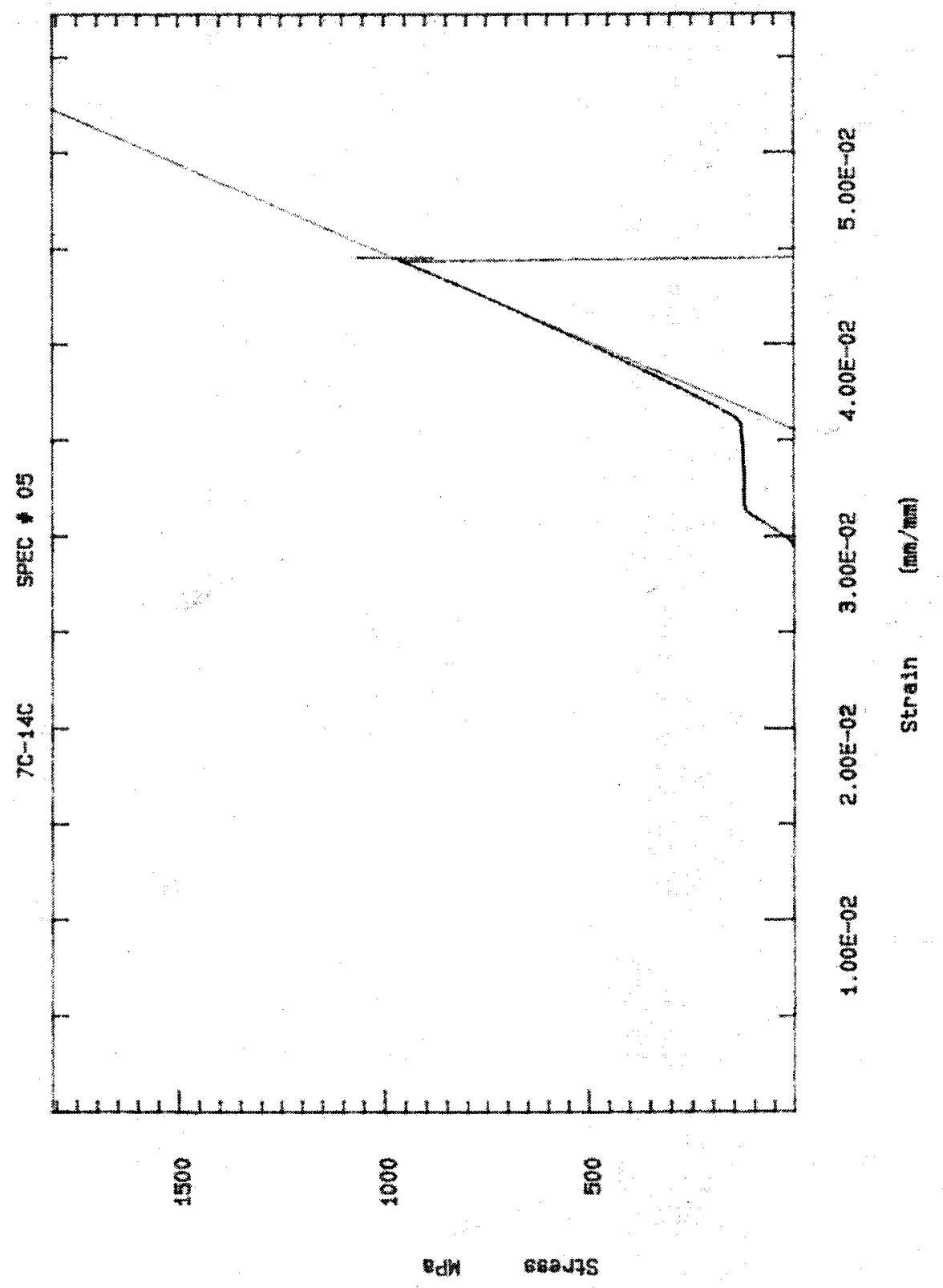

FIGURE 13 - Stress-Strain Curve of Experiment 11c 


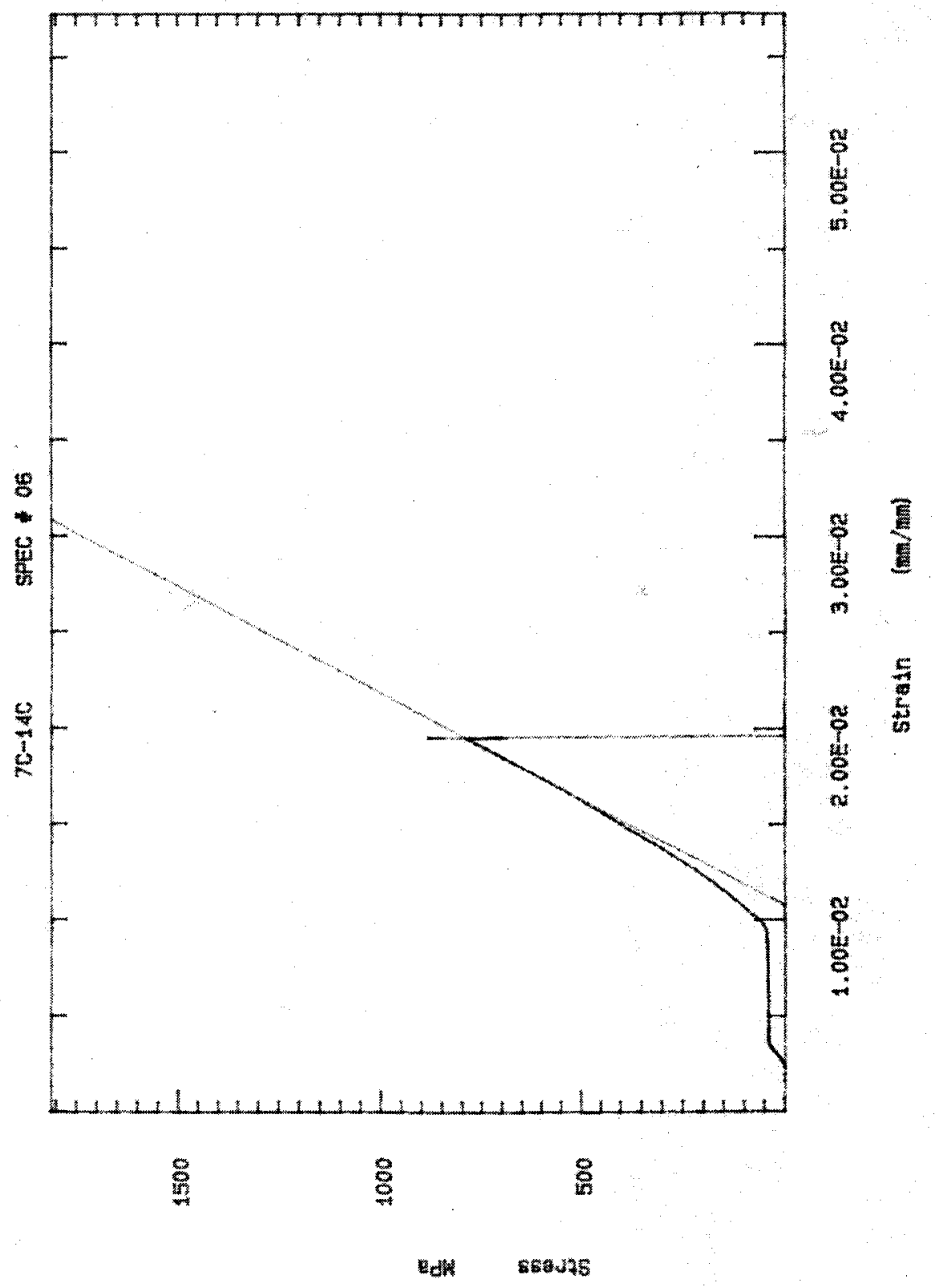

FIGURE 14 - Stress-Strain Curve of Experiment 12c 


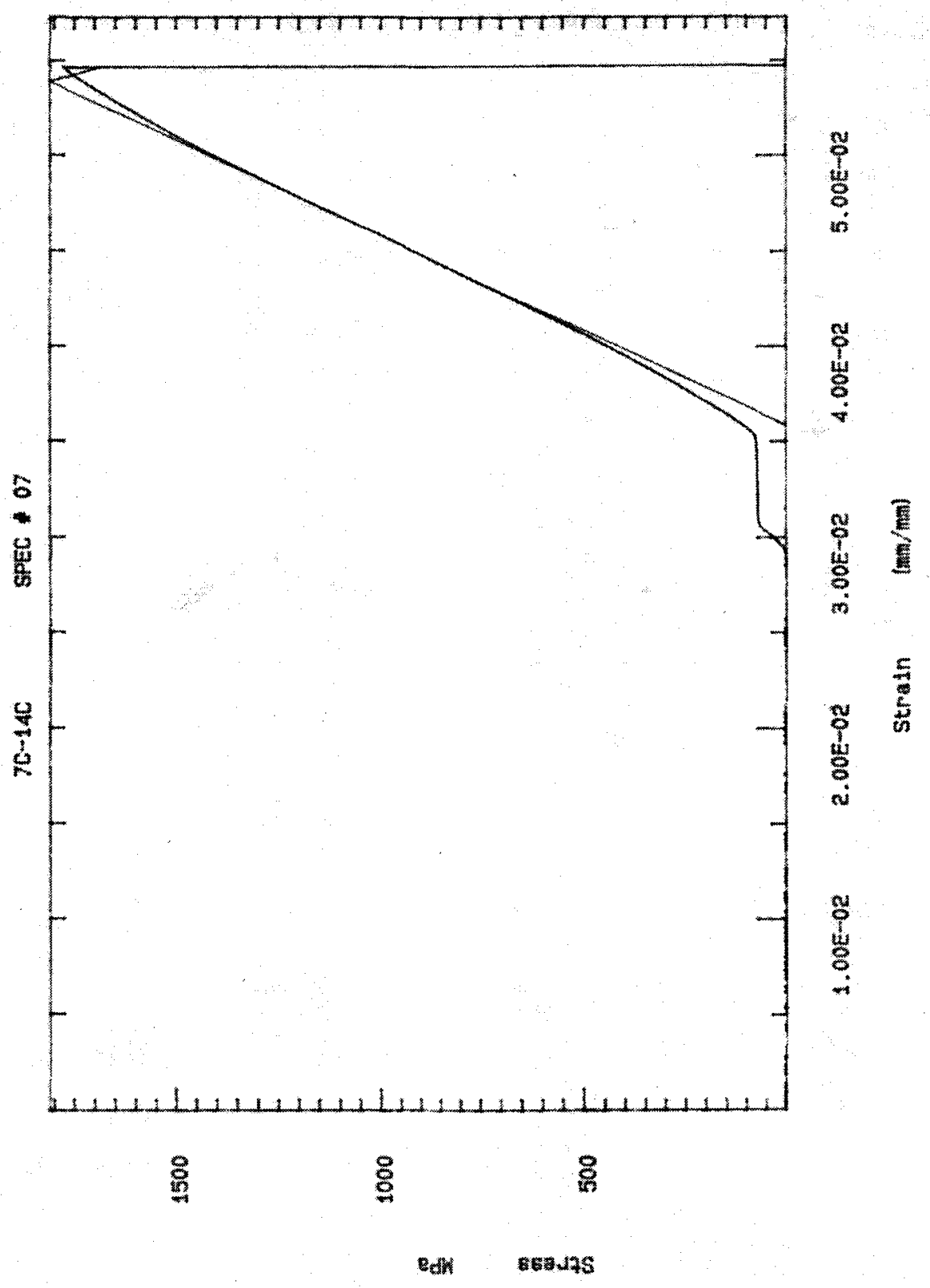

FIGURE 15 - Stress-Strain Curve of Experiment 13c 


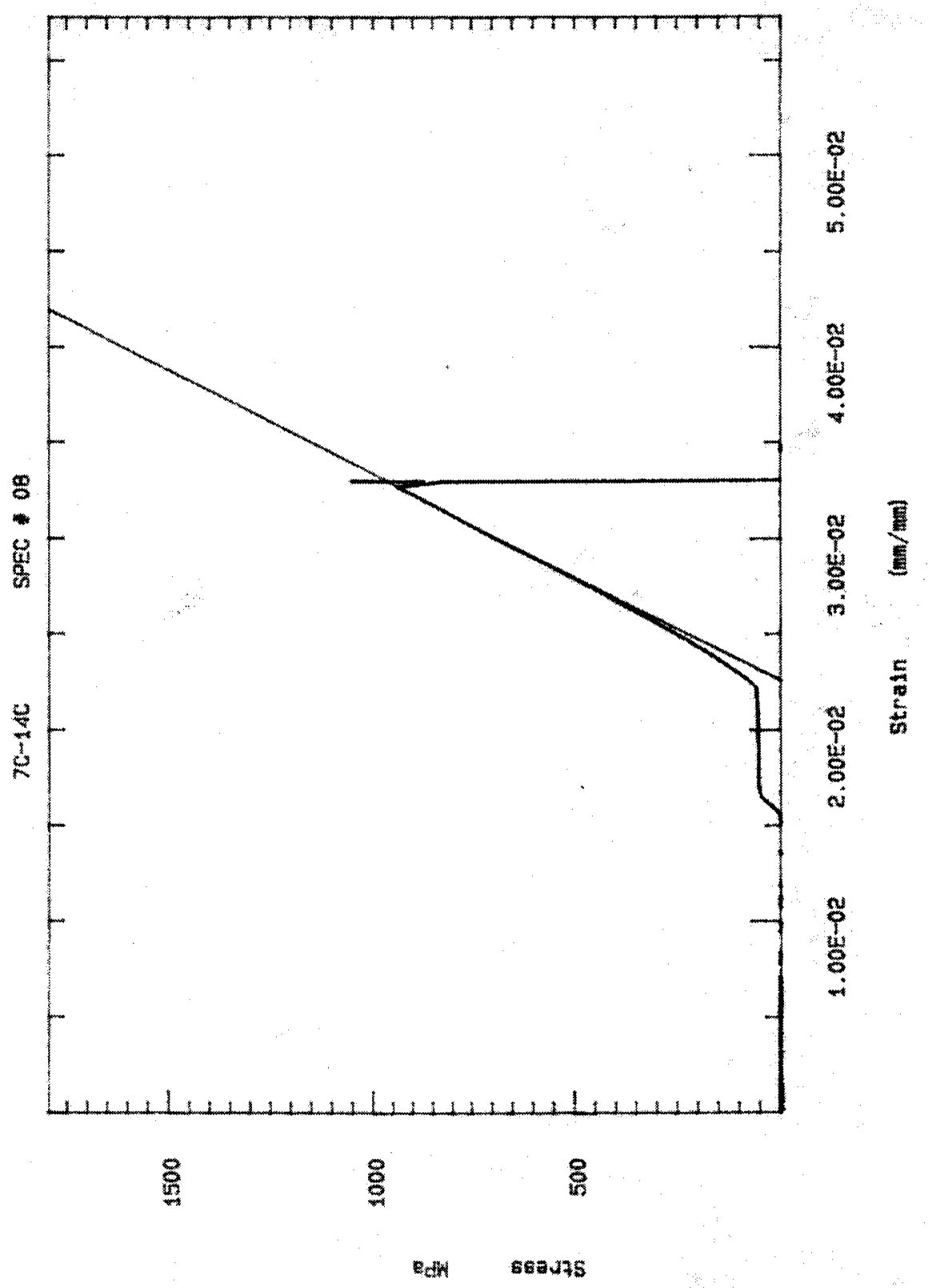

FIGURE 16 - Stress-Strain Curve of Experiment 14c 


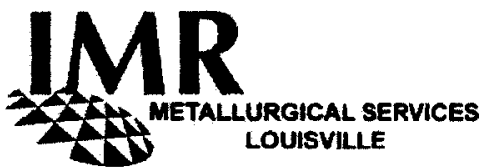

University of Louisville

J. B. Speed Scientific School

Louisville, KY 40292

Attention: Tom Starr
IMR Metalkurgical Services

4102 Bishop Lan

Louisville, Kentucky 40218

(502) 810-9007 Fax (502) 810-0380 www.mrbuisville.com Email: imr@imrlouisville.com

Report No. 21445

\section{CERTIFICATE OF ANALYSIS}

RECEIVED

Eight samples were received for oxygen analyses.

\section{CHEMISTRY}

\begin{tabular}{|c|c|c|c|c|}
\hline Element & $\begin{array}{c}\text { Sample } \\
\text { 7d }\end{array}$ & $\begin{array}{c}\text { Sample } \\
\text { 8d }\end{array}$ & $\begin{array}{c}\text { Sample } \\
\text { 9d }\end{array}$ & $\begin{array}{c}\text { Sample } \\
\text { 10d }\end{array}$ \\
\hline$O^{!}$ & 0.196 & 0.178 & 0.326 & 0.262 \\
\hline
\end{tabular}

\begin{tabular}{|c|c|c|c|c|}
\hline Element & $\begin{array}{c}\text { Sample } \\
\text { 11d }\end{array}$ & $\begin{array}{c}\text { Sample } \\
\text { 12d }\end{array}$ & $\begin{array}{c}\text { Sample } \\
\text { 13d }\end{array}$ & $\begin{array}{c}\text { Sample } \\
\text { 14d }\end{array}$ \\
\hline $\mathrm{o}^{\prime}$ & 0.234 & 0.307 & 0.210 & 0.205 \\
\hline
\end{tabular}

Determined by combustion-infrared absorbance.

Results in weight percent uniess otherwise indicated.

Method in accordance with ASTM E 1019-00.

Respectfully submitted,

Date Received:

$3 / 22 / 2004$

Date Tested:

Date Reported:

$4 / 01 / 2004$

$4 / 02 / 2004$
Hector J. Marini, Ph D

Senior Analytical Chemist
David Zauler.

Senior Chemist
4/02/04

Date

Analysis was performed at another location. The information contained in this test report represents only the material tested and may not be reproduced, except an fill without the writen approval of IMR, Inc. All samples will be retained for a minimen of 2 morths and may be destroyed thercafter unless otherwisc specificd by the

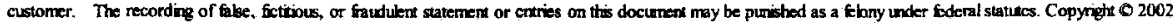
Al riofus reserved, IMR Metalurgical Senvices - Lousvile. LLC.

Page 1 of 1

FIGURE 17 - Oxygen Analysis Certificate for Experiments 7d-14d 
PARAMETER

Flexural

rectangular stress:

Flexural

cylindrical stress:

Flexural

rectangular strain:

Flexural

cylindrical strain:

Flexural

rectangular modulus:

Flexural

cylindrical modulus:
THREE-POINT BEND $\frac{3 \cdot F \cdot L}{2 \cdot b \cdot a^{2}}$

$\frac{8 \cdot F \cdot L}{\pi \cdot d^{3}}$

$\frac{6 \cdot D \cdot a}{L^{2}}$

$\frac{6 \cdot D \cdot d}{L^{2}}$

$\frac{\text { slope } \cdot L^{3}}{4 \cdot b \cdot a^{3}}$

$\frac{4 \cdot \text { slope } \cdot L^{3}}{3 \cdot \pi \cdot d^{4}}$

FIGURE 18 - Equations used in Flexural Calculations 

$D=$ displacement $\quad F_{y}=$ load at yield
$\mathrm{F}=\operatorname{load} \quad \mathrm{F}_{\mathrm{m}}=$ load at maximum
$v=$ velocity $\Delta=$ delta
$\mathrm{E}=$ energy $\sigma=$ stress
b $=$ specimen width $\varepsilon=$ strain
a = specimen thickness (or depth in flexure testing)
$\mathrm{L}=$ gauge length (or span in flexure testing)
$\mathrm{d}=$ diameter
$\mathrm{S}=$ cross-sectional area
(this is also given the symbol $A$ in some standards)
$\mathrm{t}=$ time

FIGURE 19 - Symbols used in Flexural Calculations 


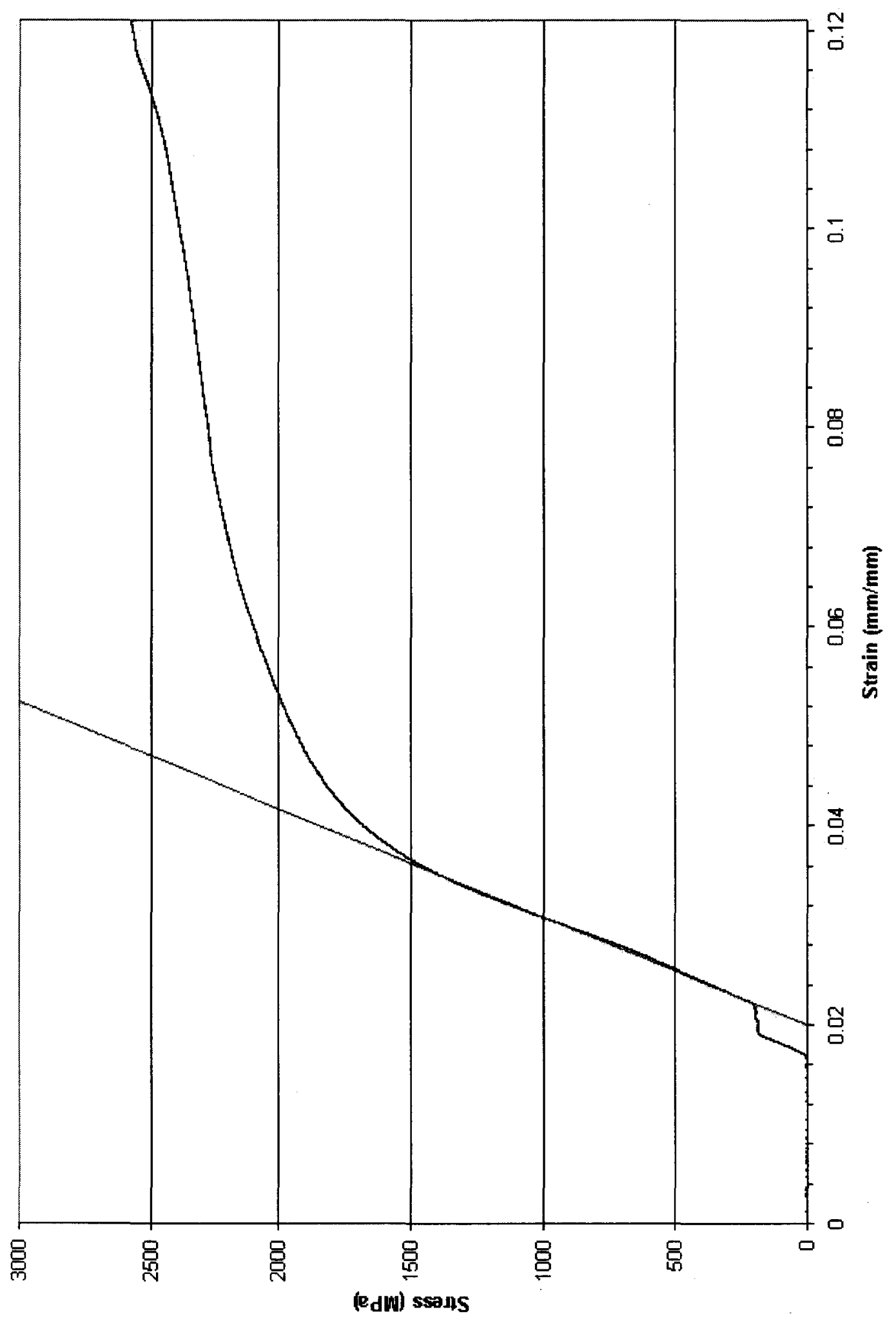

FIGURE 20 - Stress-Strain Curve of Experiment 7d 


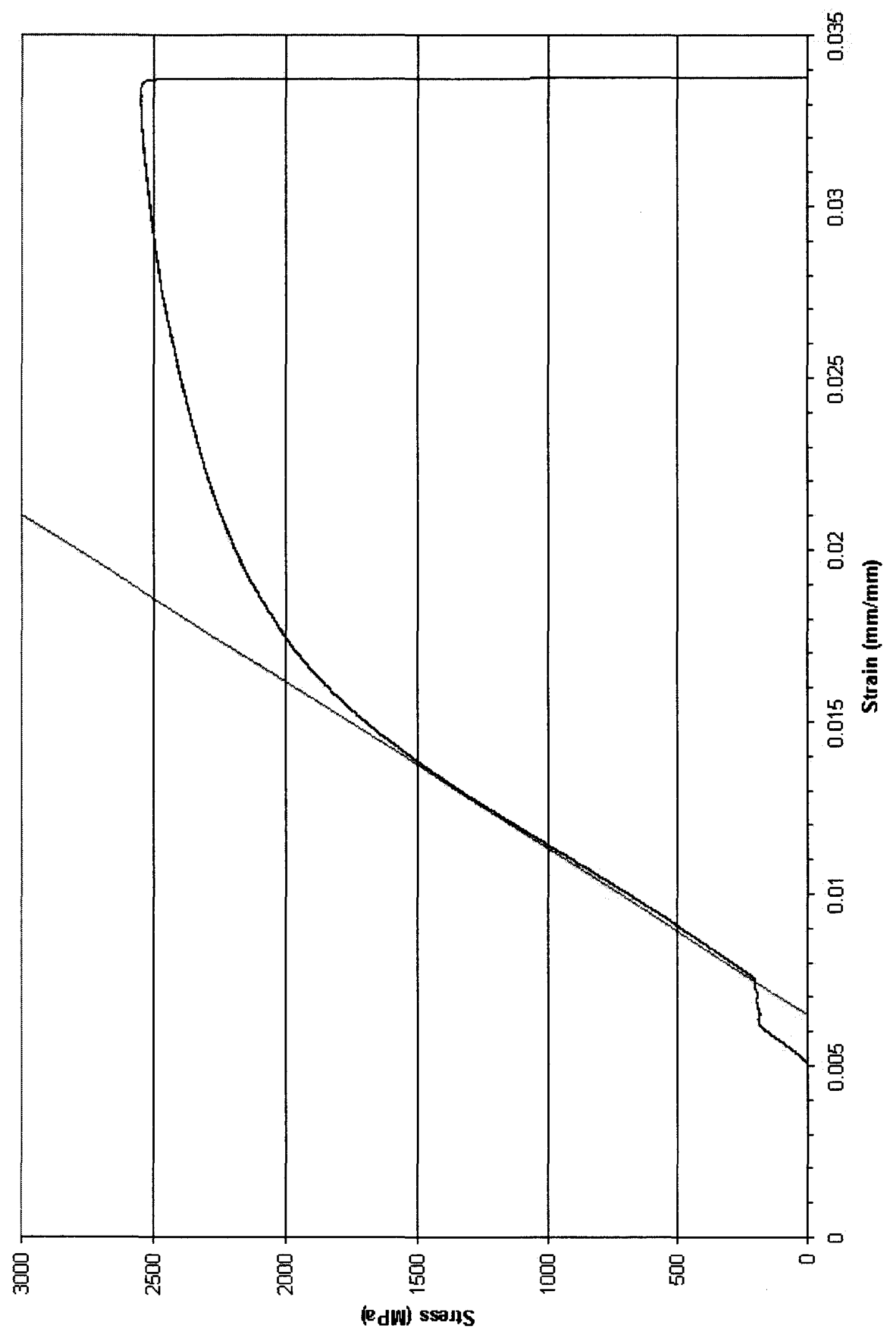

FIGURE 21 - Stress-Strain Curve of Experiment 8d 


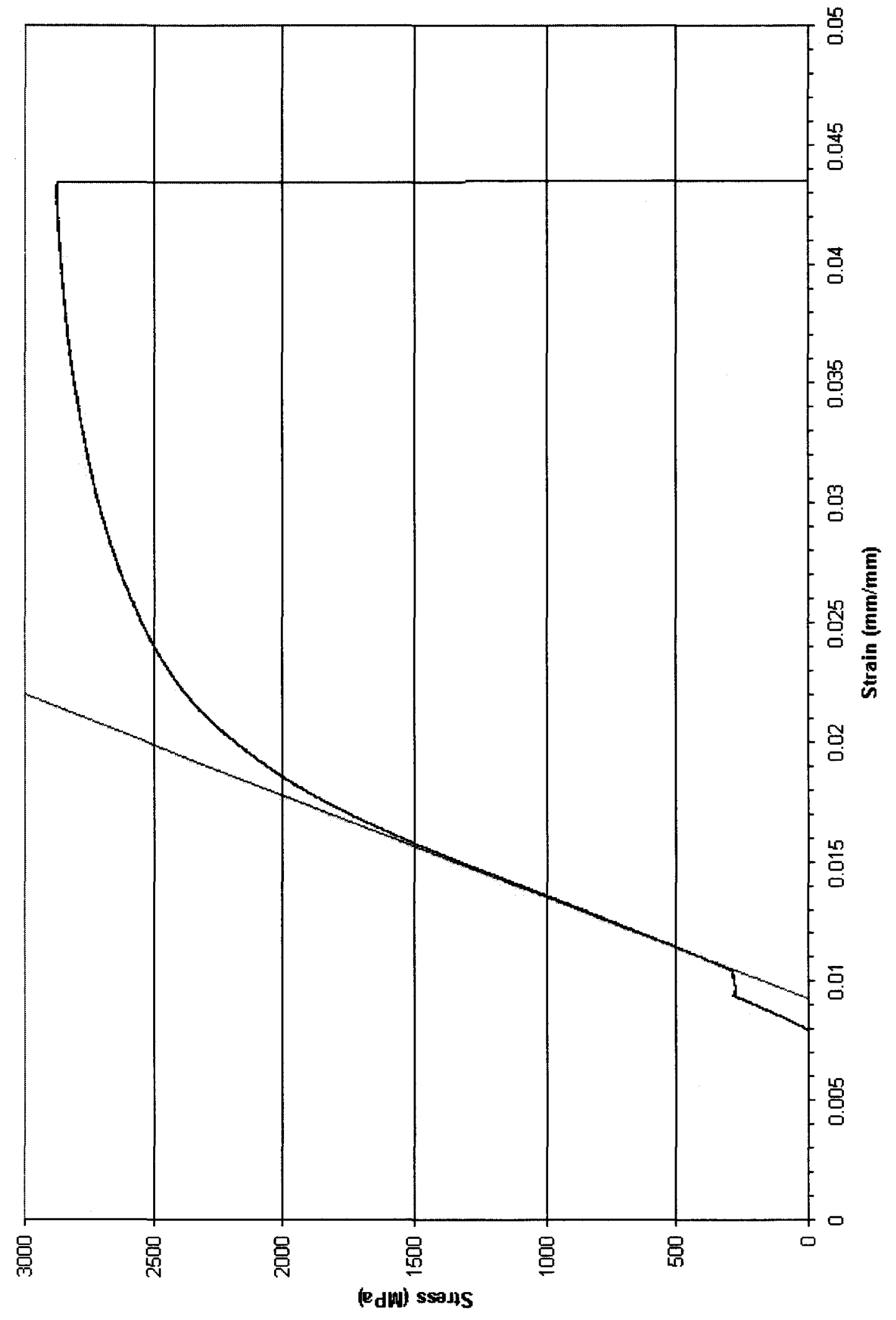

FIGURE 22 - Stress-Strain Curve of Experiment 9d 


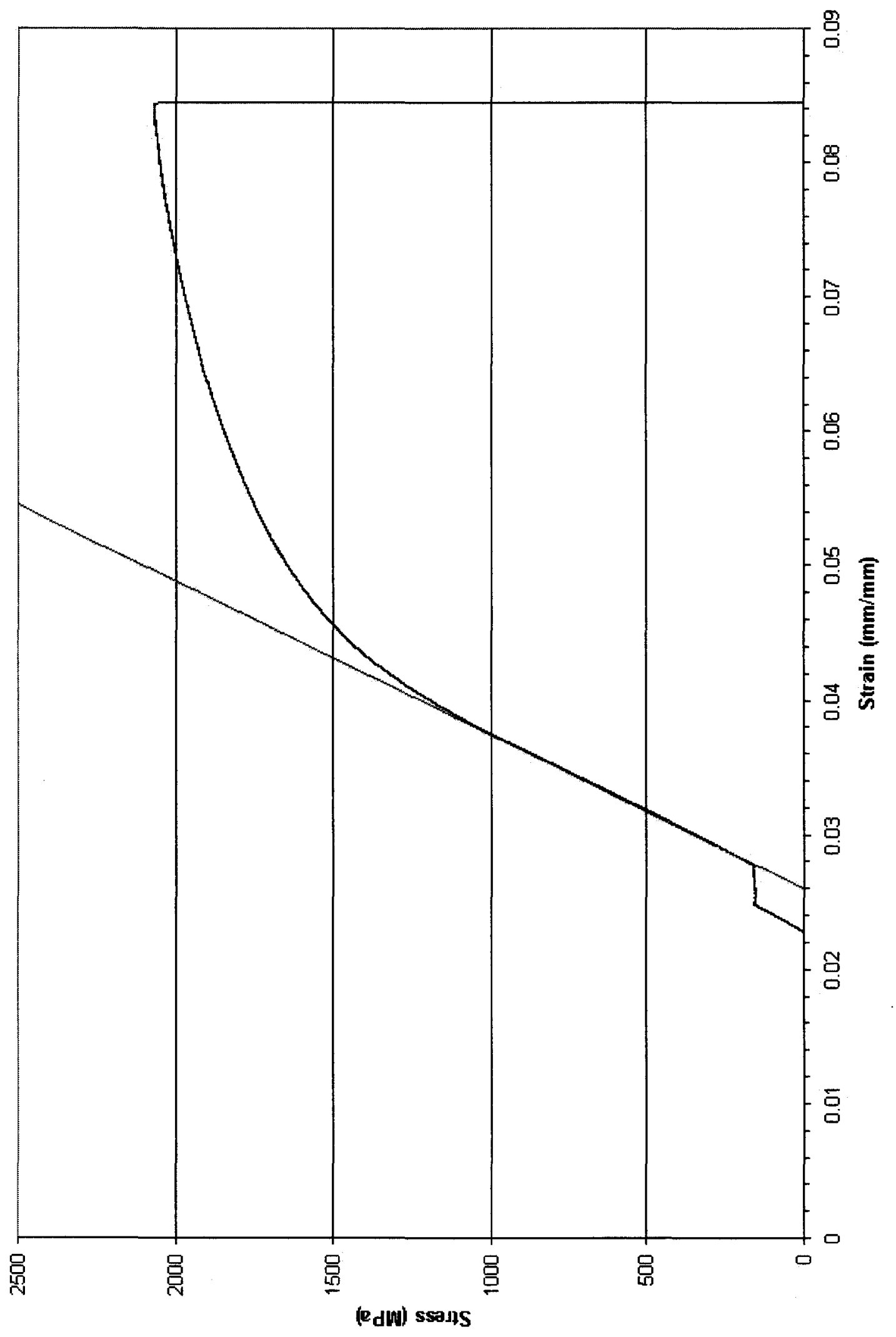

FIGURE 23 - Stress-Strain Curve of Experiment 10d 


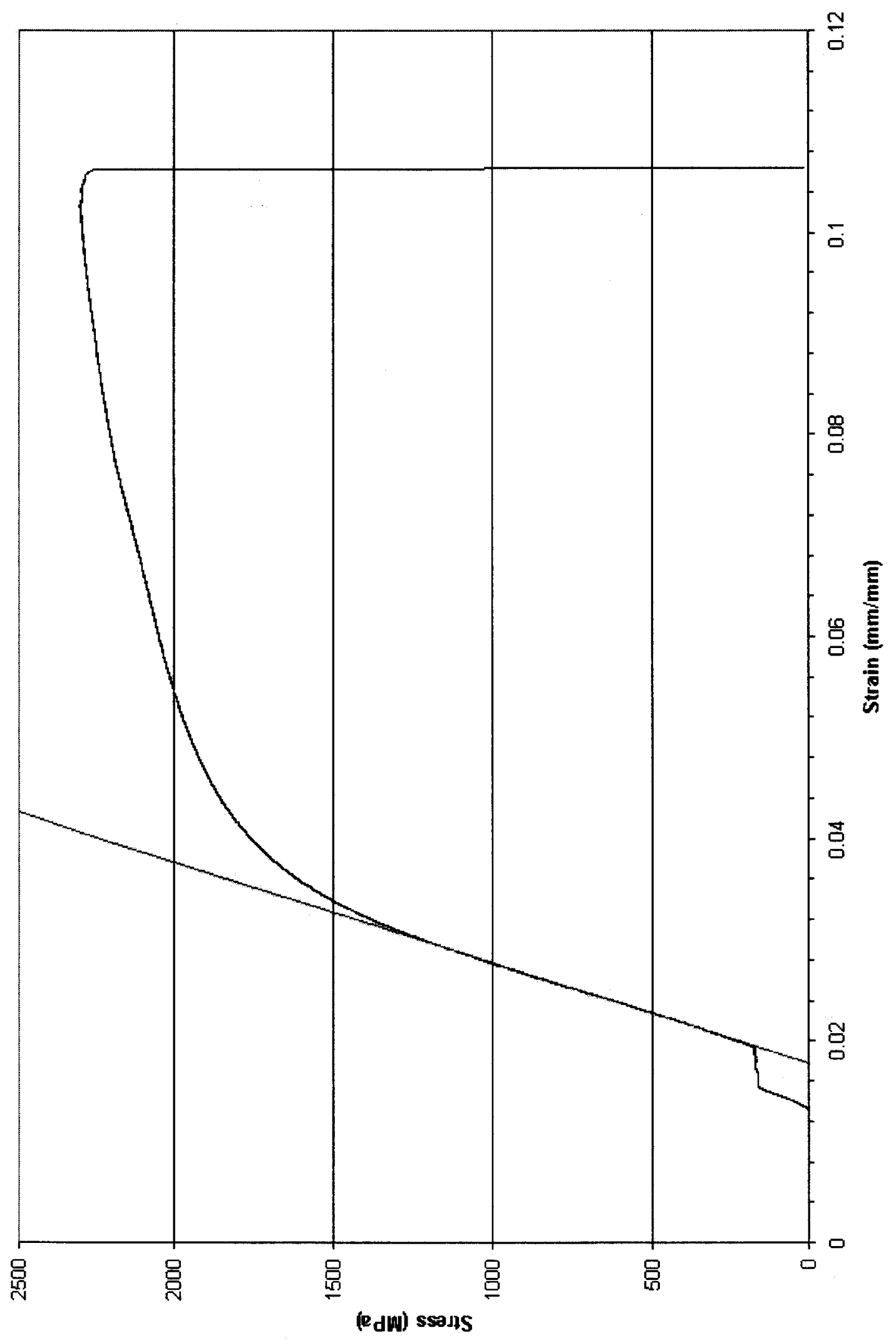

FIGURE 24 - Stress-Strain Curve of Experiment 11d 


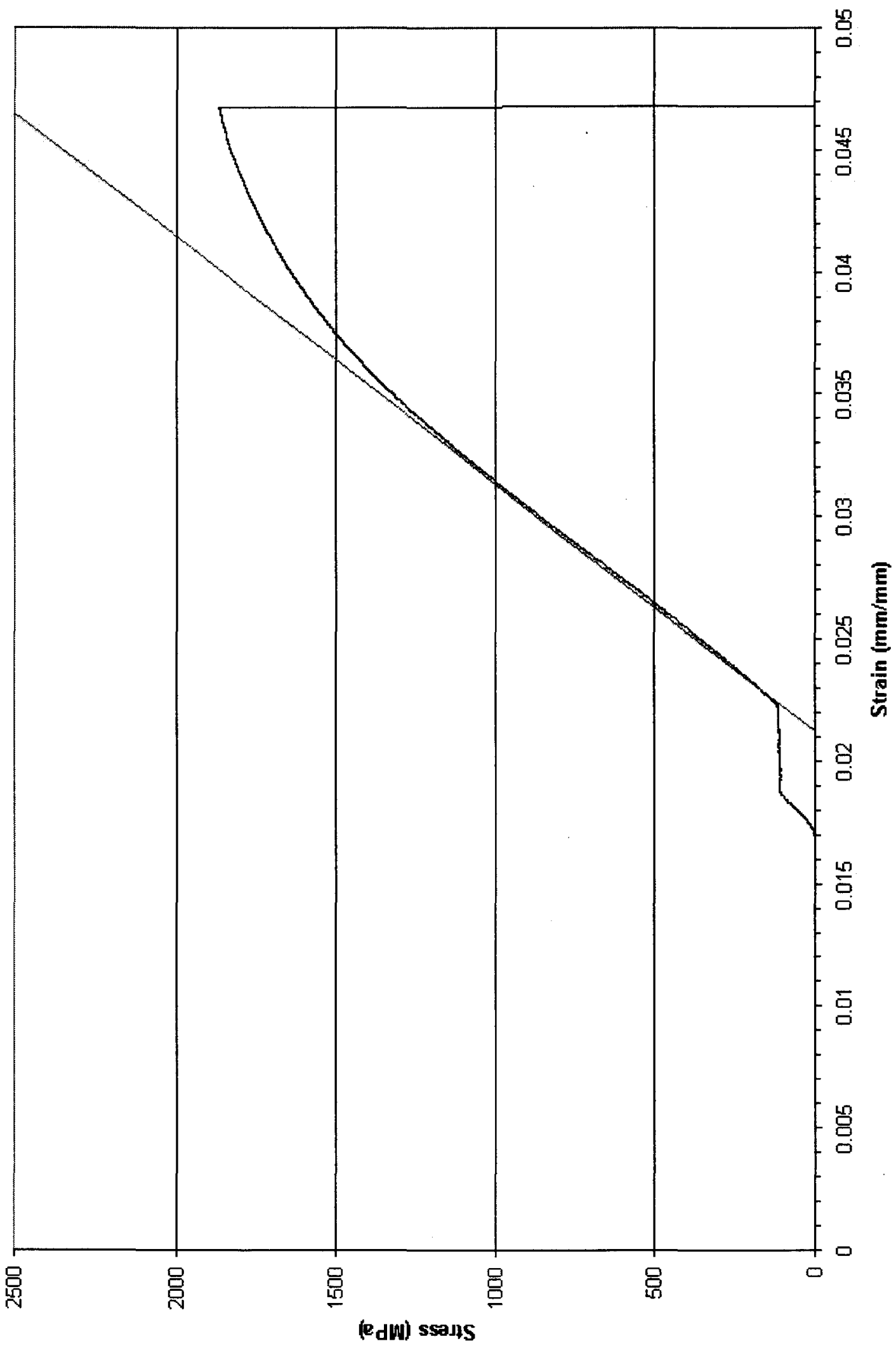

FIGURE 25 - Stress-Strain Curve of Experiment 12d

77 


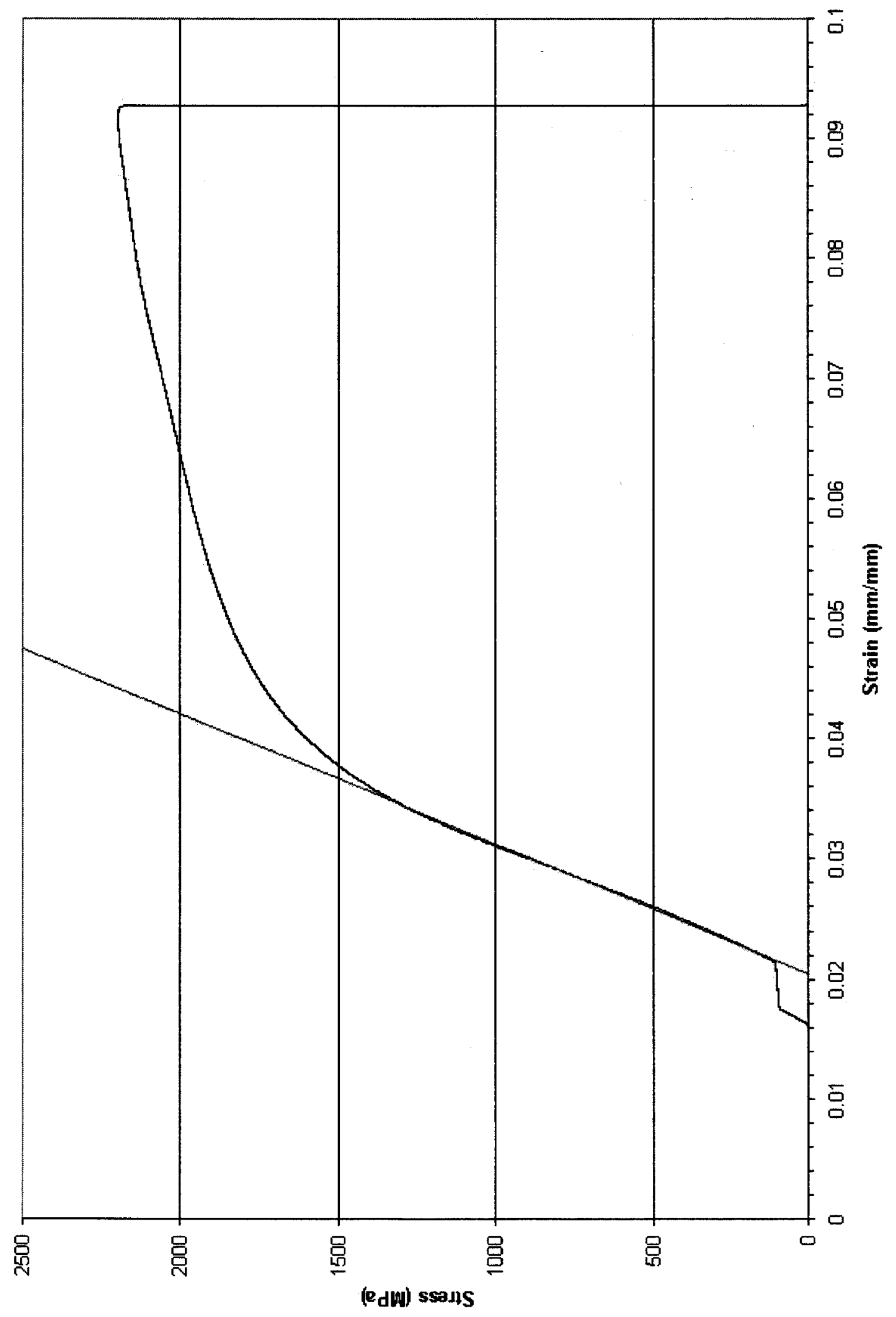

FIGURE 26 - Stress-Strain Curve of Experiment 13d 


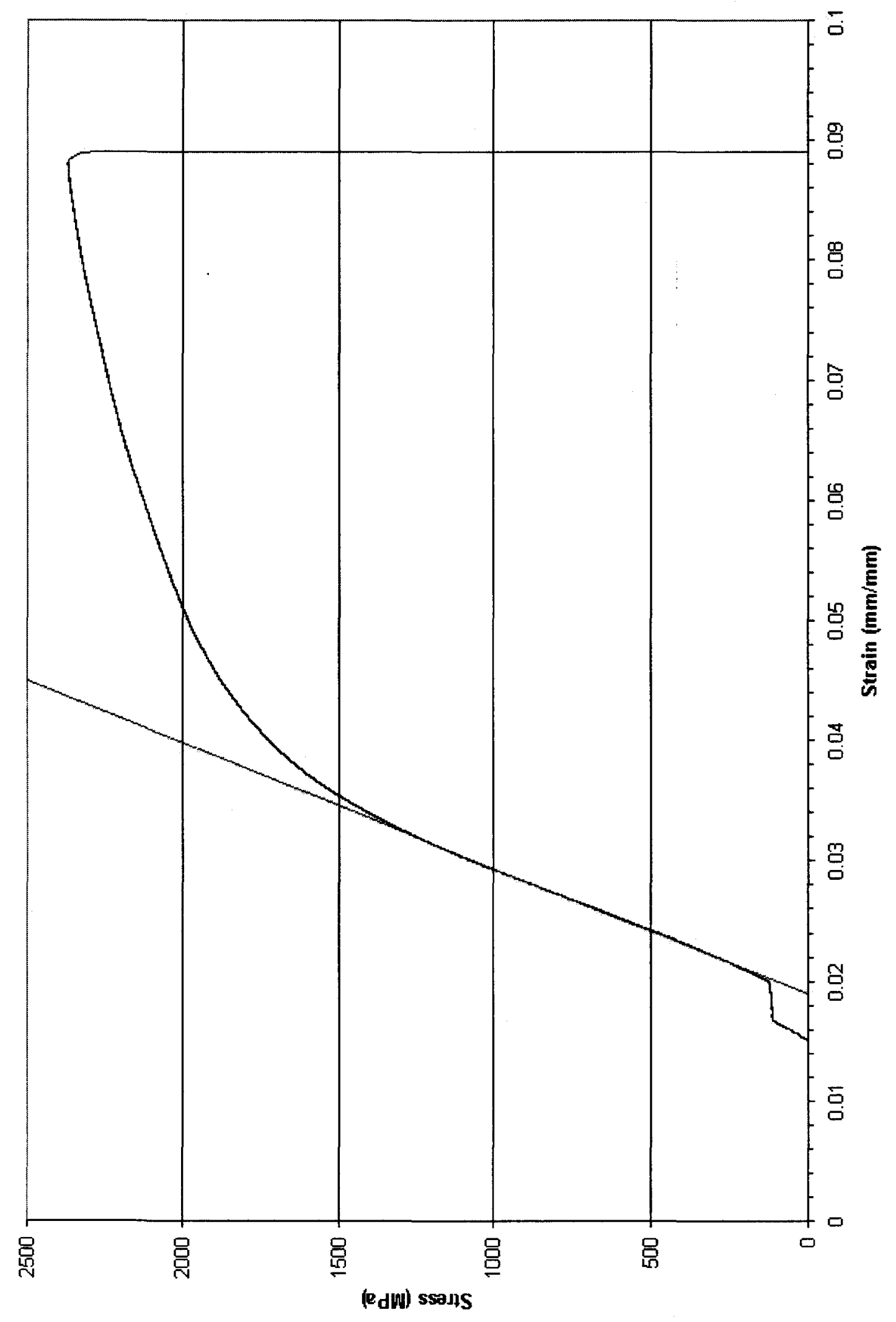

FIGURE 27 - Stress-Strain Curve of Experiment 14d 


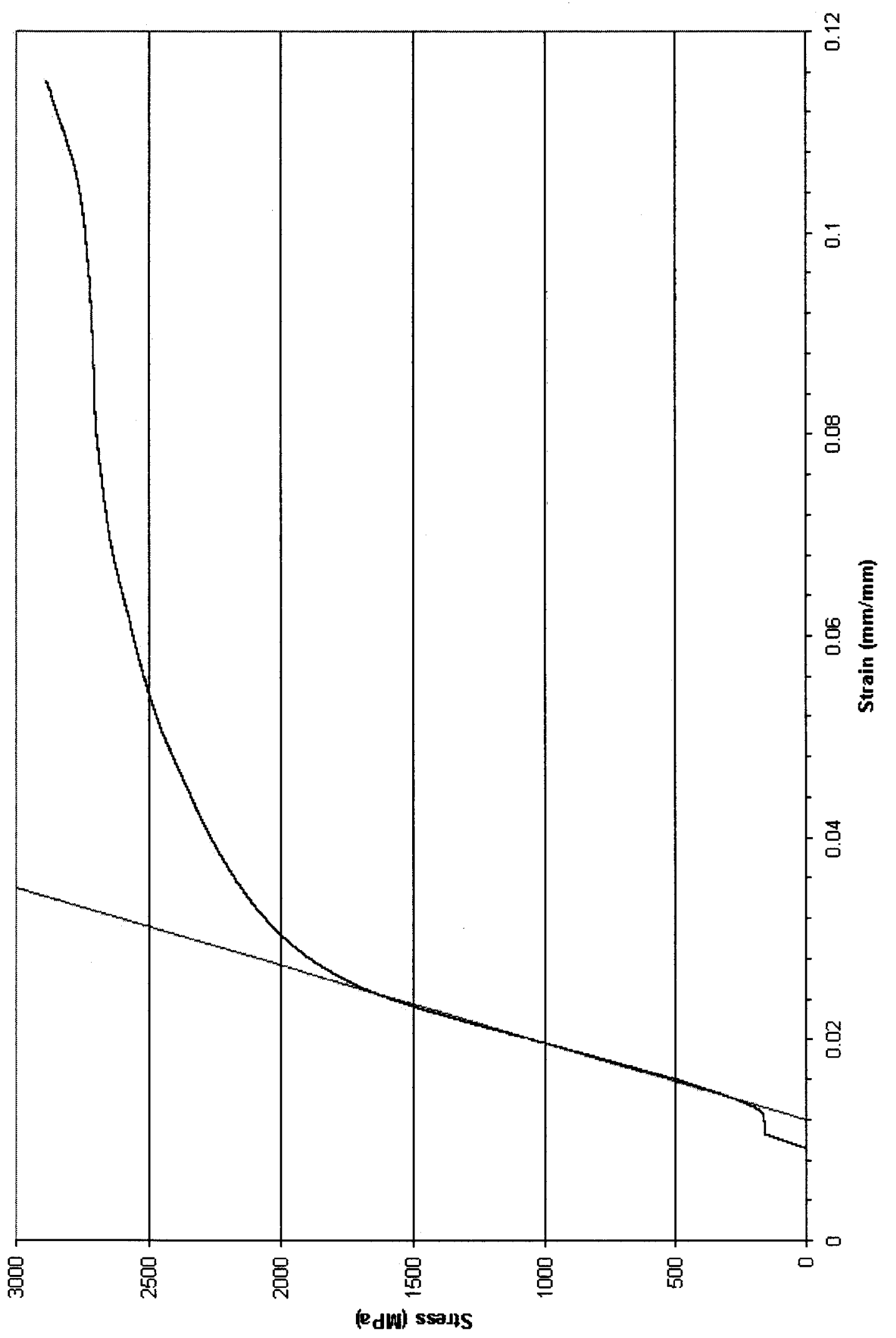

FIGURE 28 - Stress-Strain Curve of Commercial Ti-6Al-4V 


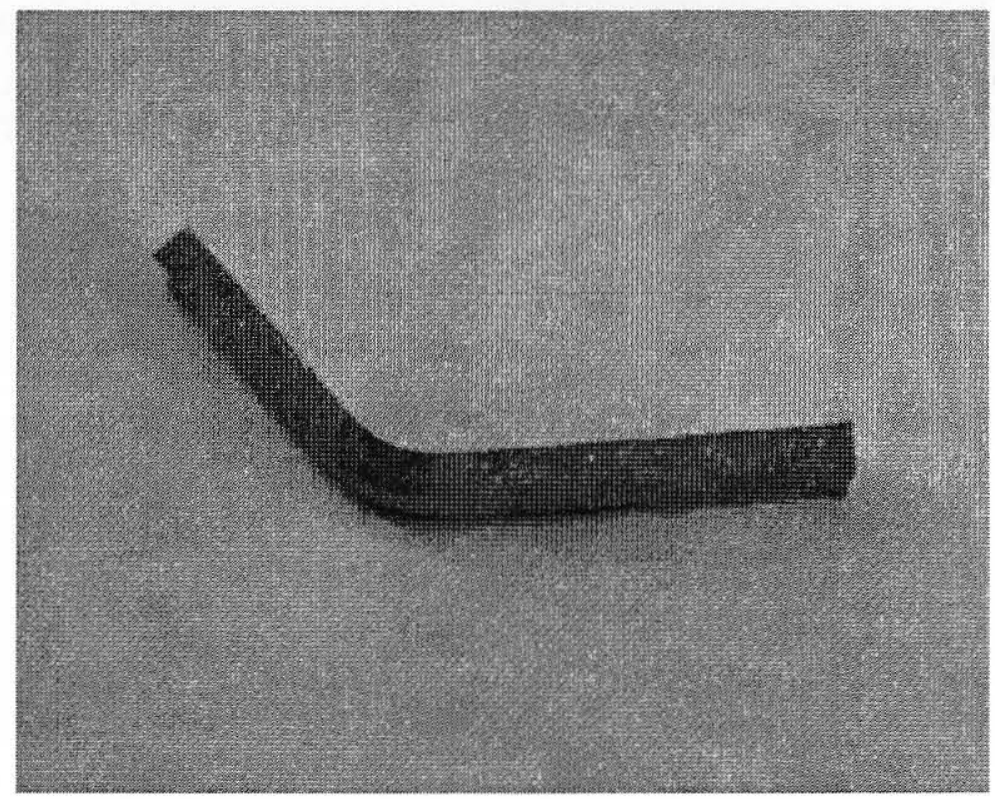

FIGURE 29 - Sample bar of Commercial Ti-6Al-4V after Mechanical Testing

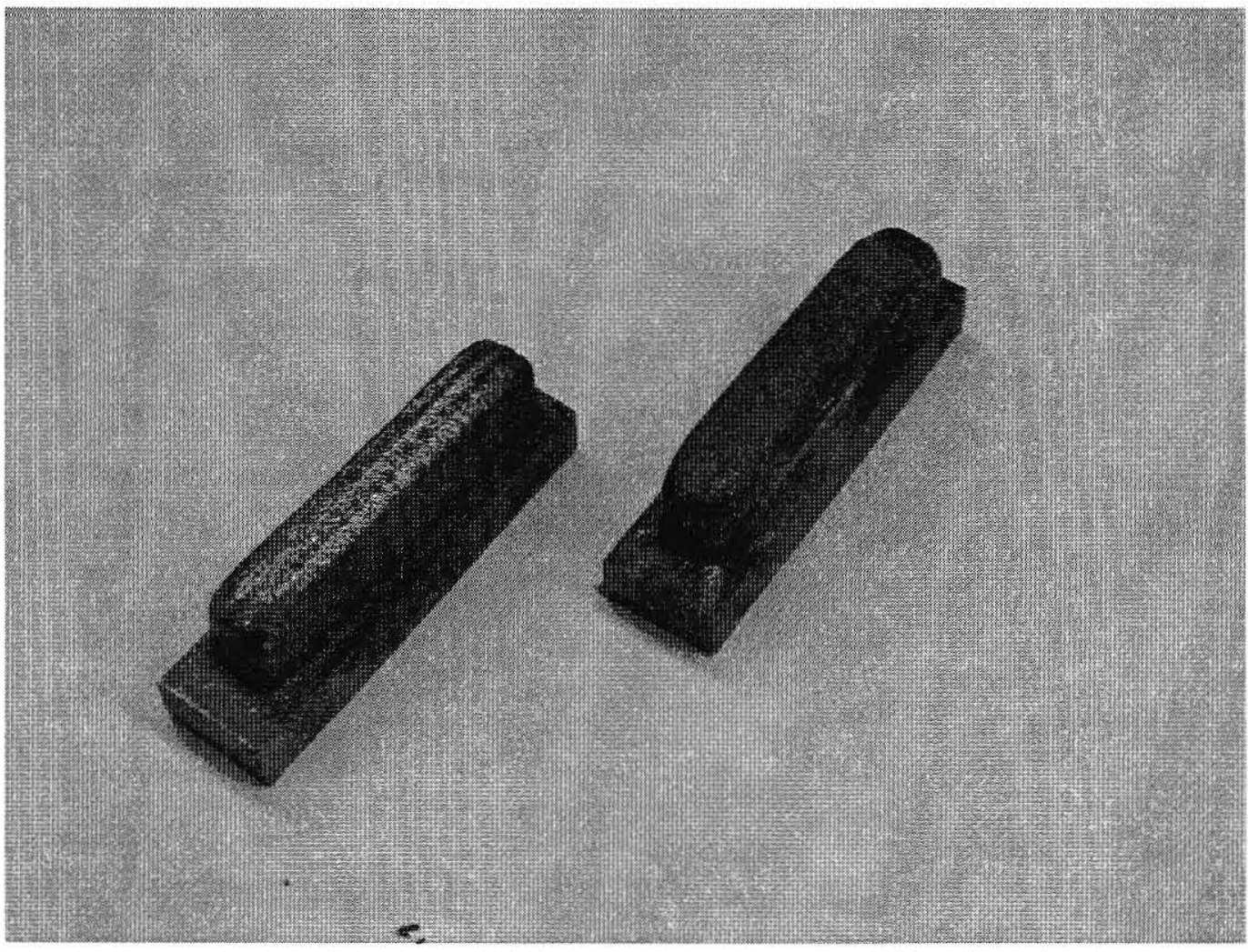

FIGURE 30 -Depositions 


\section{Crucible Research}

A division of Cracible Material Corporation

003 Campbells Run Road

Pittsburgh, PA 15205-1022

(412) 923-2955; FAX (412) 788-4665

Page 1 of 1

Date: July 14, 2003

\section{CERTIFICATE OF TEST}

Customet.

University of Louisville

CR Order: T343

Specification:

\begin{tabular}{|c|c|l}
\hline Item No.: & $\begin{array}{c}\text { Weight: } \\
10 \mathrm{lbs}\end{array}$ & $\begin{array}{l}\text { Product Description: } \\
\text { Ti-6Al-4V Gas Atomized Powder, }-100 /+325 \text { Mesh, Blend B366 }\end{array}$ \\
\hline
\end{tabular}

Chemical Analysis (Wt\%)

Biend B366 $\frac{\Delta \mathrm{l}}{6.24} \quad \frac{\mathrm{V}}{3.99} \quad \frac{\mathrm{Fe}}{0.060} \quad \frac{\mathrm{C}}{0.030} \quad \frac{\mathrm{O}}{124} \frac{\mathrm{N}}{0.011} \quad \frac{\mathrm{Ti}}{\mathrm{Bat}}$

Powder Sieve Analysis (\% Undex)

US Standard Mesh

Opening in Microns

-100
150

140

Purchase Order No:

Purchase Order Date

June 27, 2003

1000

66.9

$-200$

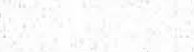

Bal.

Blend B366

100.0

29.4

17.1

\begin{tabular}{rr}
-270 & -325 \\
53 & 45 \\
\hline 80 & 25
\end{tabular}

Tap
Density
(g/cc)

Flow

$(\mathrm{g} / \mathrm{cc}) \quad(\mathrm{sec})$

2.78

25

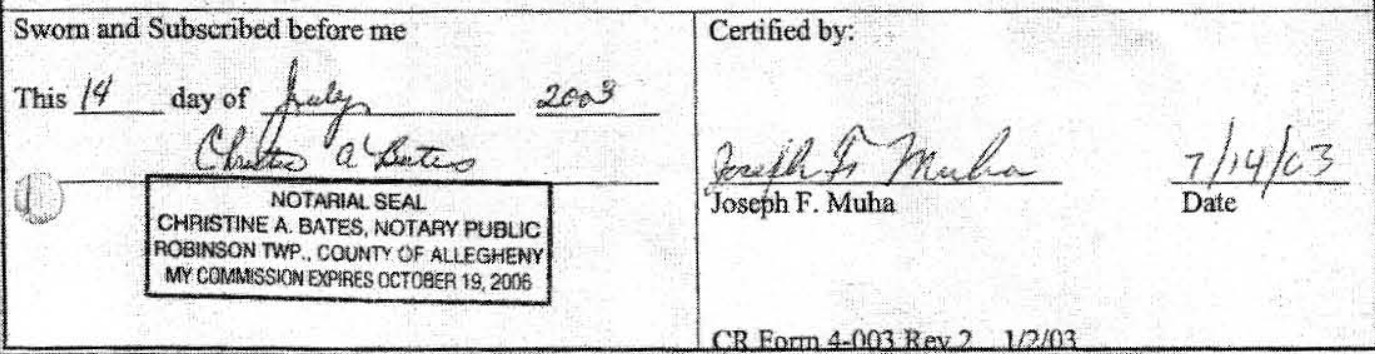

Figure 31 - Ti-6Al-4V ELI Powder Specifications 


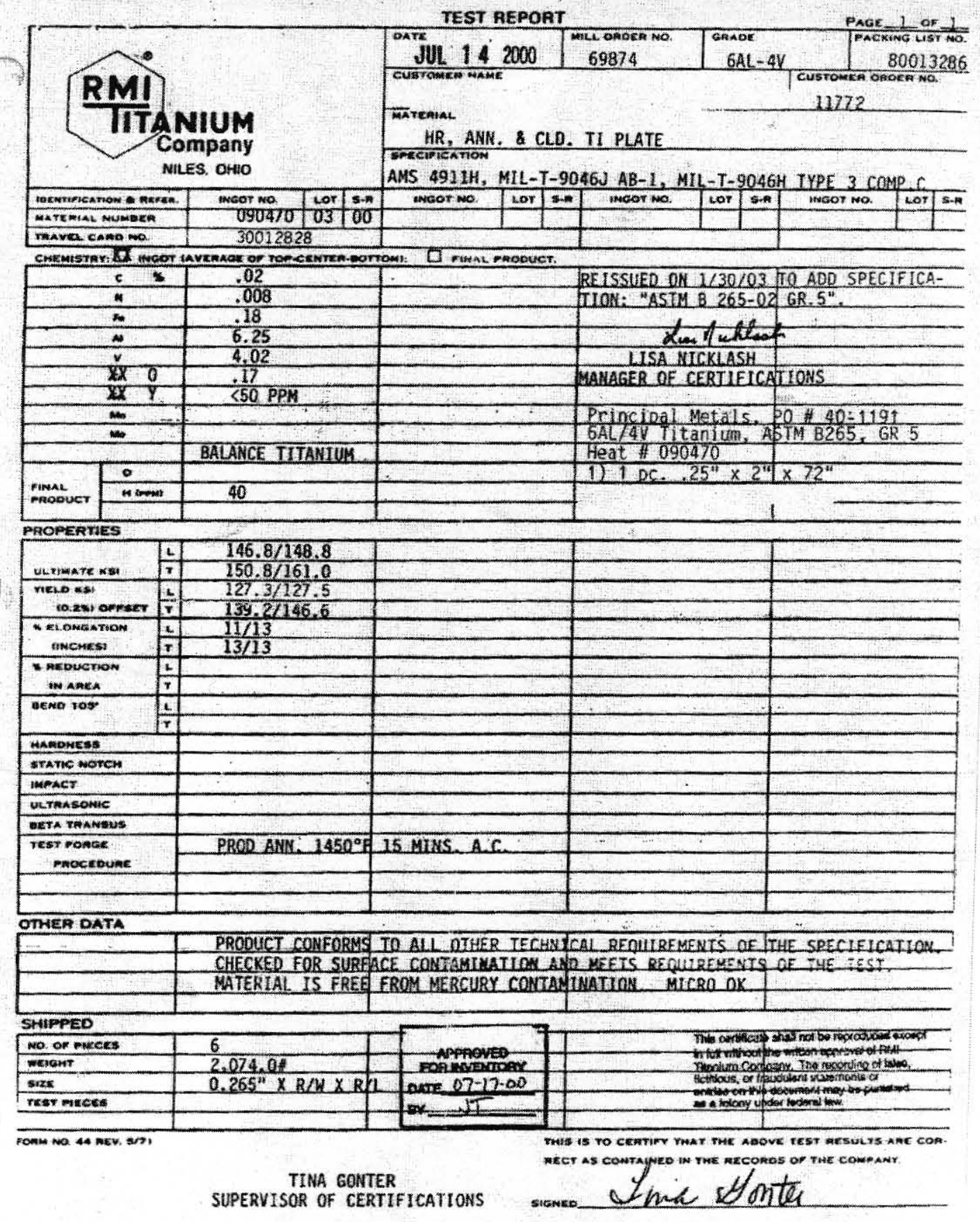

Figure 32 - Commercial Ti-6Al-4V Specifications 


\section{VITA}

Troy Davis was born on April $10^{\text {th }}$, 1981 in Louisville, KY to parents George M. Davis and Nellene W. Davis. He lived in Lebanon, Calhoun, and Radcliff, KY before moving back to Louisville in 1994. He graduated Butler Traditional High School in 1999 and then went to the University of Louisville to pursue a Master of Engineering in Chemical Engineering. After graduation, he plans to obtain a Master of Business Administration while preparing to go to Medical School. 